\title{
ESTUDO DE ASSOCIAÇÃO DE FATORES GENÉTICOS EM INDIVÍDUOS COM REAÇÕES DE HIPERSENSIBILIDADE TARDIA INDUZIDA POR ANTICONVULSIVANTES AROMÁTICOS
}

Tese apresentada à Faculdade de Medicina da Universidade de São Paulo para a obtenção de título de Doutor em Ciências

Programa de Alergia e Imunopatologia

Orientador: Prof. Dr. Jorge Elias Kalil Filho

São Paulo

2014 


\section{Dados Internacionais de Catalogação na Publicação (CIP)}

Preparada pela Biblioteca da

Faculdade de Medicina da Universidade de São Paulo

(C) reprodução autorizada pelo autor

Versão corrigida conforme resolução CoPGr618, de 18 de outubro de 2011.

A versão original está disponível na Biblioteca da Faculdade de Medicina da Universidade de São Paulo e na Biblioteca Digital de Teses de Dissertações da USP.

Tanno, Luciana Kase

Estudo de associação de fatores genéticos em indivíduos com reações de hipersensibilidade tardia induzida por anticonvulsivantes aromáticos / Luciana Kase Tanno. -- São Paulo, 2014.

Tese(doutorado)--Faculdade de Medicina da Universidade de São Paulo. Programa de Alergia e Imunopatologia.

Orientador: Jorge Elias Kalil Filho.

Descritores: 1. Hipersensibilidade a drogas; 2. Anticonvulsivantes; 3. Farmacogenética; 4. Metabolismo; 5. Antígenos de histocompatibilidade; 6. Sistema enzimático do citocromo P-450; 7. Síndrome de Stevens-Johnson; 8. Síndrome de hipersensibilidade a medicamentos; 9. Genética médica; 10. Polimorfismo genético.

USP/FM/DBD-182/14 
À minha avó querida, aos meus pais, tios, padrinhos e irmã, pelo amor incondicional. 


\section{AGRADECIMENTOS}

Aos meus avós, pais, irmã e tios, que têm me apoiado e guiado gentil e sabiamente pela vida.

Ao meu orientador Professor Doutor Jorge Kalil. Obrigada pela orientação, apoio, confiança e pela liberdade durante a realização deste trabalho.

Ao Professor Doutor Wagner Farid Gattaz pela oportunidade de colaboração.

À toda equipe do LIM-19, especialmente ao Hélcio e à Célia.

À toda equipe do LIM-27, epecialmente ao Daniel e à Leda.

À equipe do programa de pós-graduação em Alergia e Imunopatologia, em especial ao Professor Doutor Esper Kallás e Eleni.

Meus agradecimentos especias ao Sr. Jair, Serafim, Maurício, Rosana, Junior, Gisele, Sônia, Helena, Tânia, Zelinda, Margareth, Sandra, Eliza, Victor, Vanessa.

Aos docentes da Disciplina de Imunologia Clínica e Alergia que contribuiram na minha formação na especialidade. Ao Prof. Abílio Motta pelos ensinamentos sobre as reações de hipersensibilidades a fármacos.

Aos Doutores João Ferreira de Mello e Wilson Tartuce Aun pelo estímulo e apoio no estudo e pesquisa das reações de hipersensibilidades a fármacos.

Aos meus amigos.

À Fapesp, pelo apoio e financiamento deste projeto.

Aos meus pacientes. 


\section{EPÍGRAFE}

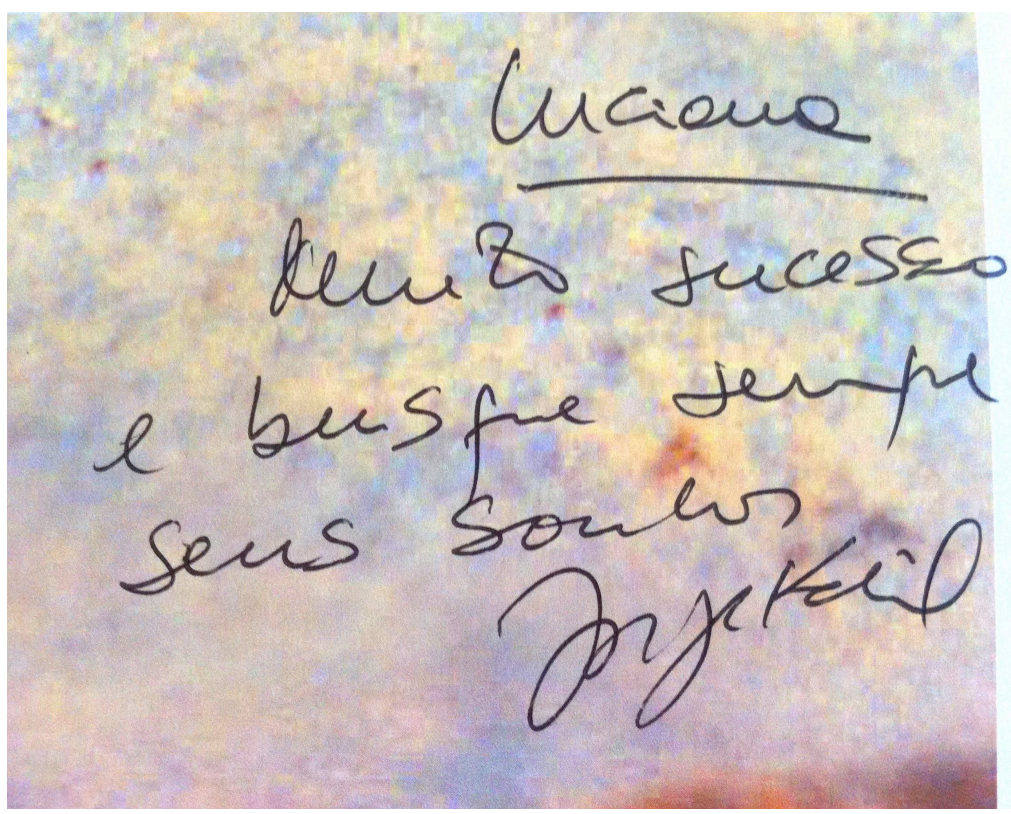

Kalil J, 2004 - encarte da data comemorativa dos 20 anos do Laboratório de Imunologia do InCor (no início da minha formação na especialidade em Imunologia Clínica e Alergia) 


\section{SUMÁRIO}

Lista de Abreviaturas

Lista de Tabelas

Lista de Figuras

Resumo

Abstract

1. INTRODUÇÃO 14

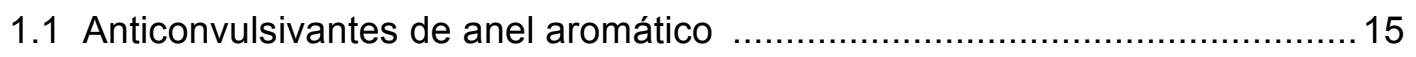

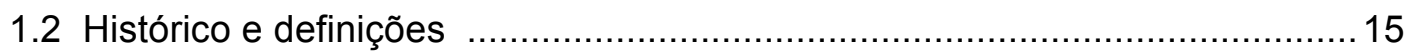

1.3 Manifestações e Diagnóstico das Reações de Hipersensibilidade a Anticonvulsivantes de Anel Aromático .................................................. 18

1.4 Fisiopatologia das Reações de Hipersensibilidade a Anticonvulsivantes de Anel Aromático ..................................................................................... 20

1.4.1 Aspectos Farmacocinéticos ….............................................. 20

1.4.2 Metabolisco dos medicamentos ...............................................20

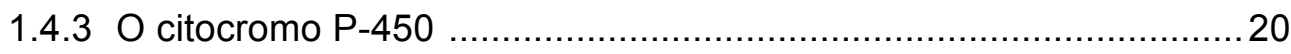

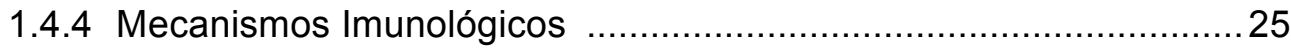

1.4.5 O Sistema Antígeno Leucocitário Humano ................................2 27

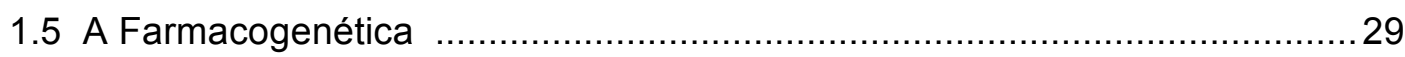

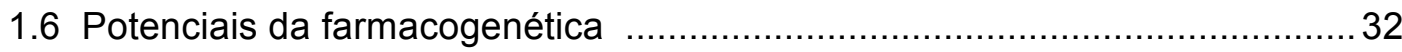

1.7 Genética e farmacogenética nas reações de hipersensibilidade a anticonvulsivantes de anel aromático .................................................... 32

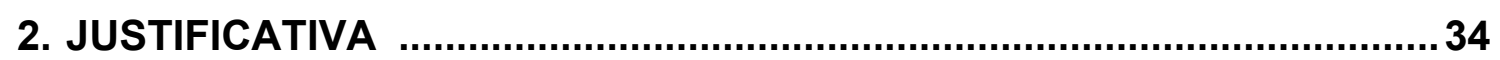

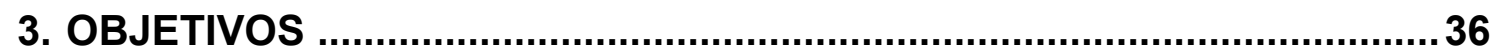

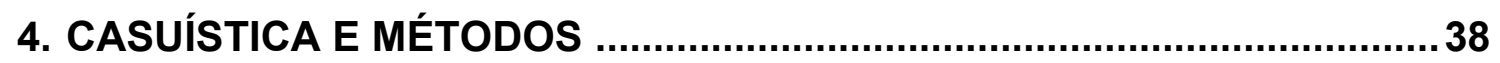

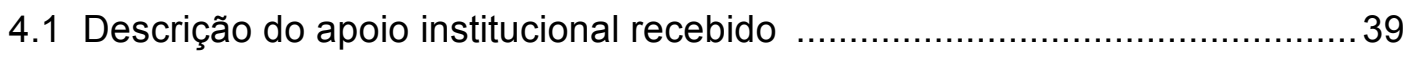

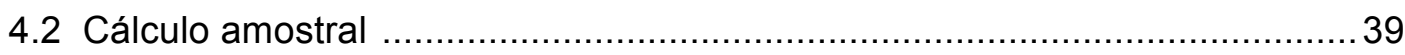

4.3 Termo de Consentimento Livre e Esclarecido ...............................................40

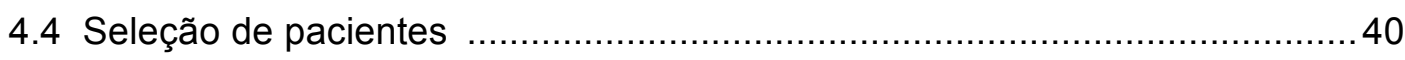

4.5 Critérios de Inclusão e Exclusão …............................................................ 40 
4.6 Critério diagnóstico de hipersensibilidade aos anticonvulsivantes de anel aromático

4.7 Critério clínicos para diagnóstico das principais reações de hipersensibilidade aos anticonvulsivantes de anel aromático ......................4 41

4.8 Teste de contato com medicamentos ....................................................... 42

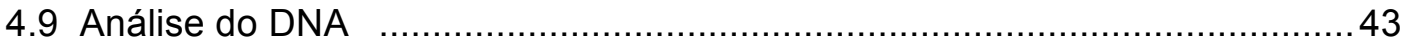

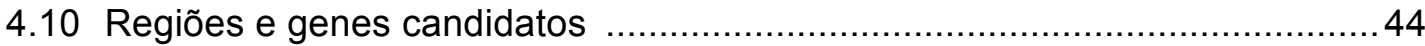

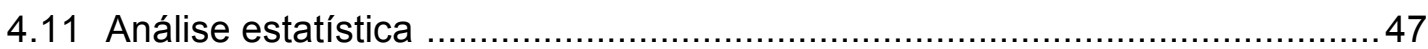

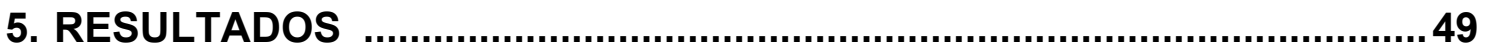

5.1 Caracterização clínico-demográfica …....................................................50

5.2 Determinação de causalidade das reações baseadas em história clínica e teste de contato com medicamentos ....................................................... 51

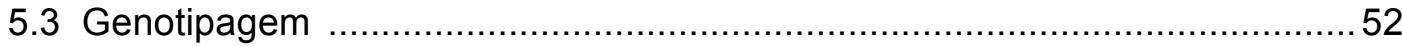

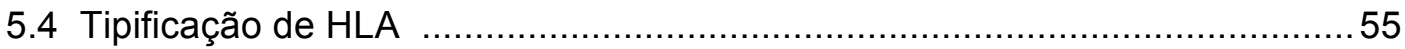

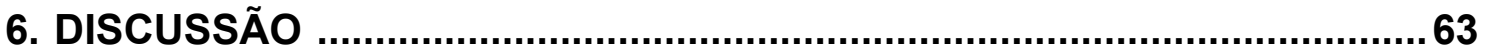

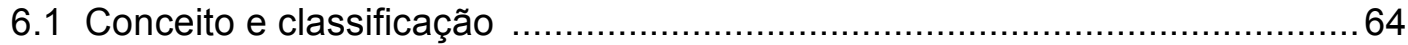

6.2 Desenho do estudo e cálculo amostral …...................................................64

6.3 Dados demográficos e composição de casos e controles ...........................66

6.4 Diagnóstico e teste de contato com medicamento .....................................68

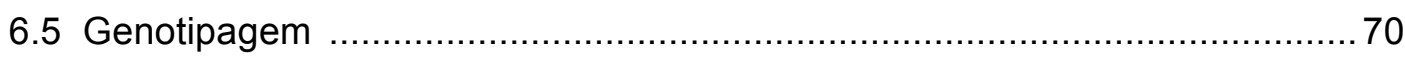

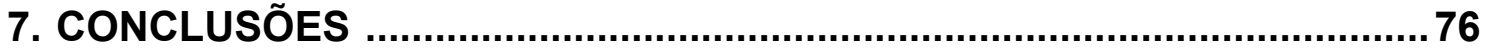

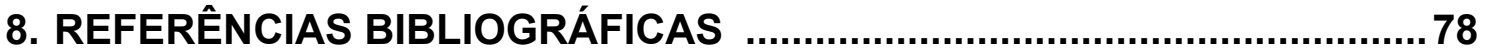

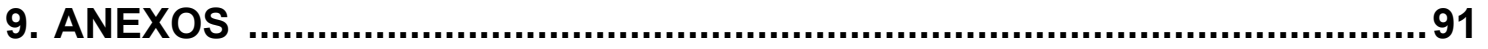




\section{LISTA DE ABREVIATURAS}

ACA: anticonvulsivantes de anel aromático

CBZ: carbamazepina

CYP: $\quad$ citocromo P450

DRESS: $\quad$ Drug Reaction with Eosinophilia and Systemic Symptoms

E Macular: Exantema Macular

E Multiforme: Eritema Multiforme

ENDA: $\quad$ European Network of Drug Allergy

HLA: antígeno leucocitário humano

HSP: proteína de choque térmico

IBGE: Instituto Brasileiro de Geografia e Estatística

LT: $\quad$ linfócito $T$

MHC: $\quad$ complexo principal de histocompatibilidade

NET: $\quad$ Necrólise Epidérmica Tóxica

OMS: $\quad$ Organização Mundial de Saúde

PCR: $\quad$ Reação em cadeia de polimerase (Polymerase Chain Reaction)

PEGA: $\quad$ Pustulose Exantemática Generalizada Aguda

RAD: $\quad$ reações adversas a drogas

RH: $\quad$ reações de hipersensibilidade

RHI: reação de hipersensibilidade imediata

RHM: reação de hipersensibilidade a medicamentos

RHNI: reação de hipersensibilidade não-imediata

SNPs: $\quad$ polimorfismos de nucleotídeo único (single nucleotide polymorphisms)

SSJ: $\quad$ Síndrome de Stevens-Johnson Syndrome

SSO: $\quad$ Sequência específica de oligonucleotídeos (Sequence-specific Oligonucleotide)

TC: $\quad$ testes de contato

TCM: $\quad$ teste de contato com medicamentos

TCR: $\quad$ receptor de células T

TNF: $\quad$ fator de necrose tumoral

VP: valores preditivos

WAO: $\quad$ Organização Mundial de Alergia (World Allergy Organization) 


\section{LISTA DE TABELAS}

Tabela 1. Classificação das reações adversas a drogas previsíveis e imprevisíveis

Tabela 2. Principais manifestações das reações de hipersensibilidade nãoimediatas conforme a gravidade

Tabela 3. Fatores genéticos associados a reações cutâneas graves a anticonvulsivantes (carbamazepina)

Tabela 4. Genes de HLA e CYP, polimorfismos (SNP) analisados e suas respectivas localizações cromossômicas

Tabela 5. Variações alélicas estudadas dos genes CYP2C19, CYP2C9 e CYP3A5

Tabela 6. Determinação do fenótipo de atividade enzimática predito para CYP2C19, CYP2C9 e CYP3A5

Tabela 7. Perfil demográfico dos indivíduos incluídos no estudo

Tabela 8. Características clínicas e demográficas dos casos de reação de hipersensisibilidade não-imediata aos anticonvulsivantes de anel aromático

Tabela 9. Frequência genotípica de polimorfismos de HLA-B*1502 e HLA$A^{*} 310149$

Tabela 10. Genotipagem de polimorfismos de enzimas do Citocromo P450 (CYP) 2C9, 3A5 e 2C19

Tabela 11. Análise do fenótipo enzimático e resultados de teste de contato com anticonvulsivantes. Os dados são apresentados como a N (\% de remendo droga grupo de teste)

Tabela 12. Tipificação de HLA: associação de HLA em casos e em indivíduos saudáveis

Tabela 13. Análise discriminativa dos resultados obtidos da tipificação de HLA em casos e em indivíduos saudáveis 


\section{LISTA DE FIGURAS}

Figura 1. Estrutura química dos anticonvulsivantes de anel aromático 15

Figure 2. Localização das CYPs na célula 22

Figura 3. Envolvimento das enzimas do Citocromo (CYP) 2C9, 2C19 e 3A5 no metabolismo hepático dos anticonvulsivantes de anel aromático

Figura 4. Subclassificação das reações tipo IV de Gell e Coombs

Figura 5. Mapa genético da região codificadora de HLA

Figura 6. Fluxograma do estudo

Figura 7. Árvore de classificação e regressão do polimorfismo de CYP3A5 ... 59

Figure 8. Árvore de classificação e decisões que demonstra a maior ou menor possibilidade do indivíduo ser caso ou tolerante de acordo com a combinação de alelos de HLA

Figura 9. Árvore de classificação e decisões, que demonstra a maior ou menor possibilidade do indivíduo ser caso ou tolerante de acordo com a combinação de polimorfismos de HLA e CYP e alelos de HLA

Figura 10. Gupos Étnicos no Brasil segundo o Instituto Brasileiro de Geografia e Estatística (IBGE)

Figura 11. Frequência alélica de HLA-A*3101 e HLA-B*1502 na população mundial 


\section{RESUMO}

Tanno LK. Estudo de Associação de Fatores Genéticos em Indivíduos com Reações de Hipersensibilidade Tardia Induzida por Anticonvulsivantes Aromáticos [tese]. São Paulo: Faculdade de Medicina, Universidade de São Paulo; 2014.

Intrdodução: As terapias com anticonvulsivantes de anel aromático (ACA) são freqüentemente associadas a reações adversas. No entanto, reações de hipersensibilidade $(\mathrm{RH})$ não-imediatas (tardias) a estes fármacos são raras, imprevisíveis e geralmente relacionadas à alta morbidade e mortalidade. Foi demonstrado que estas RH aos ACA estão fortemente associadas ao Antígenio de Leucócitos Humanos (HLA)-B*1502 em pacientes chineses e ao HLA-A*3101 em caucasianos. Polimorfismos de genes do metabolismo do Citocromo P450 (CYP)2C9 foram mais associados a estas reações em pacientes orientais. Objetivo: Nosso objetivo é analisar a associação das reações de hipersensibilidade a anticonvulsivantes de anel aromático com os polimorfismos descritos e de interesse, bem como realizar a tipificação de HLA em uma população de São Paulo, Brasil. Métodos: Estudo tipo caso-controle com genotipagem dos polimorfismos de interesse por reação em cadeia da polimerase (PCR) em tempo real e tificação de HLA A, B, C, DRB, DQA, DQB por PCR seguido de deteção utilizando método Luminex ${ }^{R}$. A avaliação fenotípica se baseou em sistemas de escores padronizados, utilizando um questionário adaptado da ENDA (Rede Européia de Alergia a Medicamentos), em registros médicos e no acompanhamento clínico. O teste de contato com o medicamento suspeito foi realizado de acordo com as recomendações da ENDA, nos pacientes que apresentaram reação. Resultados: Foram estudados 506 pacientes, $65 \%$ do gênero feminino e a idade média foi de 43,6 anos. Oitenta por cento era de etnia mista. Polimorfismos de HLA-A*3101, HLA-B*1502, CYP2C9, CYP2C19 e CYP3A5 foram analisados de 55 indivíduos com reações de hipersensibilidade $(\mathrm{RH})$ a antiepilépticos, de 85 tolerantes e de 366 controles sadios. Dos 55 casos foram validados como $\mathrm{RH}, 32$ apresentaram Reação a Drogas com eosinofilia e sintomas sistêmicos (DRESS), 12 Síndrome de Stevens-Johnson (SSJ) e 11 exantema maculo-papular. De todos os 46 testes de contato com medicamento, $29(63 \%)$ foram positivos, tanto em SSJ como em DRESS. Houve associação 
significativa entre polimorfismo de HLA-A ${ }^{*} 1502$ e casos. Nenhum de nossos grupos de estudo apresentou associação positiva com polimorfismos de HLA$A^{\star} 3101$. Verificamos uma forte associação entre a atividade normal do CYP3A5 e indivíduos tolerantes quando comparado com casos $(p=0,0002, O R=4,8)$. A tipificação de HLA demonstrou associação significante de HLA-A*31, HLA-A*74, HLA-B*35 e HLA-B*53 com reações graves aos ACA e de HLA-B*44 e HLA-C*03 com indivíduos tolerantes. Conclusão: Estes resultados sugere fortemente a existência de fatores genéticos de risco e/ou de proteção a RH a ACA em indivíduos brasileiros, mas não devem ser considerados de forma isolada. Assim, a relevância deste estudo extrapola o objetivo de estudo caso-controle e sugere um modelo como forma de prevenção primária às $\mathrm{RH}$ aos $\mathrm{ACA}$.

Descritores: Hipersensibilidade a drogas, Anticonvulsivantes, Farmacogenética, Metabolismo, Antígenos de histocompatibilidade, Sistema enzimático do citocromo P-450, Síndrome de Stevens-Johnson, Síndrome de hipersensibilidade a medicamentos, Genética médica, Polimorfismo genético. 


\begin{abstract}
Tanno LK. Association Study of Genetic Factors in Individuals with Delayed Hypersensitivity Reactions Induced by Anticonvulsants Aromatics [thesis]. São Paulo: "Faculdade de Medicina, Universidade de São Paulo"; 2014.
\end{abstract}

Background: Antiepileptics with aromatic ring (AAR) therapies are frequently associated with adverse reactions. Nevertheless non-immediate (late) hypersensitivity reactions (HR) to these drugs are rare, unpredictable and usually related with high morbidity and mortality. A strong pharmacogenetic association has been reported in Chinese patients with these HR and Human Leukocyte Antigen (HLA)-B*1502 and with HLA- $A^{*} 3101$ in caucasians. Polymorphism of genes of $\mathrm{P} 450$ Cytocrome (CYP)2C9 has been related to these reactions in patients of oriental origin. Objective: Our aim is to analyze the association between hypersensitivity reactions due to AAR and the described polymorphisms, as well as perform the typification of HLA in a population of São Paulo, Brazil. Methods: Case-control study genotyping the polymorphisms of interest by polymerase chain reaction (PCR) real time and typifying $\operatorname{HLA} A, B, C, D R B, D Q A$, DQB by PCR followed by Luminex ${ }^{R}$. The phenotype evaluation was based on standardized scoring systems using an adapted ENDA (European Network of Drug Allergy) questionnaire, medical records and on the clinical follow-up in our Allergy Clinic. The patch test with the culprit drug was performed in patients who experienced HR according to the ENDA recommendations. Results: We studied 506 subjects, $65 \%$ female and mean age was 43,6 years. Eighty percent had mixed ethnicity. Polymorphisms of HLA-B*1502, HLA- A*3101, CYP2C9, CYP2C19 e CYP3A5 were studied in 55 subjects with antiepileptics HR, 85 tolerants, and 366 control subjects. Of 55 cases were validated as AHR, 32 presented Drug Reaction with Eosinophilia and Systemic Symptoms (DRESS), 12 Stevens-Johnson Syndrome (SJS) and 11 maculopapular exanthema. Of all 46 drug patch tests, 29 (63\%) were positive, in both SJS and DRESS. A significant association between polymorphism of HLA-A*1502 and cases was found. None of our study groups presented positive association with HLA-A*3101 polymorphisms. We found a strong association between the normal activity of CYP3A5 and tolerants subjects when compared to $\operatorname{HR}(p=0.0002, O R=4.8)$. The HLA 
typification showed a significant association between HLA-A*31, HLA-A*74, HLA$B^{*} 35$ e HLA-B*53 and severe AAR reactions and HLA-B*44 and HLA-C*03 in tolerants subjects. Conclusion: These results strongly suggests the existence of genetic risk and/or protective factors to the development of HR to AAR AAR in Brazilian subjects, but it should not be considered in a isolated manner. So, the relevance of this study extrapolates the aim of a case-control study and suggests a system of primary prevention to HR due to AAR.

Descriptors: Hypersensitivity to drugs, anticonvulsants, Pharmacogenetics, Metabolism, histocompatibility antigens, Cytochrome P450, Stevens-Johnson syndrome, hypersensitivity to drugs Syndrome, Medical Genetics, Genetic polymorphism 


\section{INTRODUÇÃO}




\subsection{Anticonvulsivantes de Anel Aromático}

Os anticonvulsivantes, também conhecidos como antiepilépticos, são medicamentos importantes no arsenal terapêutico da epilepsia, sendo também empregados em outras situações clínicas como na terapêutica da dor e nas doenças psiquiátricas. Os anticonvulsivantes de estrutura aromática (ACA) mais utilizados são a Carbamazepina, a Fenitoína, o Fenobarbital, a Oxcarbazepina e a Lamotrigina. (Figura 1) (Al-Sayed AA, 2011; Bialer M., 2012; Kaufman KR, 2011)

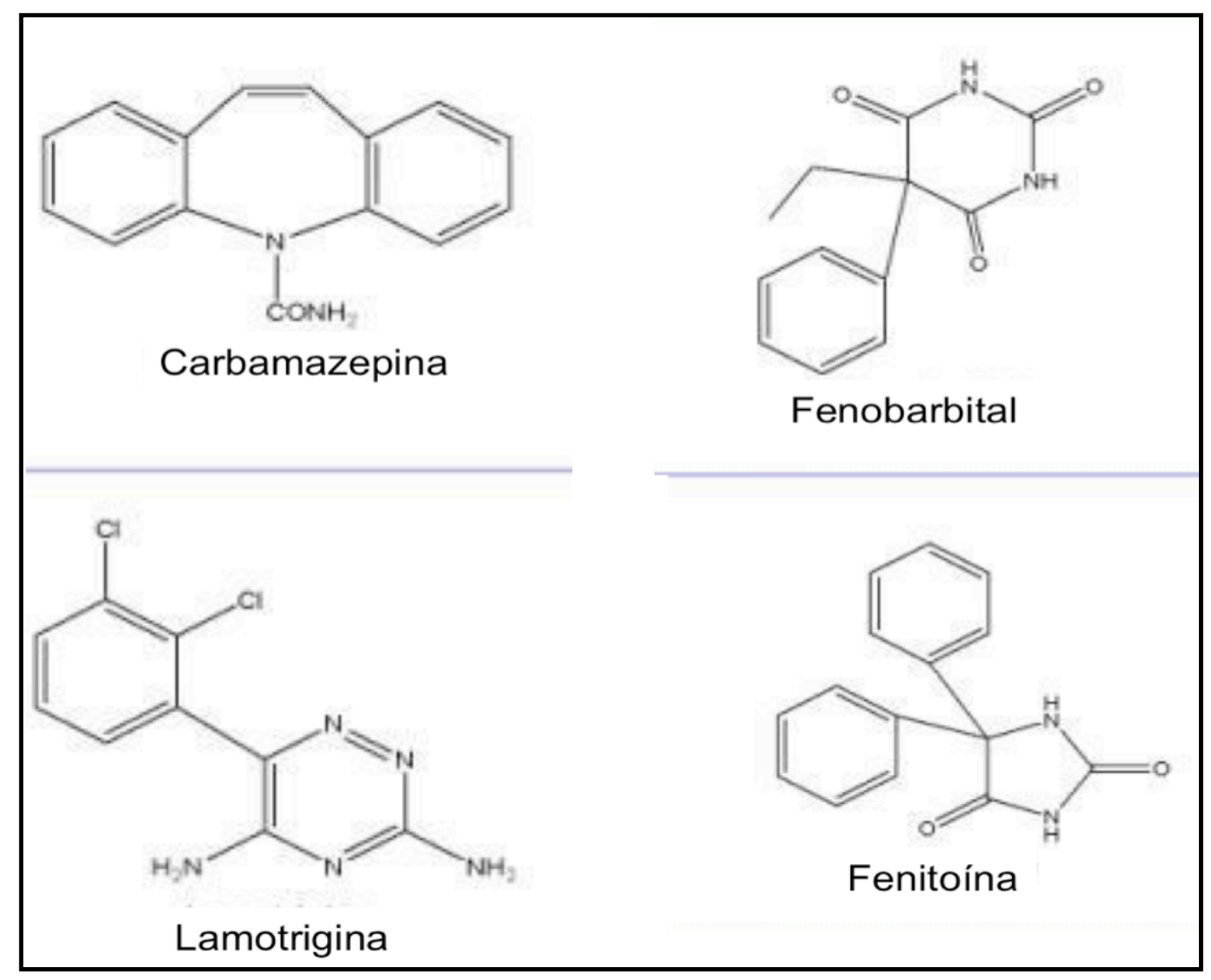

Figura 1: Estrutura química dos principais anticonvulsivates de anel aromático de utilização clínica 


\subsection{Histórico e definições}

O primeiro anticonvulsivante introduzido na prática clínica foi o sal de brometo por Locock em 1857. Novas drogas foram sendo desenvolvidas posteriormente como o fenobarbital, os hidantoinatos, a carbamazepina, o valproato entre outros (Masia SL, 2000; Klitgaard H. 2005).

Após a introdução da fenitoína como fármaco anticonvulsivante em 1938, os primeiros relatos de reações adversas a esta droga foram descritos (Gilman AG, 1991). Desde 1958, os anticonvulsivantes de anel aromático (ACA) têm sido relacionados aos primeiros casos de reações adversas graves, como a Síndrome de Stevens-Jonhson (SSJ), a Necrólise Epidérmica Tóxica (NET) e a DRESS (drug reaction with eosinophylia and systemic symptoms). (Roujeau JC, 1994)

As reações adversas a drogas (RAD) são definidas pela Organização Mundial da Saúde como "qualquer efeito não terapêutico decorrente do uso de um fármaco nas doses habitualmente empregadas para prevenção, diagnóstico ou tratamento de doenças" (WHO 1972). São causa importante de morbidade e mortalidade, contribuem em elevar as taxas de hospitalização, tendo impacto significativo na prática médica diária. (Gomes ER 2005; Pirmohamed M, 2004; Lazarou J, 1998). As RAD podem ser classificadas como previsíveis (tipo A) e imprevisíveis (tipo B) (Tabela 1). As reações previsíveis são usualmente dosedependentes, relacionadas à ação farmacológica da droga, e podem ocorrer em qualquer indivíduo. Incluem os efeitos colaterais e secundários, a toxicidade e as interações medicamentosas. Por outro lado, as reações imprevisíveis são geralmente dose-independentes, não-relacionadas diretamente com as ações farmacológicas da droga, e ocorrem apenas em indivíduos suceptíveis. As reações imprevisíveis são subdivididas em intolerância, idiossincrasia e hipersensibilidade (WHO 1972). 
A idiossincrasia é postulada como características incomuns de um indivíduo que propiciam a desenvolver determinada condição, no caso, uma RAD (WHO 1972).

Tabela 1. Classificação das reações adversas a drogas previsíveis e imprevisíveis (adaptado de WHO. International drug monitoring: the role of national centres. Tech Rep Ser WHO 1972)

\begin{tabular}{c|c}
\hline \multicolumn{2}{c}{ Reações Adversas a Drogas } \\
\hline Previsíveis (Tipo A) & Imprevisíveis (Tipo B) \\
\hline Efeitos colateais & Intolerância \\
Superdosagem & Idiossincrasia \\
Interações medicamentosas & Hipersensibilidade \\
Efeitos secundários & \\
\hline
\end{tabular}

As reações de hipersensibilidade $(\mathrm{RH})$ são definidas pela Organização Mundial de Alergia (World Allergy Organization - WAO) como "quaisquer reações objetivas, iniciadas por estímulo definido, cujos sinais e sintomas podem ser reproduzidos" (Johansson SG, 2004). Cerca de 15 a 20\% das RADs são RH ocorrendo em pelo menos 7\% da população (Gomes ER, 2005). As RHs são classificadas em alérgicas ou não-alérgicas, sendo que as alérgicas são aquelas iniciadas por mecanismos imunológicos (Demoly P 2004). De acordo com o intervalo de tempo entre o uso do medicamento e o aparecimento da reação podem ser denominadas reações de hipersensibilidade imediatas $(\mathrm{RHI})$, quando ocorrem na primeira hora após a utilização do medicamento, e reações de hipersensibilidade não-imediatas (RHNI), quando ocorrem após este período (Romano A, 2007). As manifestações mais frequentes das RHNI são o exantema maculo-papular (EMP) e a urticaria/angioedema de início tardio, mas outras apresentações clínicas podem ocorrer, algumas com maior gravidade como a Síndrome de Stevens-Johnson (SSJ), a Necrólise 
Epidérmica Tóxica (TEN) e a Síndrome de Hipersensibilidade a Medicamentos, também conhecida como Drug Reactions with Eosinophilia and Systemic Symptoms (DRESS) (Demoly 1999).

Segundo Tanno LK e colaboradores (2011), em estudo prospectivo realizado a partir de interconsultas solicitadas ao Serviço de Alergia do Hospital Servido Público Estadual de São Paulo de pacientes internados no periodo de um ano, verificou-se que $81.25 \%$ das avaliações foram motivadas por $\mathrm{RH}$ a fármacos, das quais $24.6 \%$ por ACA. Os ACAs foram implicados em todos os casos de RH graves.

\subsection{Manifestações e Diagnóstico das Reações de Hipersensibilidade a Anticonvulsivantes de Anel Aromático}

Os anticonvulsivantes estão associados a até $10 \%$ de todas as RAD de apresentação dermatológica, mas os ACA estão relacionados às reações de maior gravidade. As $\mathrm{RH}$ aos ACA se manifestam em geral como RHNI, que podem variar em extensão e/ou em gravidade (Tabela 2). A apresentação clínica pode depender de fatores farmacológicos e/ou individuais e o período em que há maior risco de se desenvolver a reação é nos primeiros 6 meses de uso do medicamento (Svensson CK 2000, Knowles SR 2007, Nagao-Dias 2009). A incidência das RHNI graves aos ACA varia de 1:10.000 a 1:100.000 exposições/ano, mas a mortalidade pode chegar a $30 \%$ dos casos (Mockenhaupt M 2011). O prognóstico destas reações depende do tipo de manifestação e da precocidade do diagnóstico e sustensão rápida do medicamento envolvido. (Tanno 2009, Mockenhaupt 2011).

Handoko KB e colaboradores demonstraram uma associação importante entre ACA e reações linfócito-T mediadas (tipo IV de Gell e Coombs) 
de apresentação cutânea. A presença do anel aromático na estrutura química destes medicamentos confere a possibilidade de reação cruzada entre seus representantes em até $75 \%$ dos casos, o que desaconselha à substituição por outro de característica farmacológica semelhante. (Kim 2008, Mockehnaupt 2008)

Tabela 2. Principais manifestações das reações de hipersensibilidade nãoimediatas a medicamentos conforme a gravidade.

\begin{tabular}{c|c}
\hline Reações brandas & Reações graves \\
\hline Exantema maculo-papular & Síndrome de Stevens-Jonhson \\
\hline Exantema macular & Necrólise Epidérmica Tóxica \\
\hline Erupção Fixa por fármaco & DRESS \\
\hline Eritema Multiforme & Pustulose Exantemática Aguda \\
\hline
\end{tabular}

O diagnóstico das $\mathrm{RH}$ aos ACA é clínico, baseado em uma história clínica detalhada e em critérios clínicos para caracterização fenotípica (Pirmohamed M 2011, Mockenhaupt 2011), além de testes in vivo e in vitro.

Os testes in vitro para a investigação das RHNI são de difícil padronização e dados sobre sua sensibilidade e especificidade são pouco definidos. (Shear 1988, Torres MJ 2009, Adam 2011).

Os testes cutâneos de leitura tardia, como o teste de contato com medicamentos (TCM) e o teste intradérmico de leitura tardia e, em casos específicos, o teste de provocação, são os métodos diagnósticos in vivo disponíveis para a investigação das RHNI. O teste de contato com o medicamento suspeito têm sido descrito como método complementar que auxilia na determinação causal das RHNI de apresentação cutânea (Barbaud 2000, 2001; Romano 1993; Osawa 1990). 
Há poucas publicações sobre a realização dos TCM em reações graves (Duong 2010), mas parece ser um importante método diagnóstico em situações em que o teste de provocação, considerado como padrão-ouro, está contra-indicado (Aberer 2003; Santiago F 2010).

\subsection{Fisiopatologia das Reações de Hipersensibilidade a} Anticonvulsivantes de Anel Aromático

\subsubsection{Aspectos Farmacocinéticos}

A farmacocinética refere-se aos processos que influenciam na entrega de um fármaco ao alvo, incluindo a absorção, metabolismo e eliminação. Diversos polimorfismos genéticos nos genes chaves deste caminho, como na família do citocromo P450 (CYP), responsável pelo metabolismo de mais de 50\% dos fármacos existentes, influenciam na biodisponibilidade dos ACA possibilitando RHs (Chadwick 1984, Peace RE 2002).

\subsubsection{Metabolismo dos medicamentos}

As enzimas metabolizadoras de medicamentos são expressas na maioria dos tecidos. Contudo, os maiores níveis de expressão são encontrados no trato gastrointestinal (fígado, intestino delgado e cólon). Desse modo, medicamentos administrados por via oral, sofrem o metabolismo de primeira passagem (também conhecido como metabolismo pré-sistêmico ou efeito de primeira passagem) que é um fenômeno no qual a concentração do medicamento é significativamente reduzida pelas enzimas hepáticas, antes de atingir a circulação sistêmica. Enquanto alguns medicamentos não sofrem esse efeito, as passagens subsequentes no fígado resultam em posterior metabolismo do medicamento até sua eliminação. 


\subsubsection{O citocromo P-450}

A família das enzimas metabolizadoras do citocromo P450, tem sido o foco importante das pesquisas farmacogenéticas. As enzimas CYPs são conhecidas por controlar o metabolismo e distribuição de muitos fármacos e estão localizadas na bicamada lipídica do retículo endoplasmático das células (Peace 2002, Koo 2006) (Figura 2). As enzimas CYP2C9, o CYP2C19 e o CYP3A5 são predominantemente encontradas no fígado, são responsáveis pela metabolização de mais de $60 \%$ de medicamentos disponíveis comercialmente nos Estados Unidos (Zanger UM 2014) e apresentam importante função na biotransformação dos ACA (Peace 2002, Stephen 2006, Dorado P 2013) (Figura 3). Os ACA são extensamente metabolizados em mais de vinte metabólitos estáveis, que podem originar metabólitos tóxicos ou imunogênicos após sofrer bioativação. A enzima CYP2C9 está diretamente relacionada à metabolização da Fenitoína e de seus substratos. A CYP3A5 está envolvida na principal via de metabolismo e depuração da Carbamazepina (Peace RE 2008) enquanto que a CYP2C19 apresenta função enzimática relevante em vários representantes deste grupo farmacológico.

Os polimorfismos das enzimas do citocromo P450 têm um grande efeito nas variações das respostas a medicamentos e têm sido relacionados ao maior risco de reações de hipersensibilidade a fármacos. Aproximadamente 55 genes de CYP estão presentes no genoma humano e são classificados de acordo com a sua atividade enzimática. Os polimorfismos genéticos do gene CYP2C9 que caracterizam os alelos CYP2C9*2 e CYP2C9*3, resultam em metabolismo mais lento ou inadequado, com maior risco de acúmulo do medicamento ou de seus metabólitos, o que pode resultar em toxicidade ou em reações de hipersensibilidade. Quando os metabólitos tóxicos não são inativados enzimaticamente, podem se ligar a células ou proteínas, formando haptenos e desencadeando o processo inflamatório. Em casos específicos, estes metabólitos 
são apresentados por meio de células apresentadoras de antígeno aos linfócitos $\mathrm{T}$, dando início à resposta imune que repercute fenotipicamente nas $\mathrm{RH}$. A freqüência de polimorfismos de CYP parece estar associada a diferenças étnicas. A variante $\mathrm{CYP} 2 \mathrm{C9}$ *3 foi encontrada em maior frequência na população caucasiana quando comparada aos asiáticos. (Stephen 2006, Q Zhou 2009)

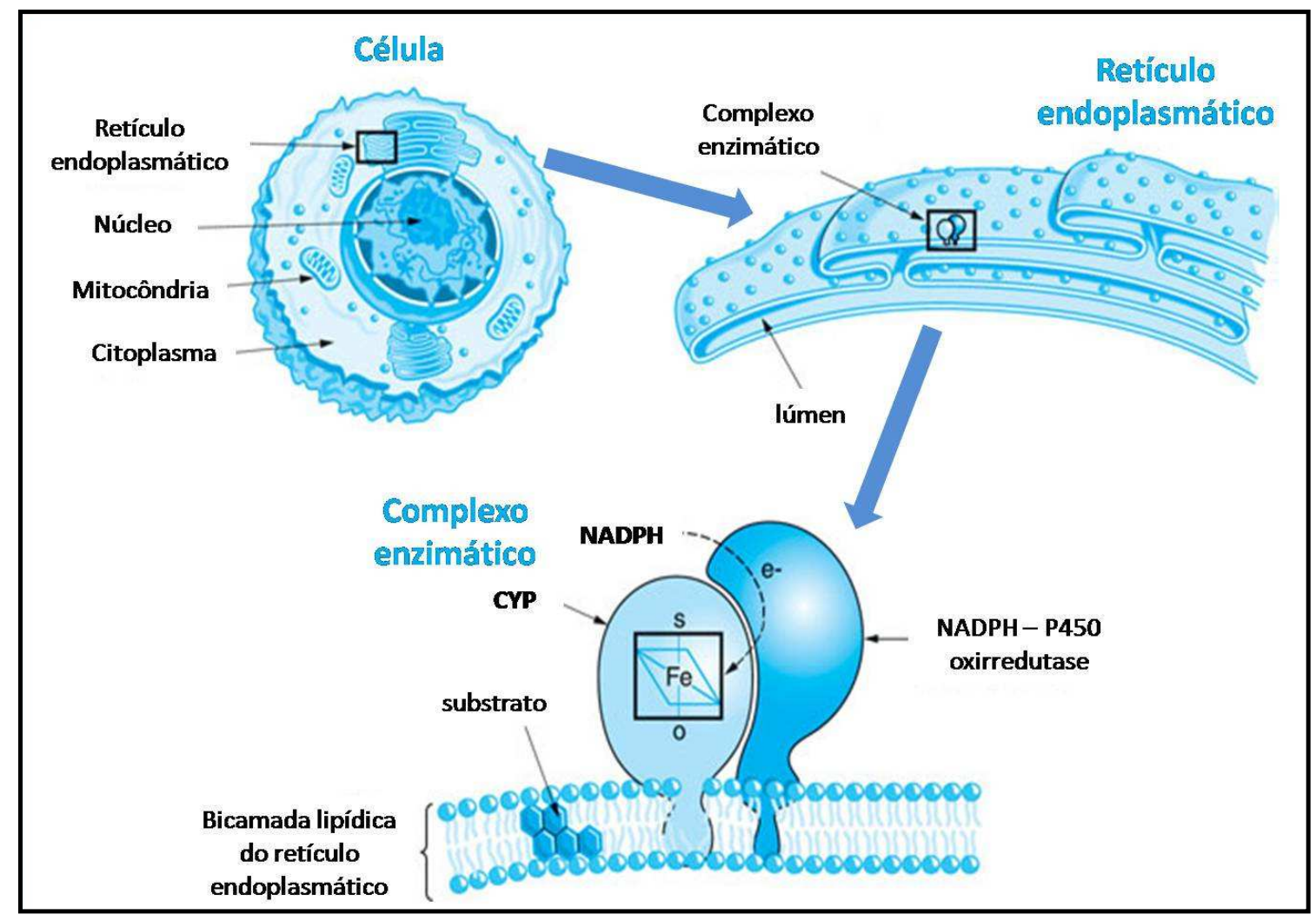

Figure 2. Localização das citocromos (CYPs) na célula. As CYPs estão encaixadas na bicamada lipídica do reticulo endoplasmático (RE). A maioria das enzimas está localizada na superfície citoplasmática do RE. Uma segunda enzima, a NADPHcitocromo P450 oxirredutase, transfere elétrons para a CYP que oxida substratos xenobióticos, na presença do $\mathrm{O} 2$, muitos dos quais são hidrofóbicos e solubilizados no RE. Uma única espécie de NADPH- CYP oxirredutase transfere elétrons para todas as isoformas CYPs no RE (adaptado de Brunton e Parker, 2008). 


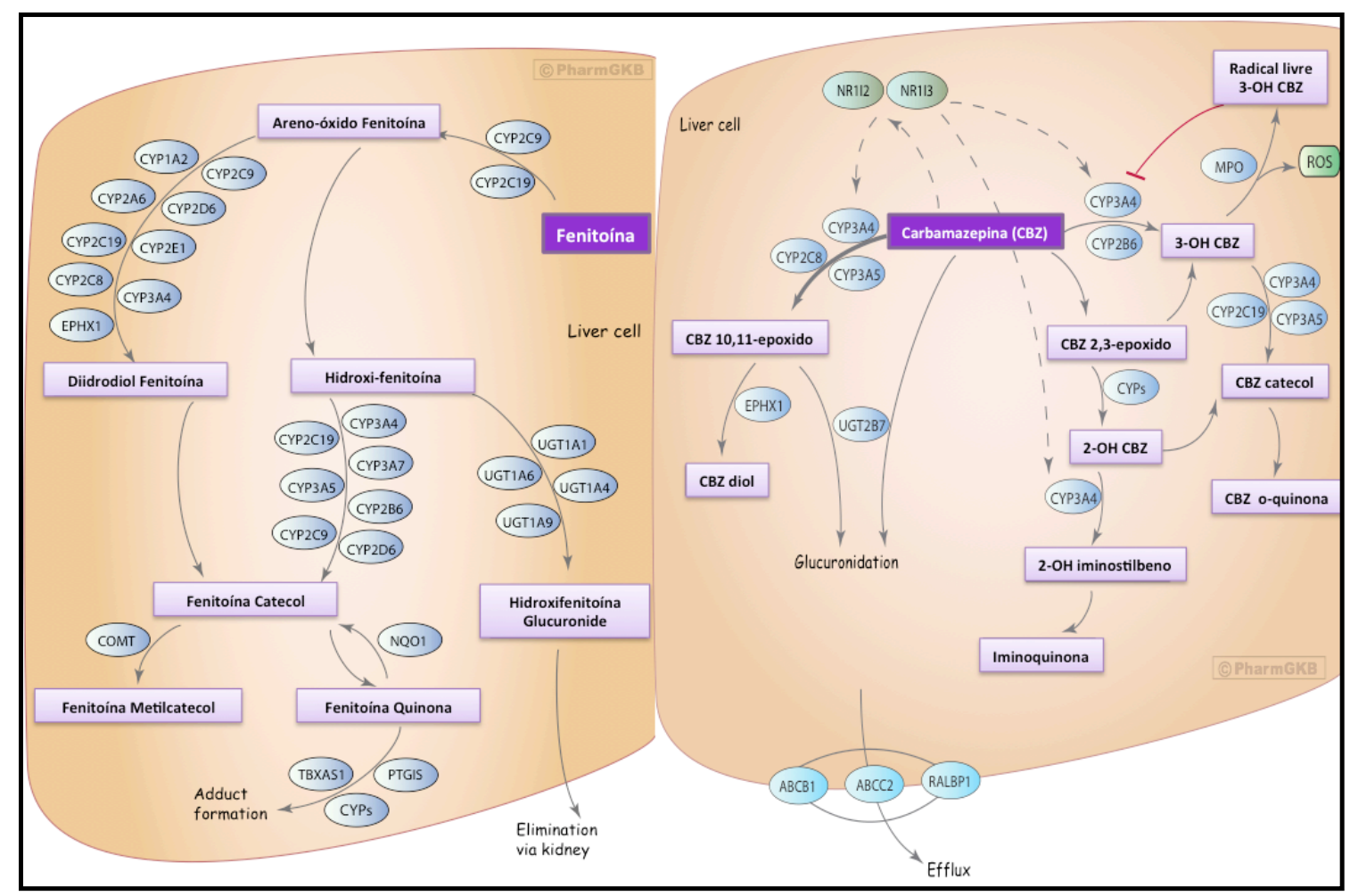

Figura 3. Envolvimento das enzimas do Citocromo (CYP) 2C9, $2 \mathrm{C} 19$ e 3A5 no metabolismo hepático dos anticonvulsivantes de anel aromático, Fenitoína e Carbamazepina

\section{a) Gene CYP2A9}

O gene CYP2C9 (Citocromo P450, família 2, subfamília C, polipeptídeo 9) possui 8 éxons e está localizado no cromossomo 10, é expresso principalmente no fígado, em níveis que são os mais elevados entre as enzimas CYP2C e representa cerca de $20 \%$ de todas as CYPs hepáticas (IngelmanSundberg et al., 2007).

Os polimorfismos de CYP2C9 apresentarem conseqüências funcionais na farmacocinética in vitro e in vivo, na resposta terapêutica e RADs. Dentre as variantes descritas para este gene, parece que apenas os alelos *2 e *3 determinam seu comportamento polimórfico (Ingelman-Sundberg et al., 2007). 
As frequências dos alelos CYP2C9*2 e CYP2C9*3 variam entre diferentes populações. Kirchheiner e Brockmoller (2005) relatam que os alelos *2 e *3 estão presentes principalmente em caucasianos (11\% e $7 \%$ respectivamente) enquanto que em africanos, a frequência é menor ( $4 \%$ e $2 \%$ respectivamente). Em asiáticos, a frequência do alelo *3 é de $3 \%$ e o alelo *2 não foi encontrado.

\section{b) Gene CYP2A19}

O gene CYP2C19 (Citocromo P450, família 2, subfamília C, polipeptídeo 19), codifica a enzima CYP2C19 responsável pelo metabolismo de aproximadamente $10 \%$ dos medicamentos mais comumente utilizados, incluindo os ACA Fenitoína e Fenobarbital (Brockmöller et al., 2008; Zhou et al., 2008).

A enzima CYP2C19 é uma proteína de 490 aminoácidos, codificada pelo gene CYP2C19 que possui 9 éxons, 90.209 pares de bases e está localizado no cromossomo 10. Até o momento, cerca de 21 variações alélicas foram identificadas para CYP2C19 (Zhou et al., 2008).

As relações entre genótipo e fenótipo para CYP2C19 conhecidas são baseadas na identificação do fenótipo EM e PM para o substrato 4-hidroximetilfenitoína que são determinados por polimorfismos genéticos (Justenhoven et al., 2008). O fenótipo PM é o resultado de dois alelos não funcionais, o que leva a codificação de uma proteína inativa, enquanto que EMs possuem pelo menos um alelo funcional (Sugimoto et al., 2008; Zanger et al., 2008). Ambos CYP2C19*2 e *3 são alelos não funcionais, que resultam em ausência de atividade enzimática. A maioria dos PMs de CYP2C19 deve-se a estas duas variações alélicas (Justenhoven et al., 2008; Zhou et al., 2008).

O fenótipo UM foi identificado com base em observações de variações na resposta a medicamento em indivíduos EM, sendo associado ao alelo CYP2C19*17 (Sim 2006). 


\section{c) Gene CYP3A5}

O gene CYP3A5 (Citocromo P450, família 3, subfamília A, polipeptídeo 5) está localizado no cromossomo 7, predominantemente expresso no fígado e no intestino. Codifica a enzima CYP3A responsável pelo metabolismo de mais de $50 \%$ dos fármacos prescritos no mundo, como a Carbamazepina, mas não foi avaliada a sua associação com RHNI aos ACA até o momento (Kuel P 2001). A elevada semelhança de sequências entre as CYP3A5 e CYP3A4 isozimas ( $>85 \%$ de identidade de sequência) leva a selectividade do substrato altamente semelhante entre as isoformas.

O Gene CYP3A5 é extremamente polimórfico, um total de 784 variantes genéticas têm sido descritos e o alelo CYP3A5*3 é o mais comum deles, relacionado à perda de atividade. As diferenças substanciais inderindividuais na expressão do gene CYP3A5 podem contribuir grandemente na biodisponibilidade e depuração de substratos desta enzima. A expressão deste gene parece menor em caucasianos quando comparados a afro-americanos. $\mathrm{O}$ genótipo CYP $3 A 5^{*} 3{ }^{*} 3$ foi associado a uma maior meia-vida de CBZ em afroamericanos; nenhuma associação significativa foi observada em caucasianos. Suarez-Kurts $\mathrm{G}$ e cols. demonstrou a distribuição de polimorfismos de CYP3A5 em indivíduos brasileiros.

\subsubsection{Mecanismos Imunológicos}

A classificação das reações imunológicas a medicamentos se baseia nos mecanismos imunopatológicos envolvidos, ou seja, baseados nos tipos de hipersensibilidade proposta por Gell \& Coombs (Weiss, 1998). Os mecanismos imunopatológicos envolvidos nas RHNI são complexos, entretanto, a maioria das reações não-imediatas/tardias são mediadas por ações de linfócitos T (Park BK, 
2012). O mecanismo celular tende a ser o preponderante nas RH aos ACA, configurando reações tipo IV de Gell e Coombs. São reações mediadas por linfócitos $T$, os quais reconhecem antígenos dos anticonvulsivantes e/ou metabólitos através do receptor de células T (TCR), desencadeando a liberação de citocinas, recrutamento de outros tipos celulares e inflamação tecidual. As descrições originais das reações imunes celulares são baseadas na resposta a haptenos. De forma geral, os metabólitos ativos dos ACA são moléculas de baixo peso molecular, que se ligam de forma covalente a substâncias carreadoras maiores, geralmente um peptídio, tornando-se imunogênicas. Assim, as drogas não constituem por si só um antígeno completo e são denominadas haptenos.

Para estimular as células $T$ virgens, células dendríticas primeiro processam $\mathrm{O}$ antígeno das drogas. $\mathrm{O}$ antígeno é então internalizado e transportado para os nódulos linfáticos regionais. $\mathrm{Na}$ chegada aos gânglios linfáticos, o antígeno é apresentado às células T virgens. Os haptenos originários dos metabólitos ativos dos ACA são apresentados por HLA específico das células apresentadoras de antígeno ao TCR do linfócito ativando-o. As células T antígeno-específicas migram para os órgãos-alvo e, uma vez re-expostos ao antigénio, que são ativadas e liberam citocinas que regulam a resposta e citotoxinas (por exemplo, perforinas, granzimas, e granulisinas) que produzem dano tecidual. O LT é responsável por infiltrar os tecidos e causar dano tissular, bem como produzir citocinas que medeiam o switching de classes de anticorpos.

Baseado no fato dos LT poderem orquestrar diferentes formas de resposta inflamatória e à grande heterogeneidade de caracteres clínicos e laboratoriais das reações celulares, Pichler WJ sugere que as reações tipo IV sejam subclassificadas em IVa - IVd (Pichler 2003, Adam 2011) (Figura 4). 


\begin{tabular}{|c|c|c|c|}
\hline Tipo IV a & Tipo IV b & Tipo IV c & Tipo IVd \\
\hline $\begin{array}{l}\text { - Mediadores: } \\
\text { IFN- } \delta \text {, TNF-a } \\
\text { (Th1) } \\
\text { - Mecanismo } \\
\text { efetor: antígeno } \\
\text { apresentado às } \\
\text { células ou } \\
\text { estímulo direto } \\
\text { LT } \\
\text { - Célula efetora: } \\
\text { Macrófago } \\
\text { ativado } \\
\text { - Manifestações: } \\
\text { Dermatite de } \\
\text { contato }\end{array}$ & $\begin{array}{l}\text { - Mediadores: } \\
\text { IL-5,IL-4/IL-13 } \\
\text { (Th2) } \\
\text { - Mecanismo } \\
\text { efetor: antígeno } \\
\text { apresentado às } \\
\text { células ou } \\
\text { estímulo direto } \\
\text { LT } \\
\text { - Célula efetora: } \\
\text { Eosinófilo } \\
\text { - Manifestações: } \\
\text { Exantema } \\
\text { maculo-papular } \\
\text { com eosinofilia, } \\
\text { DRESS }\end{array}$ & $\begin{array}{l}\text { - Mediadores: } \\
\text { Perforimas/ } \\
\text { Ganzima B } \\
\text { (LCT) } \\
\text { - Mecanismo } \\
\text { efetor: células } \\
\text { associadas ao } \\
\text { antígeno ou } \\
\text { estímulo direto } \\
\text { LT } \\
\text { - Célula efetora: } \\
\text { Célula T } \\
\text { - Manifestações: } \\
\text { Exantemas } \\
\text { bolhosos }\end{array}$ & $\begin{array}{l}\text { - Mediadores: } \\
\text { CXCL8, GM- } \\
\text { CSF (L T) } \\
\text { - Mecanismo } \\
\text { efetor: } \\
\text { antígenos } \\
\text { solúveis } \\
\text { apresentados } \\
\text { pelas células } \\
\text { ou estímulo } \\
\text { direto LT } \\
\text { - Célula efetora: } \\
\text { Neutrófilo } \\
\text { - Manifestações: } \\
\text { PEGA, Doença } \\
\text { Behçet }\end{array}$ \\
\hline
\end{tabular}

Figura 4. Subclassificação das reações tipo IV de Gell e Coombs (adaptado de Pichler WJ).

Linfócitos $\mathrm{T}$ droga específica à Carbamazepina e aos seus metabólitos foram identificados nos pacientes com história de hipersensibilidade. Estas células apresentavam padrão Th1 com produção de altos níveis de gamainterferon, além de apresentarem padrão fenotípico de células T, maior expressão de receptores "homing" na pele e perforinas, associadas à morte de queratinócitos (Borrish 1998, Pichler 2003, Adam 2011). 


\subsubsection{O Sistema Antígeno Leucocitário Humano}

O Complexo Principal de Histocompatibilidade (MHC) representa o conjunto de genes responsável por codificar as moléculas de histocompatibilidade de cada espécie. Na espécie humana, é chamado de sistema Antígeno Leucocitário Humano (HLA - Human Leukocyte Antigen). O sistema HLA é codificado no braço curto do cromossomo 6, uma região com 150 genes, envolvidos em rejeições de transplantes, doenças auto-imunes, reações de hipersensibilidade alérgica além de outras situações clínicas (Figura 5). Mais de 40 por cento destes genes está envolvida com a sinalização de linfócitos T. Os genes codificadores de HLA são os mais polimórficos do genoma humano, envolvendo mais de 1600 alelos, sendo 87 mais freqüentemente estudados. Os complementos de HLA são peculiarmente únicos, não havendo dois indivíduos com a mesma combinação de seis moléculas classe I. Os polimorfismos dos alelos têm evoluído como forma de proteção a agentes infecciosos. No entanto, alguns alelos de HLA com ação protetora a agentes infecciosos podem também predispor o indivíduo a reação adversas graves a medicamentos (Klein 2003).

O reconhecimento dos haptenos originários dos metabólitos dos anticonvulsivantes e o desencadeamento da resposta imune são dependentes de certos antígenos HLA (MHC de restrição). A ligação específica de HLA e o receptor de LT têm sido foco de investigação na fisiopatologia das RHNI, baseado no fato de haver polimorfismos genéticos de HLA associados a determinadas reações (Kim 2010) (Tabela 3). 


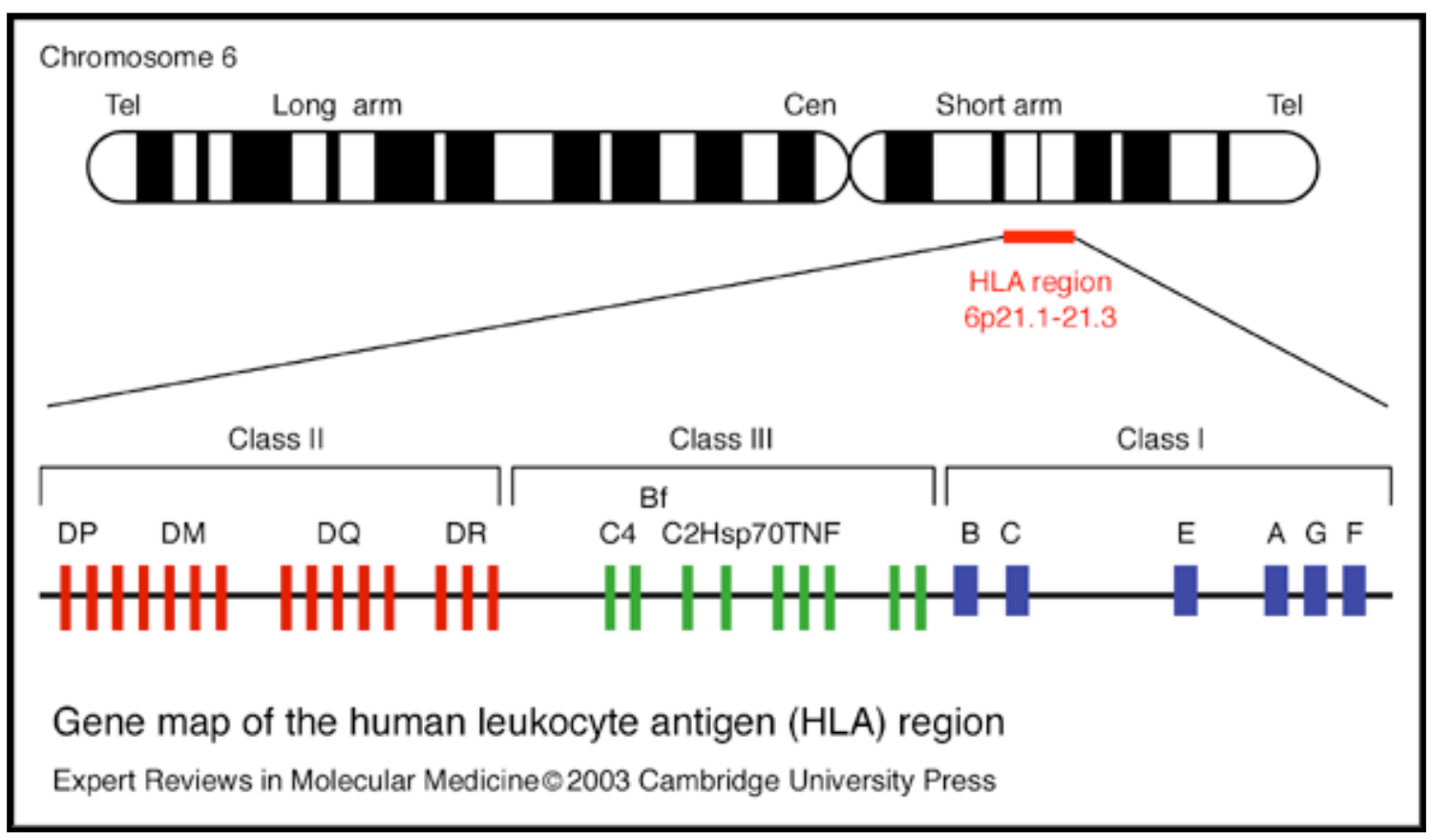

Figure 5. Mapa genético da região codificadora de HLA: A região HLA abrange $4 X$ 106 nucleótidos no cromossoma 6p21.1 a p21.3, com classe II, classe III e genes de classe I. Moléculas de HLA de classe I restringem a função de linfócitos CD8 + citotóxicos e mediam as respostas imunes contra antígenos endógenos e células-alvo infectadas por vírus, enquanto que as moléculas de HLA de classe II estão envolvidas na apresentação de antigénios "exógenas" às células T auxiliares. A região de HLA de classe III contém muitos genes que codificam proteínas que não estão relacionados com a imunidade mediada por células, mas que, no entanto, modulam ou regulam as respostas imunes, incluindo o fator de necrose tumoral (TNF), proteínas de choque térmico (HSPs) e proteínas de complemento (C2 C4). (adaptado de Narinder 2003)

\subsection{Farmacogenética}

A aplicabilidade dos estudos das variações genéticas na resposta aos medicamentos teve início no fim da década de 50 e o termo original "farmacogenética", estudo de diferenças herdadas (variações) no metabolismo e resposta do fármaco, foi inserido na literatura médica em 1957 por Vogel (Koo 2006). Desde então, houve um crescente interesse no papel dos fatores genéticos, entretanto, os maiores avanços ocorreram nos últimos 15 anos, quando houve a definição do Projeto Genoma Humano. Atualmente, entende-se o 
conceito de farmacogenoma como sendo o estudo da forma como as variações do genoma humano afetam a resposta à droga (Svensson 2000, Pirmohamed 2001, Sade 2005, Eichelbaum 2006).

Apesar de muitos fatores influenciarem na resposta aos medicamentos, estima-se que a genética pode ser a razão de até $95 \%$ da variabilidade na biodisponibilidade dos medicamentos e em seus efeitos. Uma vez que o fármaco é administrado, ele é absorvido e distribuído até seu sítio de ação, onde interage com seus alvos (receptores ou enzimas, por exemplo), é metabolizado e depois excretado. Cada um desses processos tem a capacidade de influenciar no efeito do medicamento e pode potencialmente envolver variações genéticas clinicamente significantes (Kerb 2006).

A farmacogenética associa características fenotípicas de resposta ao fármaco com marcadores genéticos tais como: tipificação de HLA, polimorfismos, incluindo polimorfismos de uma única base (single nucleotide polymorphisms - SNPs), inserções, deleções e repetições microssatélites que compõem o genótipo (Kerb 2006).

Variações funcionais causadas por polimorfismos de uma única base (SNPs) em genes que codificam as enzimas metabolizadoras de drogas, transportadores e receptores têm sido associados a variações inter-individuais na resposta ao medicamento (Kerb 2006).

Assim, a estratégia primária da farmacogenética é estudar variações nas seqüências em genes suspeitos relacionados à resposta terapêutica e às reações adversas a medicamentos. A variabilidade genética em populações humanas é importante na predisposição nas RH. Entretanto, o grau e o tipo de predisposição genética podem variar de acordo com o tipo de população estudada (Tabela 3). 


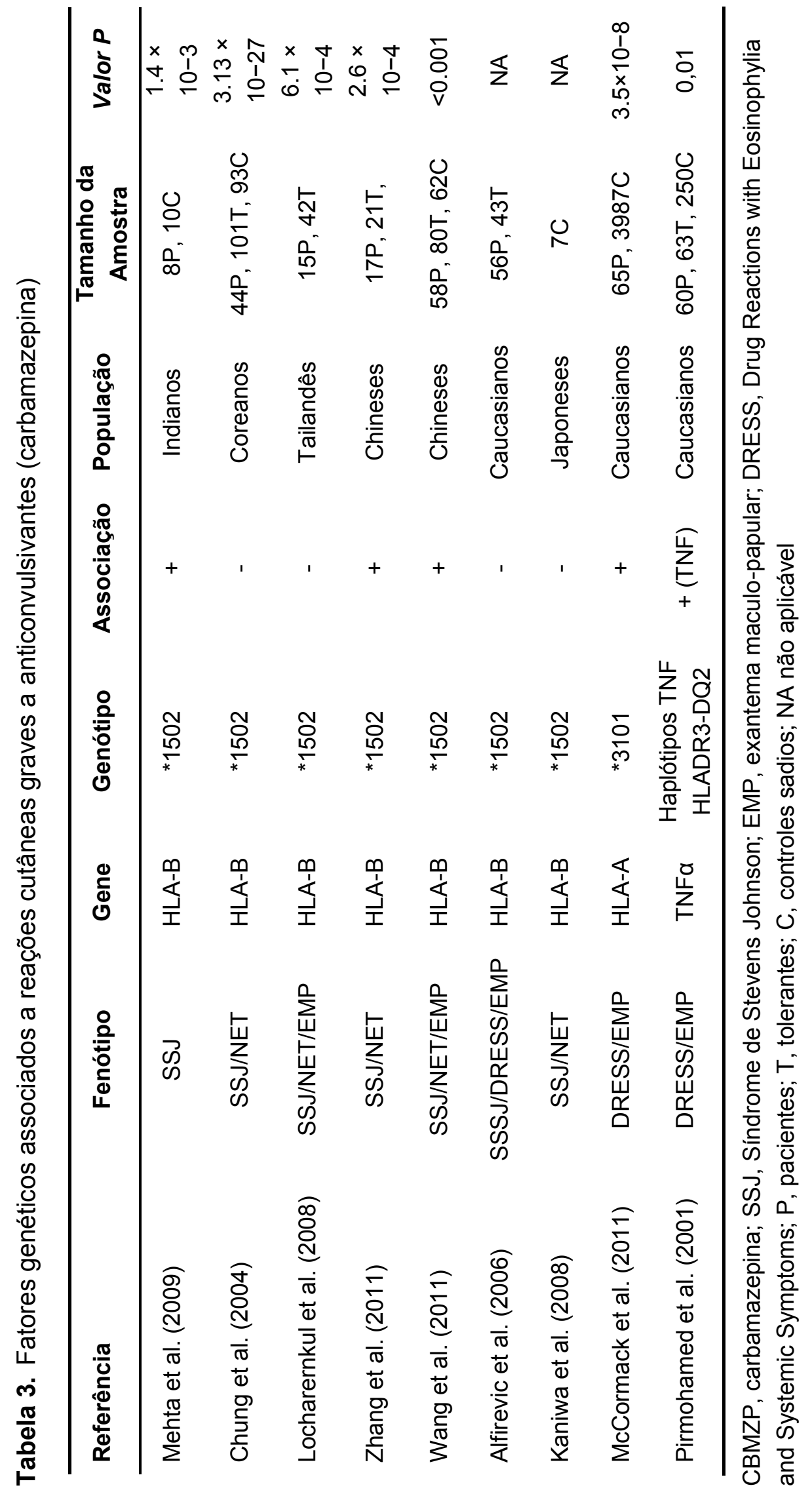




\subsection{Potenciais da Farmacogenética}

Durante a utilização clínica de um medicamento, não há meios de predizer qual será a reação do paciente ao uso do mesmo. Em alguns pacientes pode haver falha terapêutica, enquanto em outros, pode haver reações adversas. Essas respostas inesperadas ao fármaco são frequentemente o resultado de um rígido padrão de doses usualmente recomendadas, ignorando a diversidade individual dos pacientes (Shah 2005).

O descobrimento de associações de fenótipo e genótipo durante o desenvolvimento de uma droga e a demonstração de sua validade clínica e utilidade em testes clínicos, irá sem dúvida, definir o papel da farmacogenética no futuro da prática clínica.

A capacidade em prever e prevenir reações idiossincrásicas e de hipersensibilidade por testes genéticos pode, então, ser um importante avanço nas perspectivas clínicas em reduzir a morbidade e a mortalidade, além de criar novas perspectivas de uma medicina personalizada.

\subsection{Genética e farmacogenética nas reações de hipersensibilidade a anticonvulsivantes aromáticos}

Estudos têm tentado relacionar fatores genéticos às reações de hipersensibilidade a anticonvulsivantes, entretanto, os resultados obtidos não têm sido reprodutíveis em etnias diferentes (Tabela 3 ).

Uma associação farmacogenética forte foi verificada entre HLAB*1502 e SJS induzida por carbamazepina (CBZ) em pacientes chineses. Esta associação foi reprodutível nas populações indiana e taiwanesa, mas não em caucasianos e em japoneses (Mehta 2009, Kim 2009, Locharernkul 2008, Man 
2007). Por outro lado, observou-se uma associação importante entre o HLAA*3101 e a hipersensibilidade induzida por CBZ em indivíduos de ascendência norte-européia (McCormack 2011).

O metabolismo alterado do medicamento pode estar associado com RH. A CYP2C9 é uma das principais enzimas responsáveis pela metabolização de antiepiléticos. O gene CYP2C9 apresenta polimorfismos genéticos tanto na região promotora como na região codificante. Dois alelos relevantes são o CYP2C9*2 (encontrada em 1-13\% de caucasóides e em 1-4\% de africanos) e o CYP2C*3, ambos associados a uma marcada diminuição na capacidade metabólica de seus substratos, comparados ao gene normal CYP2C9*1. Outra variante foi identificada apenas nos afro-americanos, CYP2C9*5. Em todos estes casos é necessário reduzir a dose dos medicamentos prescritos, demostrando a importância da análise dos polimorfismos na farmacogenômica (Stephen 2006, Q Zhou 2009). 
Os anticonvulsivantes aromáticos são responsáveis por 10\% de todas as RADs e por $2 \%$ de todas as reações adversas dermatológicas e estão associados a manifestações de grande morbidade e mortalidade.

As RH a ACA são idiossincrásicas, portanto, imprevisíveis, não dependentes da dose e não estão relacionadas ao efeito farmacológico do medicamento. Há evidências de envolvimento imunológico em sua gênese, além da susceptibilidade genética. A predisposição genética parece ter associação importante com as $\mathrm{RH}$ a ACA. Os fatores de susceptibilidade não estão totalmente claros, mas os estudos feitos até o momento focaram apenas um fator genético por vez e em populações etnicamente homogêneas.

Não há padronização adequada do teste cutâneo de leitura tardia disponível para utilização clínica para este grupo farmacológico. Da mesma forma, não se sabe se há diferenças de intensidade na resposta cutânea local nos diferentes quadros de hipersensibilidade tardia aos anticonvulsivantes aromáticos na população brasileira. Assim, a estratificação de fatores fenotípicos adequados e a caracterização genética associada à reação de hipersensibilidade tardia aos anticonvulsivantes de estrutura aromática na população brasileira podem auxiliar a prever estas reações. Os achados de marcadores genéticos de risco e/ou de proteção podem, portanto, constituir um avanço na abordagem clínica, minimizando a morbidade e a mortalidade, além de criar novas possibilidades de uma medicina personalizada. 


\section{Objetivo Geral}

- Identificar fatores genéticos em indivíduos brasileiros, associados à reação de hipersensibilidade tardia aos anticonvulsivantes de estrutura aromática.

\section{Objetivos Específicos}

- Caracterização fenotípica dos pacientes que apresentaram reação de hipersensibilidade tardia aos anticonvulsivantes aromáticos baseado em história clínica, manifestações e teste de contato com medicamentos.

- Avaliar a associação de polimorfismos genéticos de HLA e CYP em pacientes brasileiros com reação de hipersensibilidade tardia aos anticonvulsivantes aromáticos.

- Tipificar alelos do sistema HLA de indivíduos brasileiros que apresentaram reação de hipersensibilidade tardia aos anticonvulsivantes aromáticos e controles. 


\section{Casuística e Métodos}


Os indivíduos estudados são provenientes do Complexo do Hospital das Clínicas ou voluntários. Foram estudados três grupos: um grupo de pacientes com história de reações de hipersensibilidade tardia aos anticonvulsivantes aromáticos (exantema maculo-papular, eritema multiforme, SSJ, NET, DRESS) e dois grupos controle. Um deles, constituído de indivíduos que toleram anticonvulsivantes aromáticos há pelo menos seis meses e, o outro, de indivíduos hígidos (sem história de utilização de anticonvulsivantes aromáticos). Os dados clínicos foram baseados em dados de prontuário e avaliação clínica. O estudo é prospectivo com a tipificação de HLA dos loci A, B, C, DRB, DQA, DQB e avaliados os polimorfismos genéticos de CYP e HLA em todos os grupos (Tabela 4) (Figura 6).

\subsection{Descrição do apoio institucional recebido}

O presente trabalho foi desenvolvido no Laboratório Imunologia, LIM-19, no Instituto do Coração da FMUSP e em colaboração com o Laboratório de Neurociências, LIM-27, no Instituto de Psiquiatria da FMUSP. Ambos os laboratórios têm toda a infra-estrutura necessária para o desenvolvimento do projeto.

\subsection{Apoio financeiro}

O atual projeto recebeu apoio financeiro da FAPESP sob o número do projeto $2011 / 22748-1$ 


\subsection{Cálculo amostral}

Considerando um odds ratio de 2 , são necessários $16 \%$ de casos em relação à amostra total para atingir um poder de 0,95 . O odds ratio considerado foi baseado em cálculo amostral de estudos já publicados.

\subsection{Termo de Consentimento Livre e Esclarecido}

O estudo foi analisado e aprovado pela Comissão de Ética para Análise de Projetos de Pesquisa CAPPesq do Hospital das Clínicas da FMUSP sob o número de protocolo 0554/11 (Anexo 1). Todos os indivíduos incluídos leram e assinaram o termo de consentimento livre e esclarecido.

\subsection{Seleção de pacientes}

Os indivíduos foram organizados em 3 grupos:

A. Pacientes com hipersensibilidade aos anticonvulsivantes aromáticos.

B. Pacientes que utilizam anticonvulsivantes aromáticos há 06 meses sem reação.

C. Controles: pacientes sem história de uso de anticonvulsivantes aromáticos.

\subsection{Critérios de inclusão e de exclusão}

A) CRITÉRIOS DE INCLUSÃO

- Idade igual ou maior de 18 anos. 
- Diagnóstico clínico definido de RAD.

- Relação direta evidente entre o uso do anticonvulsivante e a reação.

B) CRITÉRIOS DE EXCLUSÃO

- Diagnóstico indefinido.

- Pacientes com urticária crônica e com pênfigo ou penfigóide bolhoso por serem diagnósticos diferenciais das manifestações em estudo.

- Pacientes que apresentaram reações de remissão espontânea apesar da continuidade do medicamento.

- Indivíduos com história de consanguinidade por poder constituir um viés na análise genética.

\subsection{Critérios diagnósticos clínicos de hipersensibilidade aos anticonvulsivantes aromáticos}

História Clínica baseada em avaliação clínica e dados de prontuário dos pacientes. Serão enfatizados os seguintes dados:

- Dados demográficos e étnicos.

- Caracterização clínica e relação com o fármaco.

- Medicamento(s) suspeito(s).

- Antecedentes pessoais: reações prévias, co-morbidades, uso de outros medicamentos, presença de doença(s) atópica(s).

- Hábitos e vícios. 
- História familiar: uso de medicações semelhantes, reações a medicamentos, doenças atópicas.

\title{
4.8 Critérios clínicos para diagnóstico das principais reações de hipersensibilidade aos anticonvulsivantes aromáticos
}

\begin{abstract}
A avaliação fenotípica foi realizada com uma escala baseada no questionário diagnóstico adaptado sugerido pela ENDA (European Network of Drug Allergy) (Anexo 4), em dados de prontuário e no seguimento clínico dos pacientes (Demoly 1999). Os critérios diagnósticos utilizados são os previamente descritos (Pirmohamed 2011, Demoly 2014).
\end{abstract}

\subsection{Teste de Contato com Medicamentos}

Os testes de contato com medicamento (TCM) para investigação etiológica das reações de hipersensibilidade tardia seguiram as recomendações técnicas de Romano e colaboradores 2004, Tanno e colaboradores 2011 e Brokow e colaboradores 2013. Os testes de contato (TC) foram realizados com os medicamentos suspeitos, além do veículo utilizado para cada diluição. As concentrações e diluições utilizadas foram as sugeridas pela literatura (Romano 1993, Calvin 1993, Barbaud 2009, Vervloet 2009, Barbaud 2005, Tanno LK 2011 , Brokow 2013). Os medicamentos diluídos foram aplicados sobre a pele do dorso do paciente em câmaras do tipo Finn Chamber®. As leituras foram realizadas após 48 e 96h da aplicação. Os testes foram realizados no mínimo 06 semanas após a resolução da reação. As recomendações a respeito de medicações ou outras condições que pudessem prejudicar a interpretação do teste seguiram as orientações do Grupo Internacional de Dermatites de Contato (Adams, 1981). 
Quando o TCM resultou positivo, foi replicado em 10 indivíduos saudáveis como controles do teste para a certificação de concentrações não irritativas.

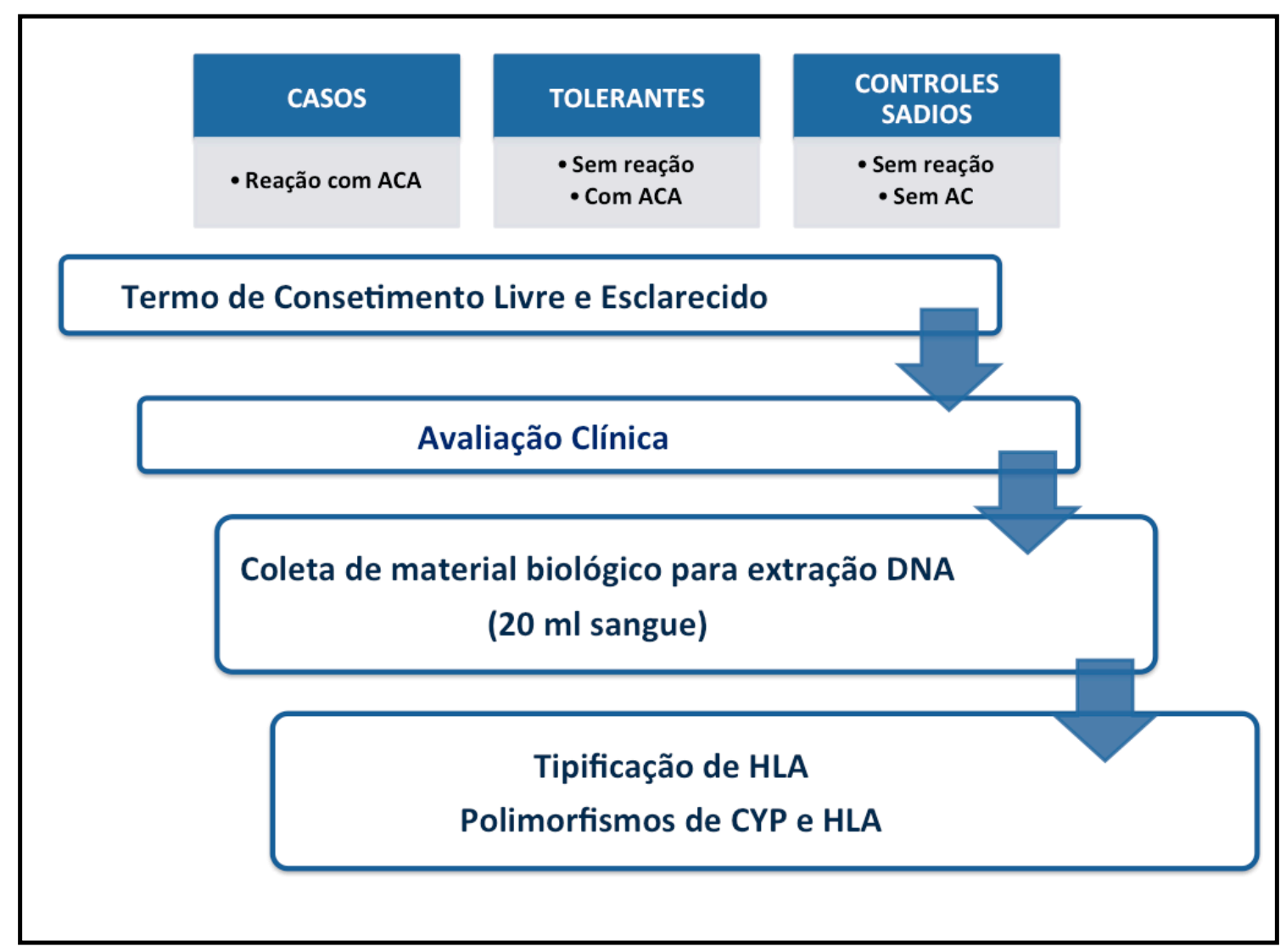

Figure 6. Fluxograma do estudo

\subsection{Análise de DNA}

O DNA foi obtido a partir de $20 \mathrm{~mL}$ de sangue heparinizado estéril para obtenção de células mononucleares a partir de veia periférica de pacientes e controles por método de coleta padrão. O DNA foi extraído pelo método salino. Os ácidos nucléicos extraídos foram quantificados em espectrofotômetro (Abs 260 e $280 \mathrm{~nm}$ ) e sua qualidade foi avaliada em géis de agarose apropriados.

Foram consideradas passíveis de utilização as suspensões com concentração de DNA de pelo menos 2,5ng/ $/$ l. 
Os polimorfismos foram avaliados por discriminação alélica utilizando o sistema TaqMan (Applied Biosystems), no aparelho de PCR em tempo real (7500 Real-Time PCR system, Applied Biosystems, Foster City, CA,

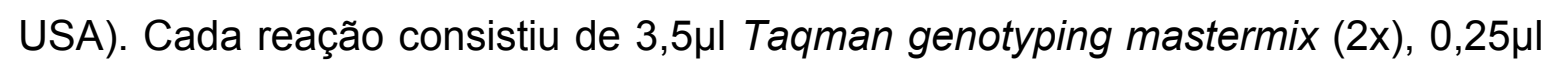
do assay Taqman genotyping, $2 \mu \mathrm{l}$ de DNA $(2,5 \mathrm{ng} / \mu \mathrm{l})$ e água milliQ para $7 \mu \mathrm{l}$. Foram realizados 45 ciclos de amplificação e os níveis de fluorescência para cada sonda específica foram associados aos respectivos alelos.

A tipificação do HLA foi realizada utilizando-se a Reação em Cadeia da Polimerase (PCR - Polymerase Chain Reaction) e amplificado com oligonucleotídeos sequencia específica (SSO - Sequence-specific Oligonucleotide) por meio de kits LABType ${ }^{R}$, que alia a tecnologia Luminex ${ }^{\mathrm{R}}$. (Cesdron-Gautier 2004)

\subsection{Regiões e genes candidatos}

Propusemos neste projeto, estudar os fatores genéticos relacionados ao metabolismo do fármaco (CYP) e ao mecanismo fisiopatológico implicado (HLA - por estudo dos SNPs e tipificação) em indivíduos brasileiro.

Os polimorfismos de DNA foram buscados na literatura (Tabela 3), no caso de SNPs já estudados. Avaliamos na nossa população a presença de polimorfismos relacionados com $\mathrm{RH}$ a ACA, descritos na literatura (Tabela 3) e os de interesse. Caracterizamos a amostra quanto ao metabolismo de anticonvulsivantes, dado pela genotipagem da CYP. Os genes de CYP candidatos foram escolhidos de acordo com a associação prévia às reações aos ACA e com a importância na metabolização dos ACA (Tabela 4).

Os ensaios para genotipagem dos SNPs foram obtidos a partir dos assays disponíveis comercialmente pela Life Technology ${ }^{R}$ e os não disponíveis 
foram customizados a partir do DB SNP (http://www.ncbi.nlm.nih.gov/snp). (Tabela 4)

De acordo com o alelo de CYP apresentado, cada indivíduo foi classificado funcionalmente como normal, reduzido ou aumentado para a atividade de cada enzima (Tabela 5). 
Tabela 4. Genes de HLA e CYP, polimorfismos (SNP) analisados e suas respectivas localizações cromossômicas

\begin{tabular}{l|c|c|c|c|c}
\hline GENES & \multicolumn{2}{|c|}{ HLA } & \multicolumn{3}{c}{ CYP } \\
\hline & HLA-B*1502 & HLA-A*3101 & CYP2C19 & CYP2C9 & CYP3A5 \\
\hline DB SNP & rs3909184 & rs1633021 & rs4244285 & rs1057910 & rs776746 \\
& rs2844682 & rs1061235 & rs4986893 & rs1799853 & \\
& rs3130690 & & rs12248560 & & \\
\hline & rs1264511 & & rs11188072 & & \\
\hline CROMOSSOMO & 6 & \multicolumn{3}{c|}{10} & 7 \\
\hline
\end{tabular}

Tabela 5. Variações alélicas estudadas dos genes CYP2C19, CYP2C9 e CYP3A5 de acordo com a página Allele Nomenclature Committee <http://www.cypalleles.ki.se.htm>. Os polimorfismos indicados pelas referências (Ref SNP ID) são os principais responsáveis pelo fenótipo correspondente a cada alelo.

\begin{tabular}{c|c|c}
\hline CYP2C19 & \multicolumn{2}{|}{} \\
\hline Alelo & Ref SNP ID & Atividade enzimática \\
\hline${ }^{* 2}$ & rs4244285 & Nula \\
\hline$* 3$ & rs4986893 & Nula \\
\hline$* 17$ & rs12248560 & Aumentada \\
\hline$* 17$ & rs11188072 & Aumentada \\
\hline CYP2C9 & & Reduzida \\
\hline$* 2$ & rs1057910 & Reduzida \\
\hline$* 3$ & rs1799853 & Reduzida \\
\hline CYP3A5 & \multicolumn{2}{|c}{} \\
\hline$* 3$ & rs776746 &
\end{tabular}


A determinação do fenótipo de atividade enzimática predito para CYP2C19 foi realizada segundo Ragia et al. (2009) que classifica como UMs homozigotos para o alelo de atividade aumentada *17; "UMs heterozigotos" a presença do alelo *17 em combinação com um alelo de atividade normal ( $\left.{ }^{*} 1\right)$ porque sua capacidade metabólica está entre UMs e EMs. Indivíduos que possuem um alelo de atividade aumentada ( $\left.{ }^{*} 17\right)$ e um alelo de atividade nula ( ${ }^{* 2}$ ou *3) foram classificados como EMs. Heterozigotos para um alelo de atividade nula e um alelo funcional foram classificados como IMs e homozigotos de alelos não funcionais classificados como PMs (Tabela 5 e 6 ).

Por outro lado, a determinação do fenótipo de atividade enzimática predita para CYP2C9 e CYP3A5 foi definida de acordo com Scott et al. (2007) que classifica como EMs homozigotos para o alelo normal *1; IMs indivíduos que possuem um alelo normal e um alelo de atividade reduzida ( ${ }^{*} 2$ ou *3) e PMs como homozigotos para alelos de atividade reduzida (Tabela 5 e 6 ). 
Tabela 6. Determinação do fenótipo de atividade enzimática predito para CYP2C19, CYP2C9 e CYP3A5 de acordo com a combinação alélica. (UM e EM = metabolizadores normais, IM e PM = metabolizadores lentos)

\begin{tabular}{l|c|c}
\hline \multirow{4}{*}{ Gene } & Fenótipo Predito & $\begin{array}{c}\text { Atividade enzimática conforme } \\
\text { combinação alélica }\end{array}$ \\
\hline \multirow{4}{*}{ CYP2C19 } & EM & $\begin{array}{c}\text { Normal+Normal; } \\
\text { Aumentado+Diminuído }\end{array}$ \\
\cline { 2 - 3 } & IM & Normal+Diminuído \\
\cline { 2 - 3 } & UM heterozigoto & Aumentado+Aumentado \\
\cline { 2 - 3 } & PM & Aumentado+Normal \\
\hline \multirow{3}{*}{ CYP2C9 } & EM & Diminuído+Diminuído \\
\cline { 2 - 3 } & IM & Normal+Normal \\
\cline { 2 - 3 } & PM & Diminuído+Diminuído \\
\hline \multirow{3}{*}{ CYP3A5 } & EM & Normal+Normal \\
\cline { 2 - 3 } & IM & Normal+Diminuído \\
\cline { 2 - 3 } & PM & Diminuído+Diminuído \\
\hline
\end{tabular}

\subsection{Análise estatística}

As análises estatísticas foram realizadas com auxílio do programa estatístico Statistical Package for the Social Sciences (SPSS), versão 14.0 para Windows (2004). Níveis de significância foram designados estatisticamente significativos quando $p \leq 0,05$. A associação das frequência alélicas entre os grupos foi analisada pelo cáculo do chi-quadrado. Utilizamos o teste de conformidade a proporções de Hardy-Weinberg para identificar eventuais falhas de genotipagem. 
Uma forma de aumentar o poder estatístico da análise é avaliar quanto à presença ou ausência de um alelo. Utilizamos o teste exato de Fisher realizado pelo programa $R$ versão 3.0.0.

Para possibilitar a correlação dos loci de HLA os grupos estudados realizamos inicialmente o cálculo de chi-quadrado. A fim permitir a discriminação de casos e da população geral baseado no método Luminex ${ }^{R}$ de média resolução, utilizamos a análise discriminante.

Com o objetivo de analisar globalmente dos resultados e suas associações, construímos árvores de classificação e regreção e calculamos sua sensibilidade. 
Objetivo 1: Caracterização fenotípica dos pacientes brasileiros que apresentaram reação de hipersensibilidade tardia aos anticonvulsivantes aromáticos e controles.

\subsection{Caracterização clinico-demográfica da população estudada}

Foram incluídos um total de 506 indivíduos distribuídos nos três grupos estudados, sendo 55 casos de reação de hipersensibilidade não-imediata (RHNI) aos ACA, 83 tolerantes e 366 controles sadios. Do total de indivíduos estudados, $75 \%$ foram do gênero feminino e a média de idade de 43,6 anos. Oitenta porcento reportaram etnia mista. Dos 55 casos validados como reações de hipersensibilidade não-imediata aos ACA, 32 preencheram critérios para reação de hipersensibilidade ao ACA, também conhecida como DRESS (Drug Reaction with Eosinophilia and Systemic Symptoms), 12 para Síndrome de Stevens-Johnson Syndrome (SSJ) e 11 para reações brandas ao ACA como o exantema máculo-papular. Todos os pacientes tiveram o ACA como principal fator etiológico das reações. Incluímos um maior número de controles sadios em relação ao número de casos e tolerantes, entretanto, houve proporção entre os grupos controles sadios e casos quanto ao gênero, faixa etária e distribuição étnica referida pelo próprio paciente. (Tabela 7) 
Tabela 7. Perfil demográfico dos indivíduos incluídos no estudo de acordo com o gênero, faixa etária e etnia reportada

\begin{tabular}{lcccc}
\hline Variáveis & $\begin{array}{c}\text { Casos } \\
\mathbf{( N = 5 5 )}\end{array}$ & $\begin{array}{c}\text { Tolerantes } \\
\mathbf{( N = 8 5 )}\end{array}$ & $\begin{array}{c}\text { Controles sadios } \\
\mathbf{( N = 3 6 6 )}\end{array}$ & $\begin{array}{c}\text { Total } \\
\mathbf{( N = 5 0 6 )}\end{array}$ \\
Variáveis categóricas & $\mathbf{N}(\%)$ & $\mathbf{N}(\%)$ & $\mathbf{N}(\%)$ & $\mathbf{N}(\%)$ \\
\hline Gênero & & & & \\
Feminino & $42(76)$ & $47(55)$ & $293(80)$ & $382(75)$ \\
Masculino & $13(24)$ & $38(45)$ & $73(20)$ & $124(25)$ \\
\hline Faixa etária & & & & \\
Adulto jovem (18-40 anos) & $23(42)$ & $26(30)$ & $147(40)$ & $196(39)$ \\
Adultos (40-60 anos) & $25(46)$ & $44(52)$ & $179(49)$ & $248(49)$ \\
Idosos (> 61 anos) & $7(12)$ & $15(18)$ & $40(11)$ & $62(12)$ \\
\hline Etnia & $7(13)$ & $23(27)$ & $67(18)$ & $97(19)$ \\
Caucasiano & $47(87)$ & $62(73)$ & $299(82)$ & $408(81)$ \\
Não-caucasiano (mista) & & & &
\end{tabular}

\subsection{Determinação de causalidade das reações de hipersensibilidade} baseadas em história clínica e resultados de teste de contato com medicamentos

O teste de contato com o medicamento suspeito têm sido descrito como método complementar que auxilia na determinação causal das RHNI de apresentação cutânea, mas há raras publicações nacionais. Apesar da positividade do teste poder variar de 32 a $50 \%$, parece ser uma ferramenta diagnóstica em casos em que o teste de provocação, considerado o método diagnóstico padrão-ouro, está contra-indicado. Assim, propusemos, inicialmente, um pré-projeto (Anexo) com o objetivo de verificar a sensibilidade, a especificidade e os valores preditivos (VP) do teste de contato com medicamentos (TCM) como método complementar na investigação etiológica in vivo das RHNI a 
medicamentos em pacientes brasileiros (Tanno 2011). Neste pré-projeto, com caráter prospectivo, realizamos 54 testes de contato (TC) com os medicamentos suspeitos em 44 pacientes com RHNI a medicamentos. O TCM foi aplicado em 10 controles. Concluímos que de todos os 55 TCM, $18(32,7 \%)$ foram positivos ( $p=$ 0,003). A sensibilidade e a especificidade foram de $33 \%$ e de $100 \%$, respectivamente. O VP positivo dos TCM foi de $100 \%$ e o negativo de $70,8 \%$. Nas reações graves (DRESS e SSJ), a sensibilidade chegou a 53\% e o VP negativo foi de 90,9\%. A sensibilidade do TCM parece variar de acordo com o medicamento testado e com a reação apresentada. Dessa forma, com base na experiência dos resultados iniciais comentados, aplicamos a técnica de TCM com ACA nos pacientes incluídos no atual estudo.

Propusemos a realização do teste de contato com ACA nos casos de RHNI em que este medicamento foi suspeito. Verificamos que de todos os 46 TCM realizados, 29 (63\%) foram positivos, tanto em SSJ e na DRESS (Tabela 8). Não houve reações adversas durante a realização dos TCM. O TCM não foi realizado em 11 casos por dificuldades de seguimento destes pacientes ou por haver contra-indicações à realização do procedimento, como uso de medicamentos que alterem a interpretação do teste.

\subsection{Caracterização clinico-demográfica dos casos de reação de hipersensibilidade não-imediata aos anticonvulsivantes aromáticos}

Com base nos dados clínicos e cronologia, os antiepilépticos foram os agentes suspeitos no desencadeamento de todos os 55 casos. A gravidade das manifestações cutâneas das reações variaram de erupção maculopapular a dermatitis esfoliativas e bolhosas. Conforme apresentado na Tabela 8, 32 pacientes foram validados como DRESS, 12 como SJS e 11 como eritema maculopapular. A carbamazepina (CBZ) foi o medicamento envolvido em $82 \%$ 
das reacções, tanto casos leves e graves. O início tardio da reação foi importante em casos de DRESS, mas ocorreu em pequena proporção em SSJ . Nenhum dos casos de exantema maculo-papular ocorreu após quatro semanas de uso de drogas. As reações cutâneas graves a medicamentos, DRESS e SSJ, mostraramse reações sistêmicas com envolvimento de órgãos internos requerendo hospitalização por longo prazo, principalmente nos casos DRESS, mas também na SSJ. A maior parte dos casos, tanto leve como grave, foi tratada com corticosteróides sistêmicos e anti-histamínicos. A Imunoglobulina intravenosa (IgIV) foi exclusivamente indicada para casos SJS. De todos os 46 testes de contato com anticonvulsivantes, 29 (63\%) foram positivos e $63 \%$ de resultados positivos foram na DRESS. No grupo de 32 pacientes com DRESS, resultado positivo foi observado em 18 casos (72\%). Aparentemente o grau de positividade de testes de contato com fármaco não mostraram correlação significativa com a intensidade da reação e o envolvimento de órgãos internos, embora resultados positivos ocorreram nos casos mais graves. A cor da pele e etnia referida pareceu não ter associação com a positividade dos testes. Os testes de contato com anticonvulsivante foram reproduzidos em 10 controles saudáveis para garantir concentrações não irritativas, que resultaram em negatividade. Nenhum dos pacientes apresentaram reações adversas durante estes procedimentos in vivo. 
Tabela 8. Características clínicas e demográficas dos casos de reação de hipersensisibilidade não-imediata aos anticonvulsivantes de anel aromático

\begin{tabular}{|c|c|c|c|c|}
\hline & $\begin{array}{l}\text { DRESS } \\
(\mathrm{N}=32)\end{array}$ & $\begin{array}{c}\text { SJS } \\
(\mathrm{N}=12)\end{array}$ & $\begin{array}{c}\text { EMP } \\
(\mathrm{N}=11)\end{array}$ & $\begin{array}{l}\text { TOTAL } \\
(\mathrm{N}=55)\end{array}$ \\
\hline Idade média & 49.7 & 48.3 & 47.7 & 43.6 \\
\hline Gênero (M/F) & $26 / 6$ & $7 / 5$ & $9 / 2$ & $42 / 13$ \\
\hline \multicolumn{5}{|l|}{ Início da reação } \\
\hline < 4 semanas $(\%)$ & $13(40)$ & $11(92)$ & $11(100)$ & $35(64)$ \\
\hline$>4$ semanas $(\%)$ & $19(60)$ & $1(8)$ & $0(0)$ & $20(36)$ \\
\hline \multicolumn{5}{|l|}{ Medicamento envolvido } \\
\hline Fenobarbital (\%) & $4(13)$ & $2(17)$ & $1(9)$ & $7(13)$ \\
\hline Fenitoína (\%) & $2(6)$ & $1(8)$ & $0(0)$ & $3(5)$ \\
\hline Carbamazepina (\%) & $26(81)$ & $9(75)$ & $10(91)$ & $45(82)$ \\
\hline \multicolumn{5}{|l|}{ Manifestações Clínicas } \\
\hline Cutânea (\%) & $32(100)$ & $12(100)$ & $11(100)$ & $55(100)$ \\
\hline Gastrointestinal (\%) & $32(100)$ & $6(50)$ & $0(0)$ & $38(69)$ \\
\hline Respiratoria (\%) & $5(15)$ & $4(34)$ & $0(0)$ & $9(16)$ \\
\hline Febre (\%) & $32(100)$ & $11(91)$ & $2(18)$ & $45(82)$ \\
\hline Tempo médio de hospitalização (dias) & 20 & 12 & 0 & 24 \\
\hline \multicolumn{5}{|l|}{ Tratamento } \\
\hline Anti-histamínicos (\%) & $32(100)$ & $8(67)$ & $11(100)$ & $51(93)$ \\
\hline Corticosteróides sistêmicos (\%) & $32(100)$ & $12(100)$ & $8(72)$ & $52(95)$ \\
\hline $\lg I V(\%)$ & $0(0)$ & $5(41)$ & $0(0)$ & $5(9)$ \\
\hline \multicolumn{5}{|l|}{ Teste contato com ACA (N: 46) } \\
\hline Positivo (\%) & $18(72)$ & $7(58)$ & $4(45)$ & $29(63)$ \\
\hline Negativo (\%) & $7(28)$ & $5(42)$ & $5(55)$ & $17(37)$ \\
\hline Não realizado (\%) & 7 & 0 & 2 & $9(16)$ \\
\hline \multicolumn{5}{|l|}{ Etinia } \\
\hline Caucasianos (\%) & $3(9)$ & $2(16)$ & $2(18)$ & $7(13)$ \\
\hline Não-Caucasianos (Misto) (\%) & $29(91)$ & $10(84)$ & $9(82)$ & $48(87)$ \\
\hline
\end{tabular}

EMP: Exantema maculo-papular, SJS: Síndrome de Stevens-Johnson, DRESS: reação de hipersensibilidade a medicamento, ACA: anticonvulsivante de anel aromático, IgIV: imunoglobulina intravenosa 
Objetivo 2: Caracterização genotípica de pacientes brasileiros que apresentaram reação de hipersensibilidade tardia aos anticonvulsivantes aromáticos e controles.

\subsection{Genotipagem de HLA}

Primeiramente, analisamos os polimorfismos dos genes antígeno leucocitário humano (HLA)-A*3101 (rs1633021 e rs1061235) e HLA-B*1502 (rs3909184, rs1264511 e rs2844682) de todos os 506 indivíduos.

Verificamos uma forte associação do polimorfismo de HLA-B*1502 (rs3909184) com o grupo que apresentaram reação ao ACA $(P=9.999 e-05)$. Não observamos significância estatística da associação entre as demais variantes HLA-B*1502 e o grupo de casos e grupos-controle. Da mesma forma, não houve associação positiva de polimorfismos de HLA-A*3101 com os grupos estudados (Tabela 9). 
Tabela 9. Frequência genotípica de polimorfismos de HLA-B*1502 e HLA-A*3101 nos grupos de indivíduos saudáveis, casos de reação de hipersensibilidade não-imediata aos anticonvulsivantes de anel aromático e tolerantes

\begin{tabular}{|c|c|c|c|c|c|c|}
\hline \multirow[b]{2}{*}{ Gene } & \multirow[b]{2}{*}{ SNP } & & \multicolumn{3}{|c|}{ Frequência genotípica (\%) } & \multirow[b]{2}{*}{ Valor de $P$} \\
\hline & & & $\begin{array}{c}\text { Saudável } \\
(\%)\end{array}$ & $\begin{array}{c}\text { Caso } \\
(\%)\end{array}$ & $\begin{array}{c}\text { Tolerante } \\
\text { (\%) }\end{array}$ & \\
\hline \multirow{6}{*}{ HLA-B*1502 } & \multirow[b]{2}{*}{ rs3909184 } & $\mathrm{CC}$ & $77(21.3)$ & $0(0.0)$ & $1(1.4)$ & \multirow[b]{2}{*}{$9.999 e-05$} \\
\hline & & $\begin{array}{l}\text { CG } \\
\text { GG }\end{array}$ & $\begin{array}{c}77(21.3) \\
207(57.4)\end{array}$ & $\begin{array}{l}14(26.9) \\
38(73.1)\end{array}$ & $\begin{array}{l}13(18,0) \\
58(80.6)\end{array}$ & \\
\hline & \multirow[b]{2}{*}{ rs1264511 } & $\mathrm{CC}$ & $34(9.5)$ & $5(9.6)$ & $7(9.7)$ & \multirow[b]{2}{*}{0.05} \\
\hline & & $\begin{array}{l}\text { CG } \\
\text { GG }\end{array}$ & $\begin{array}{l}136(37.9) \\
189(52.7)\end{array}$ & $\begin{array}{l}29(55.8) \\
18(34.6)\end{array}$ & $\begin{array}{l}37(50.0) \\
30(40.6)\end{array}$ & \\
\hline & \multirow[b]{2}{*}{ rs2844682 } & $\mathrm{AA}$ & $8(2.3)$ & $2(3.8)$ & $3(4.0)$ & \multirow[b]{2}{*}{0,53} \\
\hline & & $\begin{array}{l}A G \\
G G\end{array}$ & $\begin{array}{l}108(30.1) \\
242(67.6)\end{array}$ & $\begin{array}{l}15(28.8) \\
35(67.3)\end{array}$ & $\begin{array}{l}28(38,9) \\
43(58.1)\end{array}$ & \\
\hline \multirow{4}{*}{ HLA-A*3101 } & \multirow[b]{2}{*}{ rs1633021 } & $\mathrm{AA}$ & $226(63.1)$ & $31(60.8)$ & $45(62.5)$ & \multirow[b]{2}{*}{0,78} \\
\hline & & $\begin{array}{l}A G \\
G G\end{array}$ & $\begin{array}{c}111(31.0) \\
21(5.9)\end{array}$ & $\begin{array}{c}18(35.3) \\
2(4.0)\end{array}$ & $\begin{array}{c}25(34.7) \\
2(2.8)\end{array}$ & \\
\hline & \multirow[b]{2}{*}{ rs1061235 } & $\mathrm{AA}$ & $295(82.2)$ & $44(84,6)$ & $62(86.1)$ & \multirow[b]{2}{*}{0,17} \\
\hline & & $\begin{array}{l}\text { AT } \\
\text { TT }\end{array}$ & $\begin{array}{c}61(17.0) \\
3(0.8)\end{array}$ & $\begin{array}{c}6(11.5) \\
2(3.8)\end{array}$ & $\begin{array}{c}10(13,9) \\
0(0,0)\end{array}$ & \\
\hline
\end{tabular}

\subsection{Genotipagem de CYP}

Analisamos os polimorfismos de CYP2C9 (rs1057910 e rs1799853), CYP2C19 (rs rs4244285, rs4986893, rs12248560, rs11188072) e CYP3A5 (rs776746) de todos os indivíduos incluídos no estudo. Encontramos uma importante associação entre a atividade normal (EM) do CYP3A5 e indivíduos tolerantes quando comparado com casos ( $p=0,0002$, $O R=4,8)$, mas observouse uma distribuição similar de variantes de CYP2C19 e 2C9 em nossos grupos de estudo e controle. Nenhum dos nossos grupos apresentaram associação positiva 
com CYP2C19 e 2C9 polimorfismos (Tabela 10). Na Figura 7, a árvore de classificação e regressão do polimorfismo de CYP3A5 dentre indivíduos IM (metabolizadores lentos) e EM (metabolizadores normais) demonstra a distribuição dos grupos estudados.

Baseado no fato das enzimas CYP2C9, CYP2C19 e CYP3A5 serem expressos na pele, analisamos os fenótipos enzimáticos de acordo com os resultados de teste de contato com anticonvulsivantes (Tabela 11). Apesar de não termos obtido associações com significância estatística, verificamos que houve uma predominância de fenótipo reduzido para CYP3A5, normal para CYP2C9 e aumentado para CYP2C19.

Tabela 10. Genotipagem de polimorfismos de enzimas do Citocromo P450 (CYP) 2C9, 3A5 e 2C19, sua distribuição entre grupos de indivíduos saudáveis, casos de reação de hipersensibilidade não-imediata aos anticonvulsivantes de anel aromático e tolerantes, e sua associção com os fenótipos de metabolismo. (UM e EM = metabolizadores normais, IM e PM = metabolizadores lentos)

\begin{tabular}{|c|c|c|c|c|c|c|}
\hline \multirow[b]{2}{*}{ Gene } & \multirow[b]{2}{*}{ Polimorfismo } & \multirow[b]{2}{*}{ Grupo } & \multicolumn{3}{|c|}{ Frequência genotípica (\%) } & \multirow{2}{*}{$\begin{array}{c}\text { Valor de } \\
\text { p }\end{array}$} \\
\hline & & & $\begin{array}{c}\text { Sadios } \\
(\%)\end{array}$ & Casos (\%) & Tolerantes (\%) & \\
\hline \multirow{3}{*}{ CYP2C9 } & \multirow{3}{*}{$\begin{array}{l}\text { rs1057910 } \\
\text { rs1799853 }\end{array}$} & EM & $138(70.4)$ & $44(81.4)$ & $56(66.7)$ & \multirow{3}{*}{0.20} \\
\hline & & $\mathrm{IM}$ & $54(27.5)$ & $8(14.8)$ & $25(29.7)$ & \\
\hline & & PM & $4(2.0)$ & $2(3.7)$ & $3(3.8)$ & \\
\hline \multirow{3}{*}{ CYP3A5 } & \multirow{3}{*}{ rs776746 } & EM & $18(15.4)$ & $8(14.5)$ & $38(45.2)$ & \multirow{3}{*}{$\begin{array}{c}0.0002 \\
O R=4.8\end{array}$} \\
\hline & & $\mathrm{IM}$ & $34(29.0)$ & $23(41.8)$ & $19(22.6)$ & \\
\hline & & PM & $65(55.5)$ & $24(43.6)$ & $27(32.1)$ & \\
\hline \multirow{3}{*}{ CYP2C19 } & \multirow{3}{*}{$\begin{array}{l}\text { rs4244285 } \\
\text { rs4986893 } \\
\text { rs12248560 } \\
\text { rs11188072 }\end{array}$} & EM & $83(45.6)$ & $25(48.0)$ & $42(51.2)$ & \multirow{3}{*}{0.76} \\
\hline & & IM/PM & $42(23.0)$ & $12(23.0)$ & $21(25.6)$ & \\
\hline & & UM/UMH & $57(31.4)$ & $15(29.0)$ & $19(23.2)$ & \\
\hline
\end{tabular}




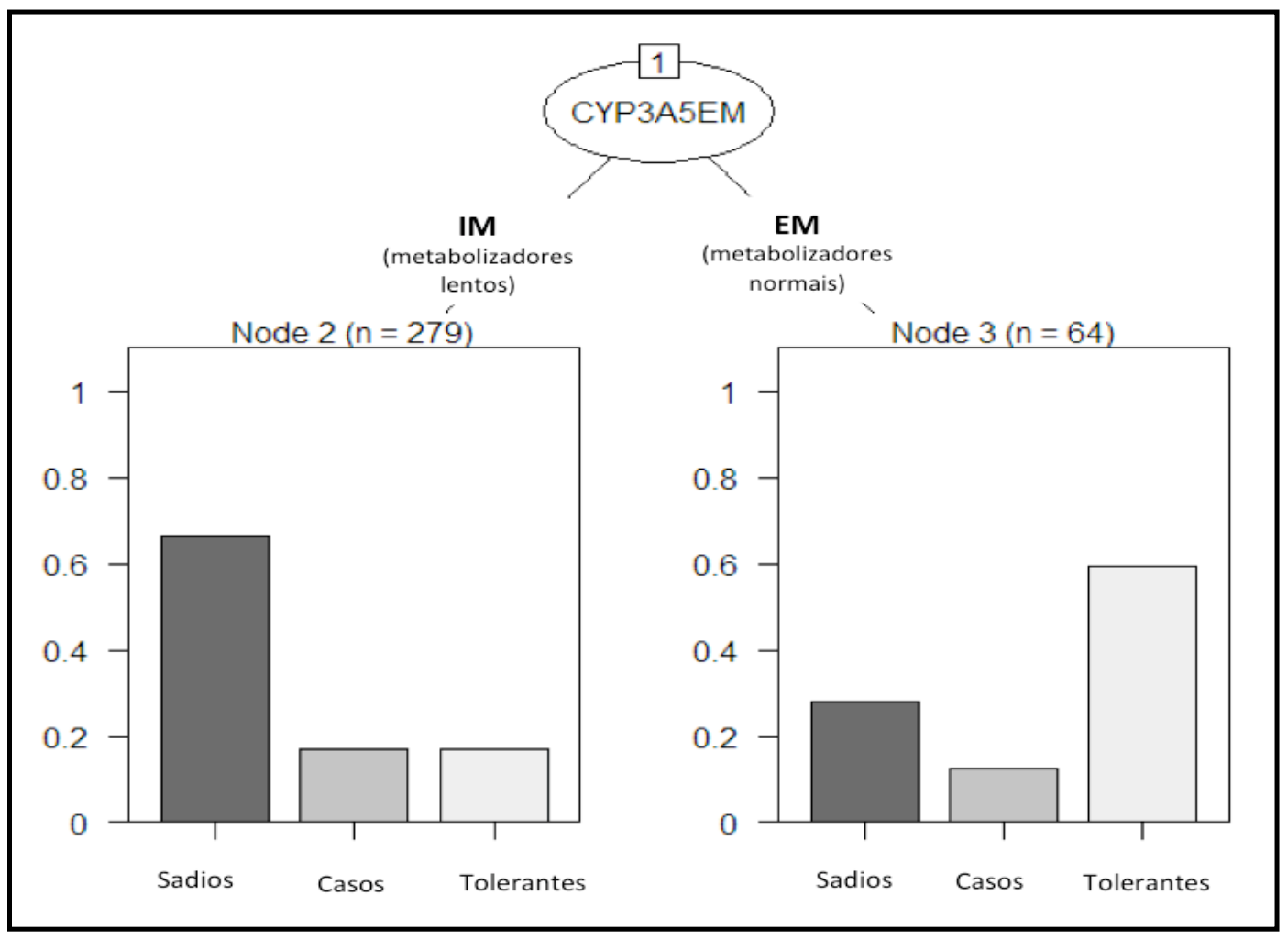

Figura 7. Árvore de classificação e regressão do polimorfismo de CYP3A5 dentre indivíduos IM (metabolizadores lentos) e EM (metabolizadores normais) e sua proporção em indivíduos sadios, casos que apresentaram reação aos anticonvulsivantes aromáticos e tolerantes

Tabela 11. Análise do fenótipo enzimático e resultados de teste de contato com anticonvulsivantes. Os dados são apresentados como a $\mathrm{N}$ (\% de remendo droga grupo de teste).

\begin{tabular}{|c|c|c|c|c|}
\hline \multirow{2}{*}{ Gene } & \multirow{2}{*}{$\begin{array}{l}\text { Fenótipo } \\
\text { enzimático }\end{array}$} & \multicolumn{2}{|c|}{ Teste de Contato com anticonvulsivante } & \multirow{2}{*}{$P$ value } \\
\hline & & Positivo & Negativo & \\
\hline \multirow{2}{*}{ CYP3A5 } & Reduzido & $22(65)$ & $12(35)$ & \multirow{2}{*}{0.354} \\
\hline & Normal & $2(40)$ & $3(60)$ & \\
\hline \multirow{2}{*}{ CYP2C9 } & Reduzido & $4(40)$ & $6(60)$ & \multirow{2}{*}{0.127} \\
\hline & Normal & $20(71)$ & $8(28)$ & \\
\hline \multirow{3}{*}{ CYP2C19 } & Reduzido & $5(62)$ & $3(37)$ & \multirow{3}{*}{0.894} \\
\hline & Normal & $12(57)$ & $9(43)$ & \\
\hline & Aumentado & $5(71)$ & $2(28)$ & \\
\hline
\end{tabular}




\subsection{Tipificação de HLA}

Foram analisados 87 alelos dos locus de HLA A, B, C, DRB, DQA, DQB dos 506 indivíduos estudodos.

Em uma avaliação preliminar para o exame de qualificação (Agosto de 2013) consideramos os resultados de 430 indivíduos, 381 controles saudáveis e 49 casos de RHNI aos ACA. Neste momento, verificamos uma associação significativa $(p \leq 0,05)$ dos $\mathrm{HLA}^{*} \mathrm{~A}^{*} 29$, HLA-B*44 e HLA-C*03 em indivíduos saudáveis e dos HLA-A*74, HLA-B*53 e HLA-DQ*05 em indivíduos que apresentaram RHA (Tabela 12). A análise discriminativa da distribuição destes resultados nos grupos "Caso" e "Saudável" demonstrou que 87,9\% dos indivíduos foram corretamente classificados (Tabela 12).

Tabela 12. Tipificação de HLA: associação de HLA em casos e em indivíduos saudáveis.

\begin{tabular}{ccccc}
\hline Saudaveis & & & & \\
\hline Locus & Alelo & $\mathbf{P}$ & OR & IC (95\%) \\
\hline A & 29 & 0.03 & & 0 \\
B & 44 & 0.007 & 5,35 & $1,60-33,29$ \\
C & 03 & 0.048 & 2,85 & $1,11-9,68$ \\
\hline Casos & & & & \\
\hline Locus & Alelo & $\mathbf{p}$ & OR & IC (95\%) \\
\hline A & 74 & 0.029 & 3.6 & $1,11-10,14$ \\
B & 53 & 0.026 & 2,93 & $1,10-7,00$ \\
DQA & 05 & 0.033 & 2,02 & $1,08-3,83$ \\
\hline
\end{tabular}


Tabela 13. Análise discriminativa dos resultados obtidos da tipificação de HLA em casos e em indivíduos saudáveis.

\begin{tabular}{lccccc}
\hline \multicolumn{5}{c}{ Resultados de acordo com a classificação } \\
\hline & \multirow{2}{*}{ Grupo } & Predição por Grupos & Total \\
& & & Saudável & Caso & \\
\hline \multirow{2}{*}{ Original } & Modelo & Saudável & 339 & 42 & 381 \\
& & Caso & 10 & 39 & 49 \\
& $\%$ & Saudável & 89.0 & 11.0 & 100.0 \\
& $\%$ & Caso & 20.4 & 79.6 & 100.0 \\
\hline
\end{tabular}

$\mathbf{8 7 . 9 \%}$ dos casos originais agrupados foram corretamente classificados.

Posteriormente, avaliamos o total de 506 amostras sob a mesma forma de análise de tipificação de HLA e consideramos os indivíduos tolerantes como o verdadeiro controle em relação à possibilidade de evoluir com RHNI ao ACA. Verificamos associação estatísticamente significativa $(p \leq 0,05)$ dos alelos HLA-A*31, HLA-A*74, HLA-B*35 e HLA-B*53 com o grupo dos pacientes que apresentaram reações graves aos ACA, enquanto o HLA-B*44 e HLA-C*03 mantiveram a associação a indivíduos sadios. Com base nestes resultados, foi possível construir uma árvore de classificação e de decisões em relação ao risco do paciente apresentar RHNI ao ACA (Figura 8), com uma sensibilidade de 91,67\%. Assim, dependendo da combinação alélica que cada indivíduo apresente, há possibilidade maior ou menor de evoluir com uma RHNI ao ACA ou tolerar o medicamento. 


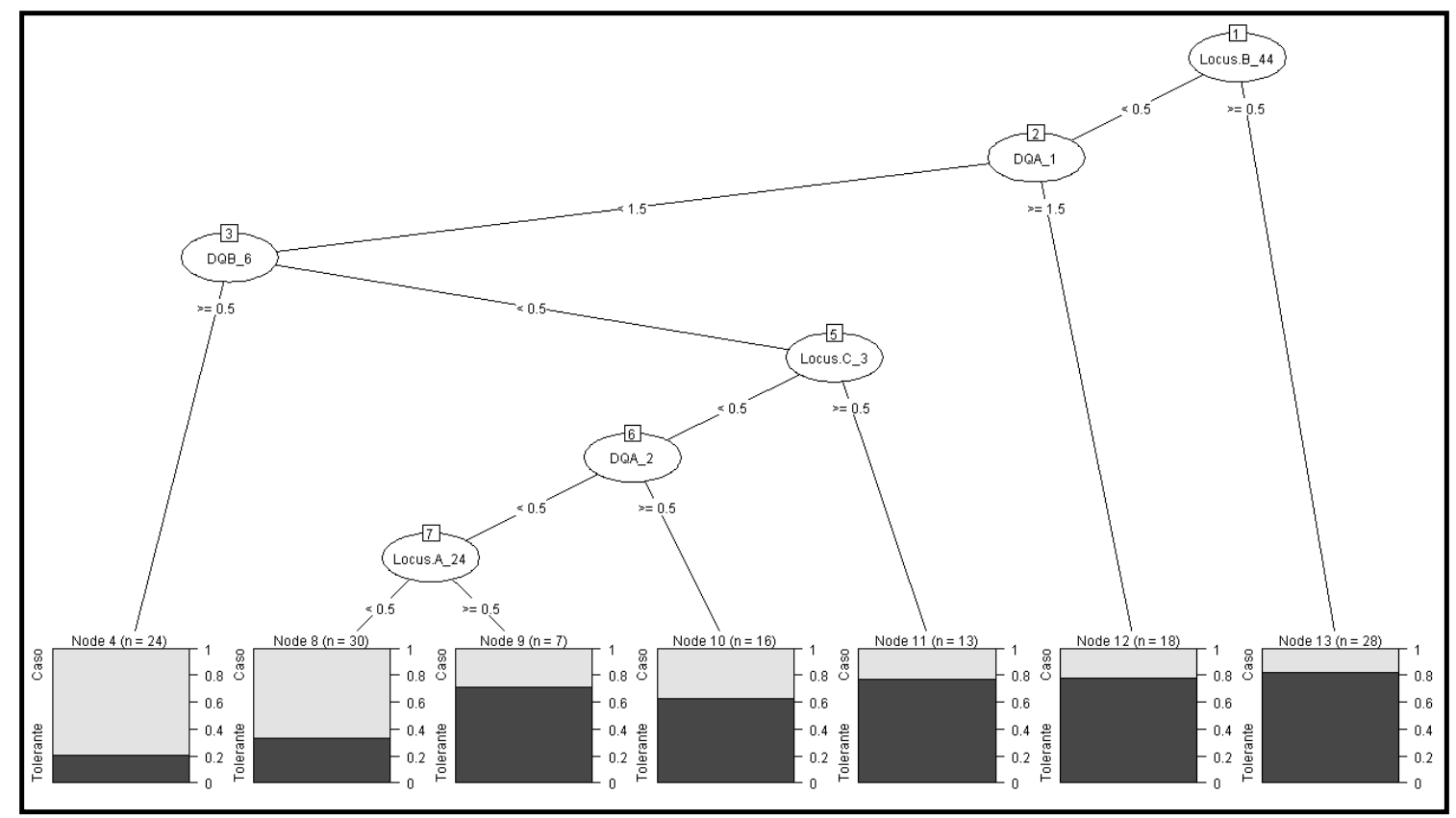

Figure 8. Árvore de classificação e decisões que demonstra a maior ou menor possibilidade do indivíduo ser caso ou tolerante de acordo com a combinação de alelos de HLA. 
Objetivo 3. Identificar fatores genéticos em indivíduos brasileiros, associados à reação de hipersensibilidade tardia aos anticonvulsivantes de estrutura aromática.

A fim de responder ao último objetivo do projeto e tomando por base os resultados globais gerados, construímos uma árvore de classificação e de decisões considernado as genotipagens de HLA, CYP e tipificação de HLA. Esta estrutura possibilitou verificar a possibilidade do individuo ser tolerante ao ACA ou desenvolver a reação. Esta análise apresentou uma sensibilidade de $78.3 \%$ para casos e uma especificidade de $74 \%$ (Figura 9).

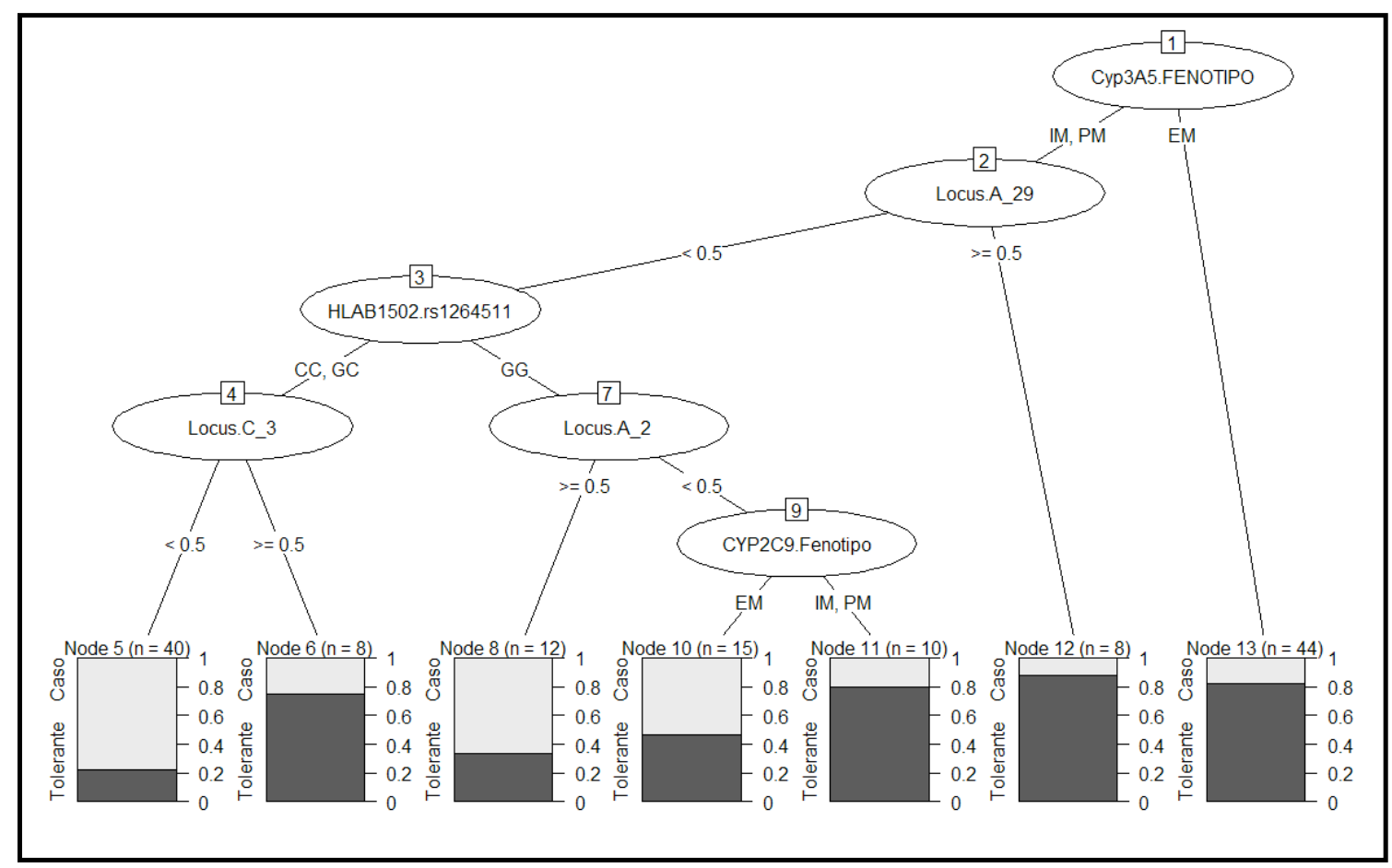

Figura 9. Árvore de classificação e decisões, que demonstra a maior ou menor possibilidade do indivíduo ser caso ou tolerante de acordo com a combinação de polimorfismos de HLA e CYP e alelos de HLA. 
6. Discussão 
Os anticonvulsivantes de anel aromático constituem importantes ferramentas terapêuticas, mas são causas de reações adversas idiossincrásicas imprevisíveis, sendo que as reações de hipersensibilidade alérgica não-imediatas (tardias) as mais relevantes. Estas reações podem se manifestar com espectros variáveis de gravidade, no entanto, verificamos que este grupo farmacológico está envolvido na gênese de reações graves como a SSJ e a DRESS. Os mecanismos imunológicos relacionados à fisiopatologia destas reações são complexos, mas o reconhecimento destes fármacos por células $T$ em pacientes geneticamente predispostos é definido como o ponto crucial do processo. (Yip 2012, Pichler 2003, Roujeau 1994)

Nos últimos anos, um número crescente de publicações têm tentado determinar fatores de susceptibilidade genética isolados às RHNI aos ACA, todos em populações etnicamente homogêneas. No entanto, não existem, até o momento, estudos em nosso meio avaliando esta associação. Uma das grandes dificuldades é caracterizar adequadamente os fenótipos das reações, bem como estabelecer a relação causal reação-fármaco e fenótipo-genótipo. Assim, nos propusemos a estudar a associação de fatores genéticos e reações de hipersensibilidade alérgica não-imediata a ACA em pacientes brasileiros.

\subsection{Conceitos e Classificação}

Desde 1972, quando a Organização Mundial de Saúde propôs a classificação de RADs, poucas inovações concetuais têm sido implememntadas neste contexto. Acreditamos que os conhecimentos gerados na última década podem contribuir para a revisão de conceitos, classificação e codificação das várias apresentações clínicas alérgicas, que claramente necessitam ser atualizadas (WHO 1972, Tanno 2012, Demoly 2014). Neste âmbito, a farmacogenômica têm avançado a ponto de impactar em alterações do conceito 
proposto inicialmente de reações previsíveis e imprevisíveis. Algumas reações de hipersensibilidade, previamente postuladas como imprevisíveis, podem pasar a fazer parte de uma categoria potencialmente previsível.

As reações idiossincráticas e de hipersensibilidade, antes consideradas de forma isolada (Tabela 1), podem ser vistas atualmente como condições sobrepostas uma vez que as reações de hipersensibilidade ocorrem em indivíduos que apresentam características incomuns que propiciam o desenvolvimento destas reações. Desta forma, propomos que as reações idiossincrásicas englobem tanto as reações imuno-mediadas, como a hipersensibilidade, e não-imuno-mediadas, como a idiossincrasia metabólica.

\subsection{Desenho do estudo e cálculo amostral}

Optamos por um estudo de caso-controle por ser mais factível para a avaliação de fatores de risco para doenças de baixa incidência como as RHNI a ACA. Os estudos de caso-controle são reconhecidamente convenientes para a determinação de fatores de susceptibilidade genética. A decisão de selecionarmos três grupos de estudo, um grupo de casos e dois de controles (indivíduos sadios e indivíduos que toleram ACA sem intercorrências), nos permitiu a análise mais apurada destes fatores genéticos em nossa população. Podemos considerar que o grupo controle de indivíduos tolerantes constitui o melhor parâmetro comparativo, entretanto, optamos incluir o grupo controle de indivíduos sadios para inferir o comportamento dos fatores genéticos em estudo na população geral. (Cardon 2003, Hattersley 2005)

Não recrutamos, no estudo, indivíduos com histórico de consanguinidade para evitar aumento de prevalência de determinados alelos ou SNPs herdados, o que poderia resultar em associações falso-positivas. 
O cálculo amostral foi baseado no odds ratio de 2 , baseado na descrição de publicações prévias neste assunto. Até o momento da análise, havíamos estudado 182 indivíduos, 54 casos de reação de hipersensibilidade não-imediata (RHNI) aos $\mathrm{ACA}, 83$ controles tolerantes e 45 controles sadios. No entanto, 379 novas amostras a serem analisadas foram incluídas, perfazendo um total de 561 indivíduos no estudo, número maior que o definido pelo cálculo amostral inicial para atingir um poder de 0,95.

\subsection{Dados demográficos e composição de casos e controles}

Do ponto de vista epidemiológico, as reações de hipersensibilidade a medicamentos são mais frequentes no gênero feminino, e os extremos de idade são descritos como populações de risco para o desenvolvimento de reações de hipersensibilidade não-imedita a medicamentos (Gomes 2005, Thong 2011). Na população estudada, o gênero feminino também foi o mais acometido, mas a proporção de gênero foi similar dentre os três grupos. Verificamos que a faixa etária de adultos e adultos jovens foi proporcionalmente maior em todos os grupos estudado.

Todos os estudos de associação de fatores de susceptibilidade genética em RHNI aos ACA foram realizados em populações etnicamente homogêneas. (Yip 2012) A composição étnica da população brasileira resulta de uma confluência de indivíduos de origens étnicas distintas e é caracterizada pela grande miscigenação racial. Baseado em dados do Instituto Brasileiro de Geografia e Estatística (IBGE) (Tendências Demográficas: Uma análise da população com base nos resultados dos Censos Demográficos 1940 e 2000), é possível observar que a maioria da população brasileira se auto-define como brancos (Figura 10). Entretanto, em nosso estudo, considerando dados étnicos de duas gerações de ancestralidade anteriores, consideramos como brancos 
(Caucasianos) apenas os indivíduos com ascendência caucasiana em que não houve relato de miscigenação. Assim, pudemos verificar que, apesar de dados reportados, a maioria da população ( $80 \%$ ) incluída em todos os grupos estudados foi considerada não-caucasiana (Mista).

Pudemos observar que os três grupos em estudo apresentam características similares em relação ao gênero, faixa etária e etnia, possibilitando uma análise mais adequada dos resultados do estudo grupo-controle proposto.

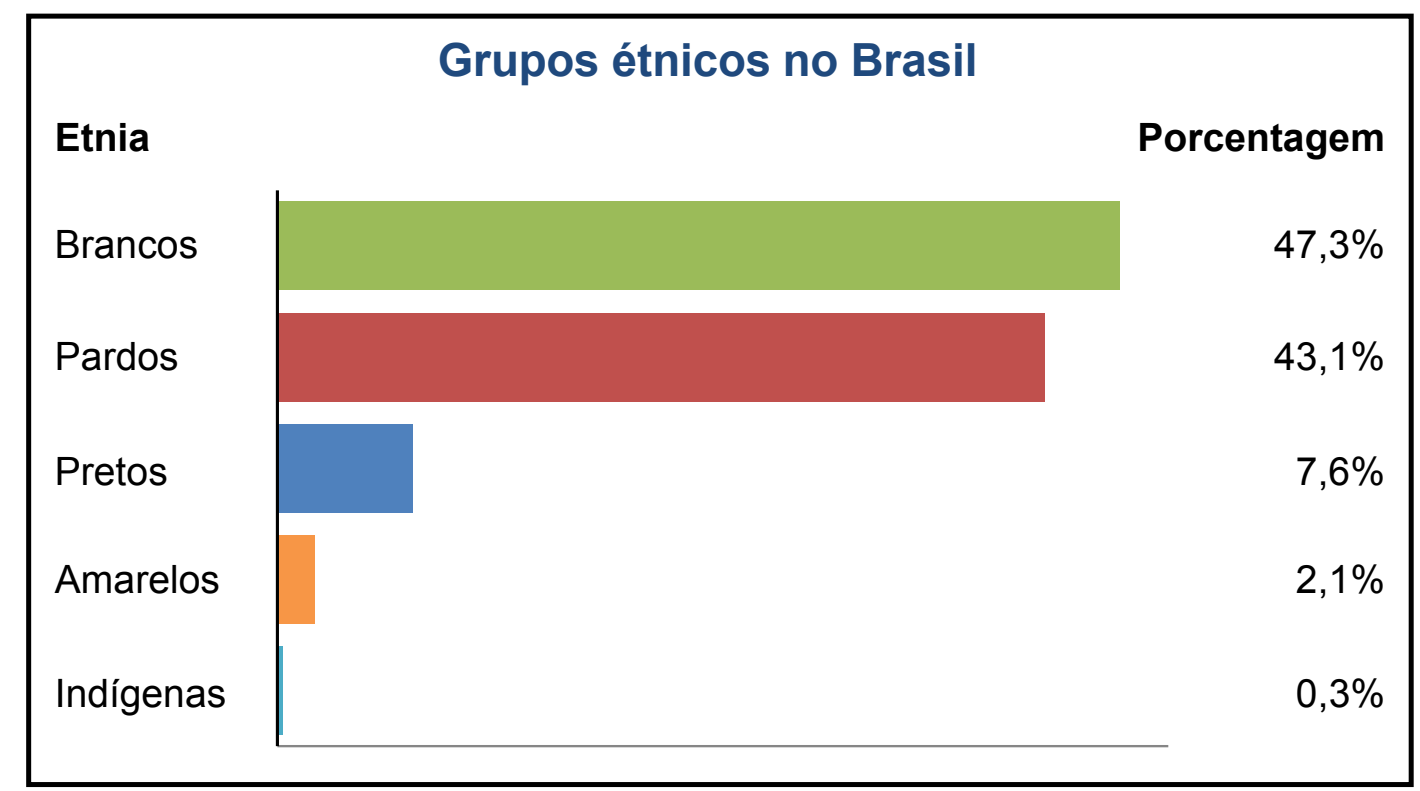

Figure 10. Gupos Étnicos no Brasil segundo o Instituto Brasileiro de Geografia e Estatística (IBGE). Tendências Demográficas: Uma análise da população com base nos resultados dos Censos Demográficos 1940 e 2000

A incidência descrita das RHNI graves aos ACA é de 1:10.000 a 1:100.000 casos por exposição a estes medicamentos (Roujeau 1994, Mockenhaupt 2008, Kano 2009, Mockenhaupt 2011). Não existem dados epidemiológicos de prevalência e de incidência destas reações que reflitam a realidade em nosso país. Apesar da baixa incidência destas reações, foram selecionados 54 casos de RHNI a ACA, a maioria $(81,5 \%)$ graves. Este achado provavelmente ocorra pelo fato das reações leves serem auto-limitadas após a 
suspensão/troca do medicamento envolvido e nem sempre referendadas para investigação e seguimento pelo especialista em Alergia e Imunologia Clínica.

A DRESS é uma RHNI grave a medicamentos que incide em 1: 10.000 expostos e a SSJ em 1:100.000 expostos (Kano 2009, Thong 2011, Mockenhaupt 2011), o que pode justificar a maior prevalência de DRESS (32 casos) em relação de SSJ (12 casos) no grupo de casos.

Optamos por incluir todos os casos de RHNI aos ACA pela baixa incidência destas reações e pela alta reatividade cruzada entre representantes deste grupo farmacológico. (Alvestad 2008, Wang 2010) A Carbamazepina (CZP) foi o medicamento mais imputado nas $\mathrm{RHNI}$, provavelmente pela frequência de prescrições deste medicamento em relação aos demais ACA em nosso meio. $O$ indivíduos em uso de CZP apresentam 11 vezes maior chance de apresentar RHNI graves. (Roujeau 1995)

Consideramos indivíduos tolerantes todos os que referiam o uso de ACA por pelo menos 6 meses contínuos sem intercorrências pelo fato deste período ser referido como o de maior risco para o desenvolvimento de RHNI.

\subsection{Diagnóstico e teste de contato com medicamento}

A acurácia do diagnóstico clínico é imprescindível em estudos de associação genética uma vez que avaliaremos os achados de genotipagem em concordância com os genótipos definidos.

O diagnóstico das $\mathrm{RH}$ a medicamentos é clínico, se baseia principalmente por uma história clínica detalhada que inclue várias questões como o tipo de manifestação, o medicamento utilizado, relação temporal entre o uso do medicamento e a reação, a evolução da reação após a suspensão do fármaco 
suspeito e a reprodutibilidade. A caracterização das reações foi baseada principalmente em parâmetros clínicos, mas a documentação médica durante a internação dos pacientes com reações graves auxiliou na identificação dos possíveis medicamentos causadores e na confirmação do quadro clínico. Os critérios diagnósticos utilizados para a definição de casos são os fomentados pela literatura (Demoly P 2014).

Os medicamentos são as principais causas de RHNI graves, particularmente da DRESS e da SSJ. Em todos os casos incluídos no estudo, o ACA foi o medicamento imputado como fator causal da reação. Benahmed S. e colaboradores concluiram que algorítmos de imputabilidade de farmacovigilância não apresentam acurácia no diagnóstico de $\mathrm{RH}$ a medicamentos e não podem substituir a avaliação do especialista e os testes de investigação. Assim, no estudo em vigência, nos propusemos a realizar o teste de contato com o medicamento (TCM) suspeito nos pacientes com história de RHNI a ACA, definir a associação entre os resultados e o quadro clínico, além de analisar as possíveis variáveis na interpretação dos resultados.

A positividade dos TCM em pacientes com história de RHNI a medicamentos na literatura, é variável. Em pacientes com alta probabilidade de uma determinado medicamento estar envolvido na reação, a positividade do teste de contato pode variar de 31,7 a 55\% (Osawa 1990, Barbaud, 2001, Romano 2002) e lembramos que TCM com resultado negativo não excluem o envolvimento do fármaco na reação. Dos 54 casos que apresentaram RHNI aos ACA, 46 (85\%) foram testados. Destes, 29 (63\%) foram positivos, uma percentagem maior do que aquela encontrada em outros estudos que analisaram populações semelhantes.

A positividade dos TCM depende do tipo de medicamento testado e da natureza da reação. A maior positividade parece ocorrer nos casos de DRESS. 
Observamos que os TC positivos nos casos de DRESS contribuíram para $62 \%$ de todos os resultados positivos do estudo. Entretanto, quando analizamos por tipo de apresentação clínica, pudemos verificar que houve proporcionalidade no percentual de resultados positivos tanto nos casos de DRESS (58\%) como nos de SSJ (54\%). O TCM se mostrou um método complementar importante para diagnóstico destas reações, uma vez que o teste de provocação, considerado como método padrão-ouro no diagnóstico das RHM, está contra-indicado. O teste intradérmico de leitura tardia é mais sensível que o TCM, mas apresenta menor número de medicamentos disponíveis para sua realização e menor segurança.

Primeau e colaboradores sugerem que talvez existam características populacionais envolvidas nas reações e nos resultados destes testes $A$ grande variabilidade genotípica da população brasileira poderia explicar o número de testes negativos.

Apesar do TCM ter sido relatado em alguns casos como desencadeante de RHNI (Barbaud 2005), em nosso estudo, o teste se mostrou seguro, uma vez que nenhuma reação adversa foi notificada.

A concentração das drogas utilizadas, veículo e local de aplicação dos testes foram os mesmos dos trabalhos anteriormente realizados e, desta forma, não existem diferenças técnicas na realização do procedimento. Não houve TCM positivo no grupo controle.

\subsection{Genotipagem}

As RAD apresentam mecanismos fisiopatológicos complexos ainda não completamente conhecidos e fatores genéticos podem ter importância em muitos casos. As RHNI a ACA podem ser incluídas neste contexto. 
Estudos recentes têm demonstrado forte associação entre reações cutâneas induzidas por ACA e alelos de HLA oferecendo a possibilidade de prevenção primária através da identificação de genótipos de alto-risco para estas reações. Foi demonstrado que os pacientes provenientes de certos países do sudeste asiático que possuem o HLA-B* 1502 são aproximadamente 100 vezes mais suscetíveis a SJS induzida por CBZ do que aqueles que não carregam o alelo. Mais recentemente, o HLA-A ${ }^{*} 3101$ foi identificado como importante fator na predisposição para diferentes tipos de ADRs cutâneas associadas com CBZ em japoneses, chineses, coreanos e populações caucasianas (Mehta 2009, Chung 2004, Zhang 2011, Wang 2011). Foi demonstrado que os pacientes que possuem - alelo HLA-A * 3101 são cerca de nove vezes mais suscetíveis à hipersensibilidade por CBZ do que aqueles que não carregam o alelo (Yip 2012, McCormack 2011). Pudemos observar que, até o momento, as publicações vêm tentando verificar a associação de fatores genéticos isolados a reações aos ACA em populações etnicamente homogêneas, como o HLA ou o CYP. Em 2010, baseado nos estudos independentes supracitados, os orgãos reguladores Americano, Canadense e Taiwanês atualizaram a bula da Carbamazepina incluindo os fatores genéticos de risco descritos e a US Food and Drugs Administration (FDA) passou a recomendar a genotipagem de HLA-A* 1502 em indivíduos com acsendência asiática antes da utilização da Carbamazepina.

Os resultados da análise dos polimorfismos de HLA por PCR-tempo real demosntraram associação significativa do polimorfismo de HLA-B*1502 (rs3909184) com o grupo de casos, dado que corrobora com o verificado na população chinesa (Tabela 3). Este dado nos chama a atenção e deve ser considerado com cautela como dado isolado uma vez que a frequência alélica do HLA-A*1502 descrita no Brasil é baixa (Figura 11). Não houve associação significativa dos polimorfismos de HLA-A*3101 entre os grupos estudados, entretanto, quando analisamos a tipificação de HLA, o alelo HLA-A*31 apresentou 
forte associação com as reações graves ao ACA (Figura 9), dado semelhante encontrado em caucasianos (Tabela 3).

A frequência alélica de HLA é variável na população mundial e estudos de associação genética podem ser influenciados por este fator. Outro dado que possa justificar estes resultados seria devido ao elevado grau de polimorfismo de HLA (Figura 5 e Tabela 3).

A variabilidade da distribuição alélica de HLA pode ser determinada pelo desequilíbrio de ligação (linkage desequilibrium), que é a associação não aleatória de alelos em dois ou mais loci, que pode ou não estar no mesmo cromossoma, levando à ocorrência de algumas combinações de alelos ou marcadores genéticos em uma população mais frequentemente ou menos frequentemente do que seria esperado a partir de uma formação aleatória de haplótipos a partir de alelos com base nas suas frequências. (Weiss 2002) Este fato pode determinar alelos mais o menos frequentes nas diferentes populações que podem ou não estar associados as doenças. Com a hipótese que tenhamos marcadores genéticos peculiares da nossa população reacionados às RHNI a ACA, realizamos a tificação de HLA. 


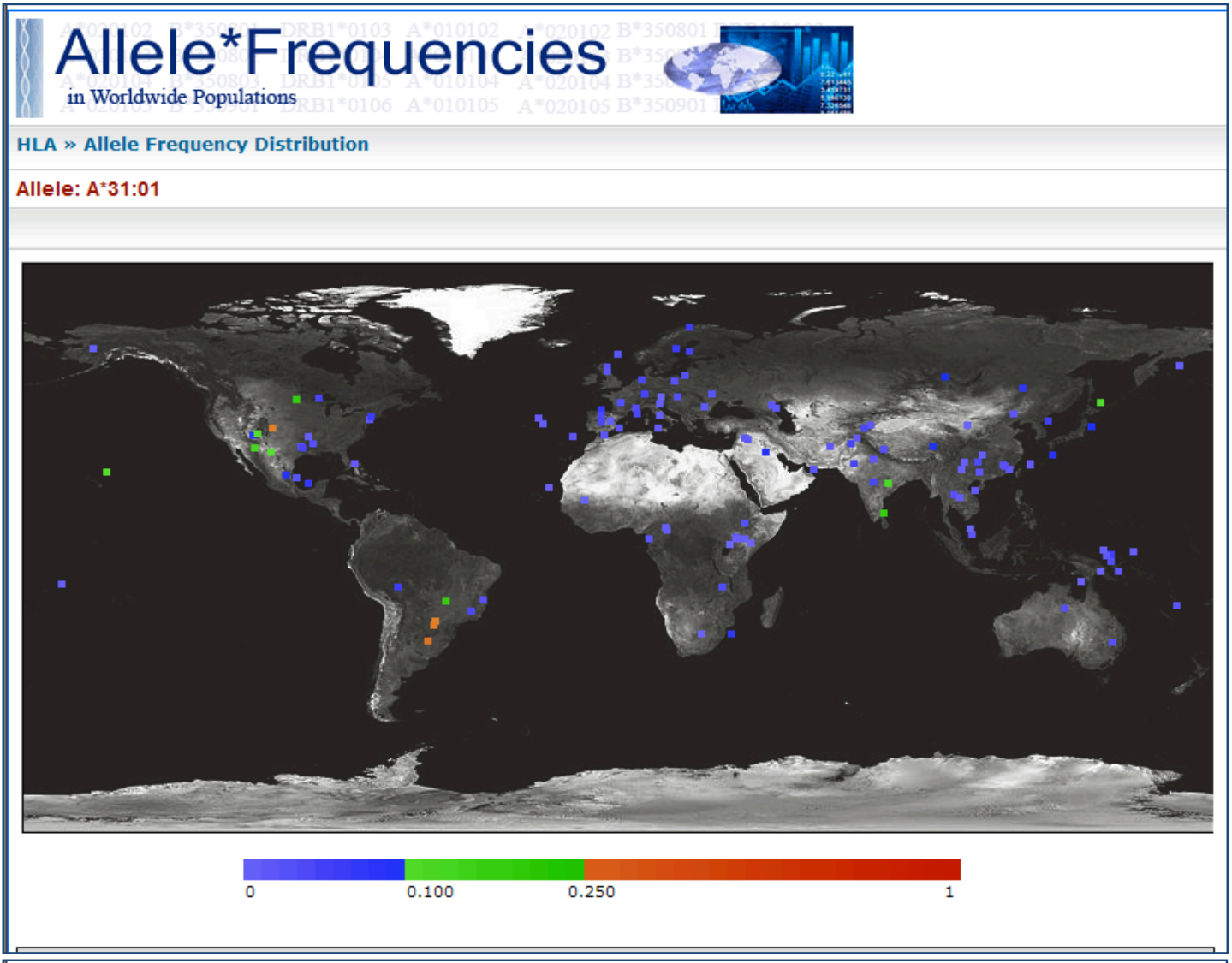

\section{Allele*Frequencies}

in Worldwide Populations

HLA » Allele Frequency Distribution

Allele: $B^{\star} 15: 02$

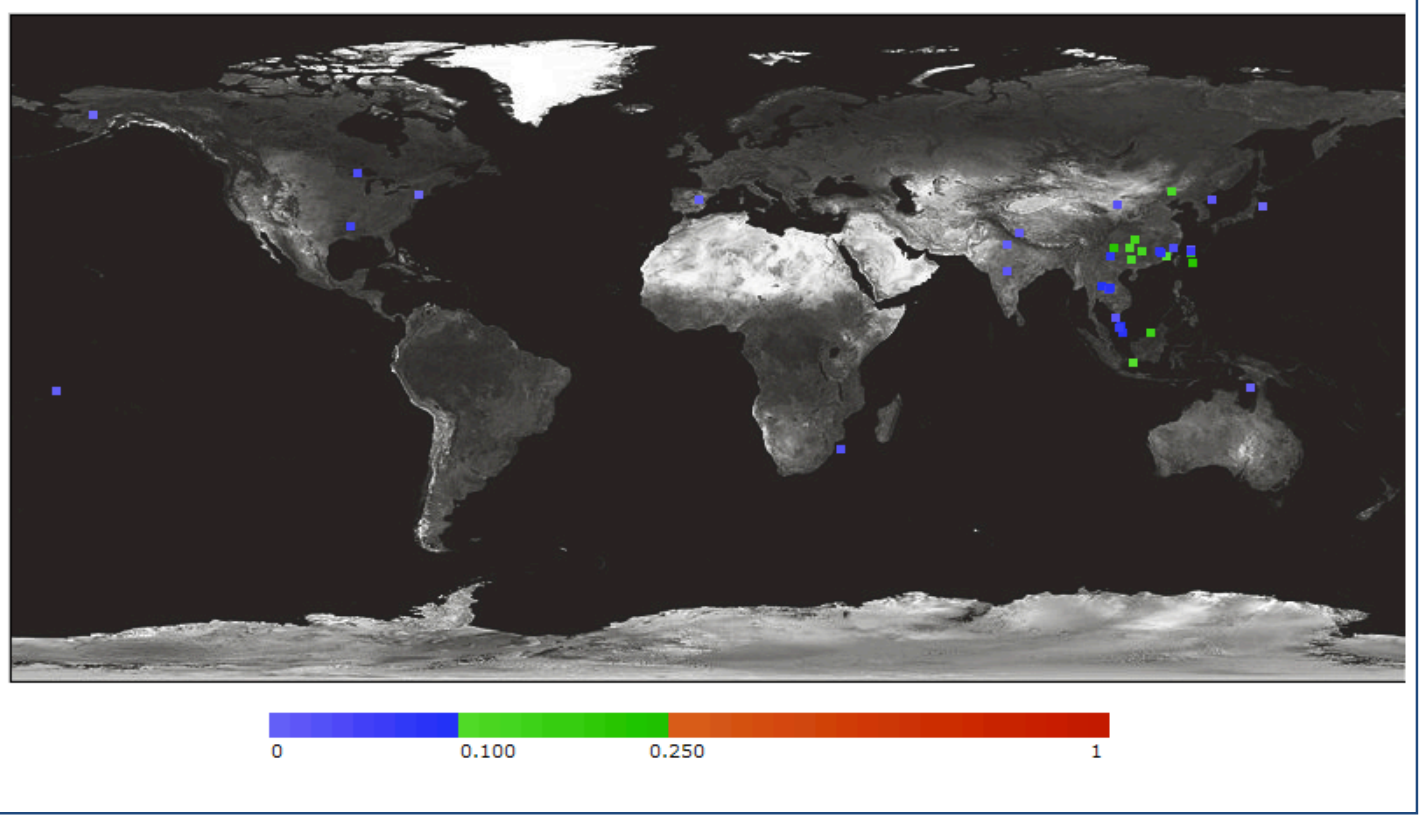

Figure 11: Frequência alélica de HLA-A*3101 e HLA-B*1502 na população mundial 
Inicialmente, na análise preliminar de 430 amostras tipificadas de casos e controles sadios, houve associação significative dos alelos HLA-A*29, HLA-B*44 e HLA-C*03 em indivíduos classificados como saudáveis, sendo o HLA-A*29 presente exclusivamente neste grupo. Apesar dos HLA-A*29 e HLA$B * 44$ estarem em desequilíbrio de ligação, sua frequência reportada na população brasileira é de $9,2 \%$ e $18,4 \%$ respectivamente. Quando incluímos o grupo dos indivíduos tolerantes no total de 506 amostras, verificamos associação entre os alelos HLA-B*44 e HLA-C*03 e o grupo de tolerantes. Considerando-se o grupo de indivíduos tolerantes seja o melhor parâmetro de avaliação do estudo uma vez que foram expostos ao mesmo fator em análise, este resultado pode indicar que estes alelos sejam marcadores de proteção.

$\mathrm{Na}$ análise preliminar, verificamos associação significativa dos HLA$A^{*} 74$, HLA-B*53 e HLA-DQ*05 em pacientes que apresentaram RHNI a ACA, e sugerimos que poderiam ser fatores de susceptibilidade genética para estas reações. Com o objetivo de melhor fomentar estes achados, propusemos a realização da análise discriminante, que nos auxilia a classificar um determinado elemento em um determinado grupo de variáveis, entre os grupos existentes. Com base nesta análise, foi possível verificar que uma proporção importante $(87,9 \%)$ da população estudada foi classificada corretamente como casos ou como controles. Foram incluídos nesta análise, $77 \%$ do total da amostra.

Com o total de amostras incluídas no estudo, observamos forte associação dos alelos HLA-A*31, HLA-A*74, HLA-B*35 e HLA-B*53 e as reações graves aos ACA. A associação entre casos e os alelos HLA-A*74 e HLA-B*53 se manteve presente. $O$ alelo HLA-A*31, bastante frequente na população européia (Figura 11), apresentou associação com as reação graves. Estes dados, vão de encontro à publicação de Pena SDJ e colaboradores (2011) que conclui que a ancestralidade genômica de indivíduos de diferentes regiões geográficas do Brasil é mais uniforme do que o esperado com predominancia da ancestralidade européia. 
Uma vez que as enzimas do citocromo P450 apresentam grande importância no metabolismo e depuração dos ACA, o estudo dos genes codificadores destas enzimas parecem ter influência em fenótipos de metabolismo bem como em reações adversas aos ACA, incluindo as RHNI. Sabemos que o alelo CYP3A5*3 é o mais prevalente na população mundial e é relacionado à atividade alterada da enzima. Verificamos em nosso estudo uma associação importante e peculiar entre o polimorfismo de CY3A5 com fenótipo EM (metabolizador normal) e indivíduos tolerantes. Este dado pode sugerir que o fenótipo EM para o alelo CYP3A5*3 pode ser um fator de proteção, minizando o risco do indivíduo desenvolver uma RHNI ao uso do ACA. Levando em consideração que a expressão deste gene é menor em caucasianos, a associação ao grupo de tolerantes que apresentou $27 \%$ de caucasianos em relação aos $13 \%$ dos casos e $18 \%$ dos controles saudáveis nos pareceu um dado interessante, apesar de ter sido auto-reportado.

Yengi $\mathrm{C}$ e colaboradores documentaram a presença de CYP2C9, CYP2C19 e CYP3A5 na pele humana. Este fato pode sugerir alguma influência destas enzimas na positividade dos testes de contato com ACA.

Quando analisamos os polimorfismos de CYP2C9 e de CYPC19 como variáveis isoladas, não observamos uma associação significativa com nenhum dos grupos estudados. Entretanto, de acordo com a árvode de classifição e decisões, pudemos verificar que quando um indivíduo apresenta o fenótipo IM/PM (metabolizados lento) para o polimorfismo CYP2C9 associado ao alelo GG do HLA-A 1502 e heterozigoze para o locus HLA-A1 a possibilidade de tolerar o ACA é de $80 \%$ (Figura 10). Assim, acreditamos que o risco de desenvolver $s$ RHNI aos ACA é multifatorial de forma que as combinações de fatores genéticos possa contribuir no mapeamento deste risco se tornando uma forma importante para promover uma medicina personalizada. 


\section{ConClusões}


A maioria das RHNI a ACA são graves. O teste de contato com ACA se mostrou uma ferramenta diagnóstica eficaz e segura, mesmo nos casos graves.

Verificamos associações significativas entre polimorfismos de HLA e CYP, tipificação de HLA e os grupos estudados, inferindo maior suscetibilidade ou proteção a desenvolver uma RHNI a ACA. Entretanto, acreditamos que a nossa população tenha características genéticas particulares devido à grande miscigenação e que variáveis genéticas não devem ser interpretados de forma isolada. Desta forma, a relevância deste estudo extrapola o objetivo de estudo caso-controle e sugere um modelo como forma de prevenção priméria às $\mathrm{RH}$ aos ACA.

Por fim, consideramos que o nosso estudo é pioneiro no Brasil em investigar marcadores genéticos relacionados às RHNI aos ACA, em uma tentativa de predizer riscos e promover uma medicina personalizada e contribuir para a prevenção primária destas apresentações clínicas. 


\section{REFERÊNCIAS BIBLIOGRÁFICAS}


1. Aberer W, Bircher A, Romano A, Blanca M, Campi P, Fernandez P, Brockow K, Pichler J, Demoly $\mathrm{P}$ for ENDA, and the EAACl interest group on drug hypersensitivity. Drug provocation testing in the diagnosis of drug hypersensitivity reactions: general considerations. Allergy 2003;58:854-863.

2. Adam J ET al. Delay drug hypersensitivity: models of T-cell stimulation. British Journal of Clinical Pharmacology, 2011;71:(5)701-707.

3. Alfirevic A, Jorgensen AL, Williamson PR, Chadwick DW, Park BK, Pirmohamed M. HLA-B locus in Caucasian patients with carbamazepine hypersensitivity. Pharmacogenomics 2006;7(6):813-8.

4. Al-Sayed AA, Al-Numay AM. Update and review on the basis of pain management. Neurosciences 2011;16(3):203-12.

5. Alvestad S, Lydersen S, Brodtkorb $E$ et al.Cross-reactivity pattern of rash from current antiepileptic drugs. Epilepsy Research 2008;80:194-200.

6. Barbaud A, Bene MC, Faure G, Schmutz JL. Tests cutane's dans l'exploration des toxidermies suppose'es de mecanisme immuno-allergique. Bull. Acad. Natl. Med. 2000;184:47-63.

7. Barbaud A, Trechot P, Reichert-Penetrat S, Commun N, Schmutz JL. Relevance of skin tests with drugs in investigating cutaneous adverse drug reactions. Contact Dermatitis 2001;45;265-268.

8. Barbaud A. Drug patch testing in systemic cutaneous drug allergy. Toxicilogy 2005;209:209-216

9. Barbaud A. Skin testing in delayed reactions to drugs. Immunol Allergy Clin $N$ Am 2009;29:517-535.

10. Benahmed S, Picot MC, Dumas F, Demoly P. Accuracy of a pharmacovigilance algorithm in diagnosing drug hypersensitivity reactions. Arch Intern Med 2005;165(13):1500-5 
11. Bialer M. Why are antiepileptic drugs used for nonepileptic conditions? Epilepsia 2012;7;26-33.

12. Borish, L; Tilles, S.A. Immune Mechanisms of Drug Allergy. Immunology and Allergy Clinics of North América. 1998;18(4):717-29.

13. Brokow K, Garvey LH, Aberer $W$ et al., Skin test concentrations for systemically administered drugs - an ENDA/EAACI Drug Allergy Interest Group position paper. Allergy 2013:68;702-12.

14. Brockmöller J, Tzvetkov MV. Pharmacogenetics: data, concepts and tools to improve drug discovery and drug treatment. Eur J Clin Pharmacol. 2008;64(2):133-57.

15. Calvin JM and Maibach HI. Delay hypersensitivity drug reactions diagnosed by patch testing. Contact Dermatitis 1993;29:223-233.

16. Cardon LR, Palmer LJ. Population stratification and spurious allelic association. The Lancet 2003;61:598-609.

17. Cesdron-Gautier A, Simon $P$, Archad $L$ et al. Technologie Luminex: application aux typage HLA par biologie moleculaire (PCR-SSO) et à l'idendification des anticorps ant-HLA. Ann Biol Clin 2004;62:93-8.

18. Chadwick, D., et al., Serum anticonvulsant concentration and the druginduced skin eruptions. J Neurol Neurosurg Psychiatry, 1984. 47: p. 642-46

19. Cham MHP, Warshaw EM. Patch Testing for Evaluation Drug Reactions Due to Systemic Antibiotics. Dermatitis 2007;18(2):63-77.

20. Chang, C.C., Too, C.L., Murad, S. \& Hussein, S.H. Association of HLA$B^{*} 1502$ allele with carbamazepine-induced toxic epidermal necrolysis and Stevens-Johnson syndrome in the multi-ethnic Malaysian population. Int. J. Dermatol. 2011:50;221-224. 
21. Chen, P. et al.; Taiwan SJS Consortium. Carbamazepine-induced toxic effects and HLA-B*1502 screening in Taiwan. N. Engl. J. Med. 2011;364: 1126-1133.

22. Chung, W.H. et al. Medical genetics: a marker for Stevens-Johnson syndrome. Nature 2004;428:486.

23. Demoly $P$, Hillaire-Buys D. Classification and epidemiology of hypersensitivity drug reactions. Immunol Allergy Clin North Am. 2004; 24: 345-56.

24. Demoly P, Kropf R, Bircher A, Pichler WJ. Drug hypersensitivity: questionnaire. EAACI interest group on drug hypersensitivity. Allergy 1999; 54:999-1003.

25. Demoly P, Adkinson NF, Brockow K, Castells M, Chiriac MA, Greenberger PA. International Consensus on drug allergy. Allergy 2014;69:420-437.

26. Demoly P, Tanno LK, Akdis CA, Lau S, Calderon MA, Santos AF, SanchezBorges M, Rosenwasser LJ, Pawankar R, Papadopoulos NG. Global classification and coding of hypersensitivity diseases - An EAACI - WAO survey, strategic paper and review. Allergy 2014;69:559-570.

27. Dorado P, López-Torres E, Penã-Lledó EM, Martinez-Antón J, Llerena A. Neurological toxicity after phenytoin infusion in a pediatric patient with epilepsy: influence of CYP2C9, CYP2C19 and ABCB1 genetic polymorphisms. Pharmacogenomics J. 2013;13(4):359-61.

28. Duong T, Lee H, Assier H, Haddad C, Gouvello SL, Wolkenstein P, Roujeau JC, Valeyrie-Allnore L. Patch testing in severe cutaneous adverse reactions: a study of 111 patients. European Ann Allergy and Clin Immunol 2010;42: 63-62.

29. Eichelbaum M, Ingelman-Sundberg M, Evans WE. Pharmacogenomics and individualized drug therapy. Annu Rev Med. 2006;57:119-37. 
30. Garcia-Martin E, Martinez C, Ladero JM, gamito FJ, Agúndez JA. High frequency of mutations related to impaired CYP2C9 metabolism in a Caucasian population. Eur J Clin Pharmacol, 57:47-49, 2001

31. Gilman AG, Rall TW, Nies AS, Taylor P. Drogas Eficazes no Tratamento das Epilepsias. In: Goodman \& Gilman. As Bases Farmacológicas da Terapêutica. $8^{a}$ ed. Rio de Janeiro: Guanabara Koogan, 1991: 290.

32. Gomes ER and Demoly P . Epidemiology of hypersensitivity drug reactions, Curr Opin Allergy Clin Immunol 2005;5:309-316.

33. Gonzalez-Galarza FF, Christmas S, Middleton D and Jones AR. Allele Frequency in Worldwide Populations: www.allelefrequency.net. Nucleic Acid Research 2011;39:913-919.

34. Hattersley AT, McCarthy M. What makes a good genetic associationstudy? The Lancet 2005;366;1315-23.

35. Ingelman-Sundberg M, Sim SC, Gomez A, Rodriguez-Antona C. Influence of cytochrome P450 polymorphisms on drug therapies: pharmacogenetic, pharmacoepigenetic and clinical aspects. Pharmacol Ther. 2007;116(3):496526.

36. Instituto Brasileiro de Geografia e Estatística (IBGE). Tendências Demográficas: Uma análise da população com base nos resultados dos Censos Demográficos 1940 e 2000

37. Johansson SG, Bieber T, Dahl R, Friedmann PS, Lanier BQ, Lockey RF, et al. Revised nomenclature for allergy for global use: Report of the Nomenclature Review Committee of the World Allergy Organization, October 2003. J Allergy Clin Immunol. 2004;113:832-836.

38. Justenhoven $\mathrm{C}$, Hamann U, Pierl CB, Baisch C, Harth V, Rabstein S, Spickenheuer A, Pesch B, Brüning T, Winter S, Ko YD, Brauch $H$. CYP2C19*17 is associated with decreased breast cancer risk. Breast Cancer Res Treat. 2009;115(2):391-6. 
39. Kaniwa N, Saito Y, Aihara M, Matsunaga K, Tohkin M, Kurose K e cols. HLAB locus in Japanese patients with anti-epileptics and allopurinol-related Stevens-Johnson syndrome and toxic epidermal necrolysis. Pharmacogenemics 2008;9(11):1617-22

40. Kano Y. and Shiohara T., The Variable Clinical Picture of Drug-Induced Hypersensitivity Syndrome/Drug Rash with Eosinophilia and Systemic Symptoms in Relation to the Eliciting Drug. Immunol Allergy Clin N Am 2009;29:481-501.

41. Kaufman KR. Antiepileptic drugs in the treatment of psychiatric disorders. Epilepsy Behav. 2011;21(1):1-11.

42. Kerb R. Implications of genetic polymorphisms in drug transporters for pharmacotherapy. Cancer Lett. 2006;234(1):4-33.

43. Kim B. Handoko, Euge`ne P. van Puijenbroek, Annemarie H. et al. Influence of Chemical Structure on Hypersensitivity Reactions Induced by Antiepileptic Drugs The Role of the Aromatic Ring Drug Safety 2008;31(8):695-702

44. Kim SH, Lee $\mathrm{KH}$, Kim SH, et al. HLA genotypes in Korean patients with carbamazepine-induced severe cutaneous adverse reaction. Korean J Asthma Allergy Clin Immunol 2009; 29:S248.

45. Kim SK, Ye YM, Nani SP, Kim JE, Park HS. Genetic and ethnic risk factors associated with drug hypersensitivity. Curr Opin Allergy Clin Immunol 2010; $10: 280-90$

46. Klein J, Sato A. Advances in Immunology: The HLA System. NEJM. 2003; 343(10):702-9

47. Klitgaard H. Antiepileptic drug discovery: lessons from the past and future challenges. Acta Neurol Scand. 2005;181(suppl): 68-72

48. Knowles SR et al., Recognition and Management of Severe Cutaneous Drug Reactions Dermatol Clin 2007;25:245-253. 
49. Koo SH, Lee EJ. Pharmacogenetics approach to therapeutics. Clin Exp Pharmacol Physiol. 2006 May-Jun;33 (5-6): 525-32.

50. Krejsa C, Rogge M, Sadee W. Protein therapeutics: new applications for pharmacogenetics. Nat Rev Drug Discov. 2006 Jun;5(6):507-21. Review.

51. Kirchheiner J, Brockmöller J.Clinical consequences of cytochrome P450 2C9 polymorphisms. Clin Pharmacol Ther. 2005 Jan;77(1):1-16. Review.

52. Kuehl P, Zhang J, Lin Y, Lamba J, Assem M e cols. Sequence diversity in CYP3A promoters and characterization of the genetix basis of ppolymorphic CYP3A5 expression. Nature Genetics 2001;27:383-391.

53. Lammintantausta $\mathrm{K}$, Kortekangas-Savolaien $\mathrm{O}$. The usefuness of skin tests to prove drug hypersensitivity. Br J Dermatol 2005;152:968-74.

54. Lars E French. Toxic Epidermal Necrolysis and Stevens Johnson Syndrome: Our Current Understanding, Allergology International. 2006;55:9-16.

55. Lazarou J, Pomeranz BH e cols.Incidence of adverse drug reactions in hospitalized patients: a meta-analysis of prospective studies. JAMA 1998;279:1200-5.

56. Locharernkul C, Loplumlert J, Limotai C, et al. Carbamazepine and phenytoin induced Stevens - Johnson syndrome is associated with HLA-B 1502 allele in Thai population. Epilepsia 2008;49:2087-2091.

57. Man CB, Kwan P, Baum L, et al. Association between HLA-B* 1502 allele and antiepileptic drug-induced cutaneous reactions in Han Chinese. Epilepsia 2007;48:1015-1018.

58. Masia SL, Devinsky O. Epilepsy and behavior: A brief history. Epilepsy Behav. 2000;1(1):27-36.

59. McCormack $M$, Alfirevic AB, Bourgeois $S$ et al. HLA-A*3101 and Carbamazepine-Induced Hypersensitivity Reactions in Europeans. N Engl J Med 2011;364:1134-43. 
60. Mehta TY et al., Association of HLA*B 1502 allele and carbamazepineinduced Stevens - Johnson syndrome among Indians. Indian J Dermatol Venereol Leprol 2009;75:579-582.

61. Mockehnaupt M, Viboud C, Dunant A, Naldi L, Halevy S, Bavinck JNB, Sidoroff A, Schneck J, Roujeau JC, Flahault A. Stevens-Johnson Syndrome and Toxic Epidermal Necrolysis: assessment of medication risks with emphasis on recently marketed drugs. The Euro-SCAR-study. Journal of Investigative Dermatology 2008;128:35-44

62. Mockenhaupt M. The current understanding of Stevens-Johnson Expert Rev Clin Immunol. 2011;7(6):803-13

63. Nagao-Dias AT, et al, Diagnosing immune-mediated reactions to drugs, Allergol e Immunopathol. 2009;37(2):98-104

64. Narinder K. Mehra and Gurvinder Kaur. Expert Reviews in Molecular Medicine, Vol. 5; 24 February 2003 5; 24 January 2003 Cambridge University Press

65. Osawa J, Naito S, Aihara M, Kitamura K, Ikezawa Z, Nakajima H. Evaluation of skin test reactions in patients with non-immediate type drug eruptions. J. Dermatol. 1990;17:235-239.

66. Osawa J, Naito S, Aihara M, Kitamura K, Ikezawa Z, Nakajima H. Evaluation of skin test reactions in patients with non-immediate type drug eruptions. J. Dermatol. 1990;17:235-239.

67. Park BK, Naisbitt DJ, Demoly P. Drug hypersensitivity. In: Holgate S, Church M, Broide D, Martinez F, editors. Allergy. New York: Elsevier Ltd, 2012: $321-$ 330.

68. Peace RE et al, Pathways of Carbamazepine Bioactivation in vitro I. Characterization of Human Cytochromes P450 Responsible for the Formation of 2- and 3- Hydroxilated Metabolites. Drug Metabolism and Disposition, 2002;30:1170-1179. 
69. Peace RE et al, Pathways of Carbamazepine Bioactivation in vitro III. The role of Human Cytochrome P450 enzymes in the formation of 2,3dihydroxycarbamazepine. Drug Metabolism and Disposition, 2008; 36(8):1637-1649.

70. Pena SDJ, Di Pietro G, Fuchshuber-Moraes M, Genro JP, Hutz MH, et al. (2011) The Genomic Ancestry of Individuals from Different Geographical Regions of Brazil Is More Uniform Than Expected. PLoS ONE 2011;6(2): e17063.

71. Pichler WJ, Delayed Drug Hypersensitivity Reactions, Ann Intern Med. 2003;139:683-693.

72. Pirmohamed $\mathrm{M}$, James $\mathrm{S}$ e cols. Adverse reactions as cause of admission to hospital: prospective analysis of 18820 patients. BMJ 2004;329:15-9

73. Pirmohamed M. et al. Phenotype Standardization for Immune-Mediated Drug-Induced Skin Injury. Clinical Pharmacoly and Therapeutics, 2011; 1-6

74. Pirmohamed $\mathrm{M}$. Pharmacogenetics and pharmacogenomics. $\mathrm{Br} \mathrm{J}$ Clin Pharmacol, 2001;52:345-347.

75. Pirmohamed, M., et al., Adverse drug reactions as cause of admission to hospital - Admissions to ear, nose, and throat departments were not mentioned - Reply. British Medical Journal, 2004;329(7463):460-460.

76. Pohl, L.R., et al., Immunologic and metabolic basis of drug hypersensitivities. Ann Rev Pharmacol, 1988. 28: p. 367-87.

77. Primeau, M.-N., R. G. Hamilton, et al. Negative patch tests and skin tests in patients with delayed cutaneous manifestation to penicillin. J Allergy Clin Immunol. 2002;109(1):816.

78. Q Zhou ET al., Genetic polymorphism, linkage disequilibrium, haplotype structure and novel allele analysis of CYP2C19 and CYP2D6 in Han Chinese, The Pharmacogenomics Journal 2009:9:380-394. 
79. Ragia G, Arvanitidis KI, Tavridou A, Manolopoulos VG. Need for reassessment of reported CYP2C19 allele frequencies in various populations in view of CYP2C19*17 discovery: the case of Greece. Pharmacogenomics. 2009;10(1):43-9.

80. Rawlins, M.D. and J.W. Thompson, Mechanisms of adverse drug reactions, in Textbook of Adverse Drug Reactions, D.M. Davies, Editor. 1991, Oxford University Press: Oxford. p. 18-45

81. Romano A, Demoly P. Recent advances in the diagnosis of drug allergy. Current Opinion in Allergy and Clinical Immunology 2007;7:299-303.

82. Romano A, Di Fonso M, Pietrantonio F, Pocobelli D, Giannarini L, Del Bono A, Fabrizi G, Venuti A. Repeated patch testing in delayed hypersensitivity to beta-lactam antibiotics. Contact Dermatitis 1993;28:190.

83. Romano A, Viola $M$, Mondino $C$ et al. Diagnosing nonimmediate reactions to penicillin's by in vivo tests. Int Arch Allergy Immunol 2002;129:169-74.

84. Roujeau JC et al., Severe Adverse Cutaneous Reactions to Drugs. The New England Journal of Medicine 1994;331:1272-1285.

85. Roujeau, J.C. et al. Medication use and the risk of Stevens-Johnson syndrome or toxic epidermal necrolysis. N. Engl. J. Med. 1995;333:16001607.

86. Sade'e $W$ et al. Pharmacogenetics/genomics and personalized medicine. Human Molecular Genetics, 2005,14:207-14.

87. Santiago F, Goncalo M, Vieira R et al. Epicutaneous patch testing in drug hypersensitivity syndrome (DRESS). Contact Dermatitis 2010; 62:47-53.

88. Scott SA, Edelmann L, Kornreich R, Erazo M, Desnick RJ. CYP2C9, CYP2C19 and CYP2D6 allele frequencies in the Ashkenazi Jewish population. Pharmacogenomics. 2007;8(7):721-30. 
89. Shah RR. Pharmacogenetics in drug regulation: promise, potential and pitfalls. Philos Trans R Soc Lond B Biol Sci .2005;29;360(1460):1617-38.

90. Shear, N.H. et al., Anticonvulsant hypersensitivity syndrome: in vitro risk assessment. J Clin Invest, 1988. 82: p. 1826-32

91. Sim SC, Risinger C, Dahl ML, Aklillu E, Christensen M, Bertilsson L, Ingelman- Sundberg M. A common novel CYP2C19 gene variant causes ultrarapid drug metabolism relevant for the drug response to proton pump inhibitors and antidepressants. Clin Pharmacol Ther. 2006;79(1):103-13.

92. Stephen Bernard, Interethnic Differences in Genetic Polymorphisms of CYP2D6 in the U.S. Population: Clinical Implications, The Oncologist 2006;11:126-135.

93. Suarez-Kurtz G, Vargens DD, Santoro AB, Hutz MA, Morais ME e cols. Global Pharmacogenomics: Distribution of CYP3A5 Polymorphisms and Phenotypes in the Brazilian Populatio. PlosOne 2014 9(1):1-6

94. Sugimoto $\mathrm{K}$, Uno $\mathrm{T}$, Yamazaki $\mathrm{H}$, Tateishi $\mathrm{T}$. Limited frequency of the CYP2C19*17 allele and its minor role in a Japanese population. $\mathrm{Br} \mathrm{J}$ Clin Pharmacol. 2008;65(3):437-9.

95. Svensson CK et al., Cutaneous Drug Reactions, Pharmacological Reviews 2000;53:357-379.

96. Tanno LK et al. Dermatite Esfoliativa Aguda, Síndrome de Stevens-Johnson e Necrólise Epidérmica Tóxica. Tratado de Medicina de Urgência do Idoso. Ed Atheneu, 2010:767-77

97. Tanno LK, Ensina LFC, Aun MV et al. Drug patch tests in evaluation of nonimmediate hypersensitivity reactions. Rev Bras Alerg Imunopatol 2011;34(6):251-6

98. Tanno LK, Curi SV, Dracoulakis M, Aun WT, Mello JF. XXII World Allergy Congress 2011, Cancun, México. World Allergy Organization Journal 2012, 5(Suppl 2):1-607 
99. Tanno LK, Ganen F, Demoly P, Tosacno CM, Bierrenbach AL. Undernotification of anaphylaxis deaths in Brazil due to difficult coding under the ICD-10. Allergy 2012;67:783-789.

100. Thong BY, Tan TC. Epidemiology and risk factors for drug allergy. Br J Clin Pharmacol 2011;71(5):684-700.

101. Torres MJ, Mayorga C, Blanca M. Non-immediate allergic reactions induced by drugs: phathogenesis and diagnostic tests. J Investig Allergol Clin Immunol 2009;19(2):80-90.

102. Vervloet D, Pradal M, Birnbaum J, Koeppel MC. Drug Allergy, 2009

103. Wang $X Q$, Lang SY, Shi $X B$ et al. Cross-reactivity of skin rashes with current antiepileptic drugs in Chinese population. Seizure 2010;19(9):562-6.

104. Wang, Q. et al. Association between HLA-B ${ }^{*} 1502$ allele and carbamazepineinduced severe cutaneous adverse reactions in Han people of southern China mainland. Seizure 2011;20:446-448.

105. Weiss KM, Clark AG. Linkage disequilibrium and the mapping of complex human traits. Trend in Genetics 2002;8(1):19-24

106. WHO. International drug monitoring: the role of national centres. Tech Rep Ser WHO 1972, no 498

107. Xu C, Goodz S, Sellers EM, Tyndale RF. CYP2A6 genetic variation and potential consequences. Adv Drug Deliv Rev 2002;54:1245-1256.

108. Yengi LG, Xiang Q, Pan J, Kao J, Ball SE, Fruncillo R, Ferron G, Roland WC. Quantitation of cytochrome P450 MRNA levels in human skin. Anal Biochem 2003;316(1):103-10.

109. Yip VL, Marson AG, Jorgensen AL et al. HLA Genotype and CarbamazepineInduced Cutaneous Adverse Drug Reactions: A Systemic Review. Clin Pharmacol Therapeutics 2012:92;757-65. 
110. Zang UM, Klein K, Thomas M, Rieger JK, Tremmel R, Kandel BA, Klein M, Magdy T. Genetics, epigenetics, and regulation of drug-metabolizing cytochrome p450 enzymes. Clin Pharmacol Ther. 2014;95(3):258-61.

111. Zanger UM, Turpeinen M, Klein K, Schwab M. Functional pharmacogenetics/genomics of human cytochromes P450 involved in drug biotransformation. Anal Bioanal Chem. 2008;392(6):1093-108.

112. Zhang, $Y$. et al. Strong association between HLA-B*1502 and carbamazepine-induced Stevens-Johnson syndrome and toxic epidermal necrolysis in mainland Han Chinese patients. Eur. J. Clin. Pharmacol. 2011; $67: 885-887$.

113. Zhou SF, Di YM, Chan E, Du YM, Chow VD, Xue CC, Lai X, Wang JC, Li CG, Tian M, Duan W Clinical pharmacogenetics and potential application in personalized medicine. Curr Drug Metab. 2008;9(8):738-84. 
Anexo 1. Aprovação do projeto pela CAPPesq

\section{Hospital das Clínicas da FMUSP \\ 'Comissăo de Ética para Análise de Projetos de Pesquisa \\ CAPPesq}

$N^{\circ}$ Protocolo: 0554/11

Título: ESTUDO DE ASSOCIAÇÃO DE FATORES GENÉTICOS EM INDIVÍDUOS COM REAÇÕES DE HIPERSENSIBILIDADE TARDIA INDUZIDA POR ANTICONVULSIVANTES AROMÁTICOS

Pesquisador Responsável: Jorge Elias Kalil Filho

Pesquisador Executante: Luciana Kase Tanno

Co-autores: Daniel Shikanai Kerr, Carolina Martins do Prado, Wagner Farid Gattaz, Edécio Cunha Neto, Pedro Giavina-Bianchi,Helcio Rodrigues Diologo, Maria Lucia A.C. Marin . Antonio Abilio Motta

Finalidade Acadêmica: Doutorado

Departamento: CLÍNICA MÉDICA

A Comissão de Ética para Análise de Projetos de Pesquisa CAPPesq da Diretoria Clínica do Hospital das Clínicas da Faculdade de Medicina da Universidade de São Paulo, APROVOU / TOMOU CIÊNCIA na sessão datada de 14/09/2011 o protocolo acima.

A CAPPesq em obediência à Resolução CNS 196/96, solicita ao pesquisador (a) s elaboração de relatório parcial e final.

No caso de relatório parcial é necessário informar o tempo previsto para a conclusão do protocolo e breve resumo dos resultados obtidos.

CAPPesq, 14 de Setembro de 2011

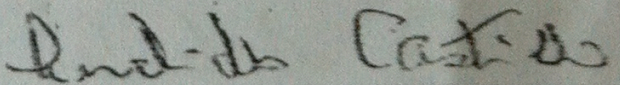

PROF. DR. EUCLIDES AYRES DE CASTILHO Coordenador Comissão de Ética para Análise de Projetos de Pesquisa - CAPPesq 
Anexo 2. Termo de Consentimento Livre e Esclarecido destinado aos controles sadios e tolerantes

\section{HOSPITAL DAS CLÍNICAS DA FACULDADE DE MEDICINA DA UNIVERSIDADE DE SÃO PAULO-HCFMUSP TERMO DE CONSENTIMENTO LIVRE E ESCLARECIDO}

DADOS DE IDENTIFICAÇÃO DO SUJEITO DA PESQUISA OU RESPONSÁVEL LEGAL

1. NOME:

DOCUMENTO DE IDENTIDADE No: __ SEXO: M F

No: APTO:

ENDEREÇO: CIDADE:

BAIRRO: TELEFONE: DDD (__

CEP:

2. RESPONSÁVEL LEGAL:

NATUREZA (grau de parentesco, tutor, curador etc.)

DOCUMENTO DE IDENTIDADE No:

SEXO: $M$

$\mathrm{F}$

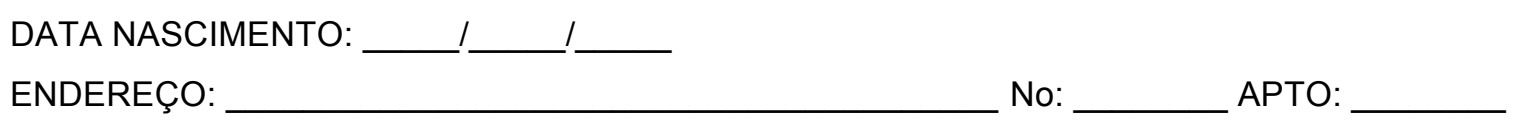

BAIRRO: CIDADE:

CEP: TELEFONE: DDD (

DADOS SOBRE A PESQUISA

Título do protocolo de pesquisa: Estudo de Associação de Fatores Genéticos em Indivíduos com Reações de Hipersensibilidade Tardia Induzida por Anticonvulsivantes Aromáticos

Pesquisador: Luciana Kase Tanno; Cargo/Função: Médica Alergista e Imunologista;

Inscrição Conselho Regional: No 103845-CRM;

Unidade do HCFMUSP: Divisão de Imunologia Clínica e Alergia
Avaliação do risco da pesquisa:
(X) RISCO MÍNIMO
( ) RISCO MÉDIO
( ) RISCO BAIXO
( ) RISCO MAIOR

Duração da pesquisa: 2 anos

Os medicamentos anticonvulsivantes geralmente são utilizados no tratamento de ataques epilépticos (epilepsia), mas também no tratamento de dor ou em algumas doenças psiquiátricas. Alguns pacientes que usam estes medicamentos podem desenvolver reações alérgicas, muitas vezes graves. O objetivo deste estudo é saber se existem alterações genéticas que aumentam ou não a chance destas reações alérgicas. Pessoas que não usam estes medicamentos também podem voluntariamente participar do estudo para verificar se apresentam estas alterações genéticas.

A sua participação neste estudo é voluntária e os resultados da pesquisa serão disponibilizados caso tenha interesse. Você deverá comparecer ao Ambulatório de Alergia e Imunologia do Hospital das Clínicas. 
Nesta visita ao ambulatório, deverão ser realizados os seguintes procedimentos:

1. Avaliação médica: é uma consulta médica comum na qual serão feitas perguntas para preenchimento de um questionário de avaliação. A única diferença em relação a uma consulta normal é que serão feitas perguntas sobre seus antecedentes raciais.

2. Exame de sangue (retirando mais ou menos $20 \mathrm{ml}$ ) a partir de veia do braço para realização do estudo genético.

Em qualquer etapa do estudo, você terá acesso aos profissionais responsáveis pela pesquisa para esclarecimento de eventuais dúvidas. A principal responsável é a pesquisadora Luciana Kase Tanno que pode ser encontrada no telefone 11 - 26616098/ 11 - 26616225. Prédio dos Ambulatórios PAMB Av. Dr. Enéas de Carvalho Aguiar, 44, 5o andar, bloco 4B Cerqueira Cesar - São Paulo. Se você tiver alguma consideração ou dúvida sobre a ética da pesquisa, entre em contato com o Comitê de Ética em Pesquisa (CEP) - Rua Ovídio Pires de Campos, 225 - 5o andar - tel: 2661-6442 ramais 16, 17, 18 ou 20, FAX: 3069-6442 ramal 26 - E-mail: cappesq@hcnet.usp.br.

É garantida a liberdade da retirada de consentimento a qualquer momento e deixar de participar do estudo, sem qualquer prejuízo à continuidade de seu tratamento na Instituição.

Direito de confidencialidade - As informações obtidas serão analisadas em conjunto com outros pacientes, não sendo divulgada a identificação de nenhum paciente.

É garantido o direito de ser mantido atualizado sobre os resultados parciais da pesquisa ou de resultados que sejam do conhecimento dos pesquisadores.

Despesas e compensações: não há despesas pessoais para o participante em qualquer fase do estudo, incluindo exames e consultas. Também não há compensação financeira relacionada à sua participação. Se existir qualquer despesa adicional, ela será absorvida pelo orçamento da pesquisa.

Acredito ter sido suficientemente informado(a) a respeito das informações que li ou que foram lidas para mim, descrevendo o estudo "Estudo de Associação de Fatores Genéticos em Indivíduos com Reações de Hipersensibilidade Tardia Induzida por Anticonvulsivantes Aromáticos". Eu discuti com a pesquisadora Luciana Kase Tanno sobre a minha decisão em participar desse estudo. Ficaram claros para mim quais são os propósitos do estudo, os procedimentos a serem realizados, seus desconfortos e riscos, as garantias de confidencialidade e de esclarecimentos permanentes.

Ficou claro também que minha participação é isenta de despesas e que tenho garantia do acesso a tratamento hospitalar quando necessário. Concordo voluntariamente em participar deste estudo e poderei retirar o meu consentimento a qualquer momento, antes ou durante o mesmo, sem penalidades ou prejuízo ou perda de qualquer benefício que eu possa ter adquirido, ou no meu atendimento neste Serviço.

Assinatura do paciente/representante legal

Data:

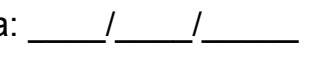

Assinatura da testemunha

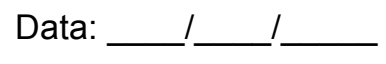

Para casos de pacientes menores de 18 anos, analfabetos, semi-analfabetos ou portadores de deficiência auditiva ou visual.

(Somente para o responsável do projeto)

Declaro que obtive de forma apropriada e voluntária o Consentimento Livre e Esclarecido deste paciente ou representante legal para a participação neste estudo.

Assinatura do responsável pelo estudo

Data:

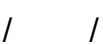


Anexo 3: Termo de Consentimento Livre e Esclarecido destinado aos pacientes que apresentaram reação

\section{HOSPITAL DAS CLÍNICAS DA FACULDADE DE MEDICINA DA UNIVERSIDADE DE SÃO PAULO-HCFMUSP \\ TERMO DE CONSENTIMENTO LIVRE E ESCLARECIDO}

DADOS DE IDENTIFICAÇÃO DO SUJEITO DA PESQUISA OU RESPONSÁVEL LEGAL

1. NOME:

DOCUMENTO DE IDENTIDADE No:

SEXO: $M$

$\mathrm{F}$

DATA NASCIMENTO:

1

ENDEREÇO:

No:

APTO:

BAIRRO: CIDADE:

CEP: TELEFONE: DDD (

2. RESPONSÁVEL LEGAL:

NATUREZA (grau de parentesco, tutor, curador etc.)

DOCUMENTO DE IDENTIDADE No:

SEXO: $M \quad F$

DATA NASCIMENTO: 1

ENDEREÇO: No: APTO:

BAIRRO: CIDADE:

CEP: TELEFONE: DDD

\section{DADOS SOBRE A PESQUISA}

Título do protocolo de pesquisa: Estudo de Associação de Fatores Genéticos em Indivíduos com Reações de Hipersensibilidade Tardia Induzida por Anticonvulsivantes Aromáticos

Pesquisador: Luciana Kase Tanno; Cargo/Função: Médica Alergista e Imunologista;

Inscrição Conselho Regional: No 103845-CRM;

Unidade do HCFMUSP: Divisão de Imunologia Clínica e Alergia
Avaliação do risco da pesquisa:
(X) RISCO MÍNIMO
( ) RISCO MÉDIO
( ) RISCO BAIXO
( ) RISCO MAIOR

Duração da pesquisa: 2 anos

Os medicamentos anticonvulsivantes geralmente são utilizados no tratamento de ataques epilépticos (epilepsia), mas também no tratamento de dor ou em algumas doenças psiquiátricas. Alguns pacientes que usam estes medicamentos podem desenvolver reações alérgicas, muitas vezes graves. Algumas alterações genéticas podem aumentar a chance destas reações. $O$ objetivo deste estudo é saber se você apresenta estas alterações genéticas que aumentam ou não a chance de reações alérgicas a medicamentos anticonvulsivantes.

A sua participação neste estudo é voluntária e os resultados da pesquisa serão disponibilizados caso tenha interesse. Você deverá comparecer ao Ambulatório de Alergia e Imunologia do Hospital das Clínicas. 
Nesta visita ao ambulatório, deverão ser realizados os seguintes procedimentos:

1. Avaliação médica: é uma consulta médica comum na qual serão feitas perguntas para preenchimento de um questionário de avaliação. A única diferença em relação a uma consulta normal é que serão feitas perguntas sobre seus antecedentes raciais.

2. Exame de sangue (retirando mais ou menos $20 \mathrm{ml}$ ) a partir de veia do braço para realização do estudo genético.

Em qualquer etapa do estudo, você terá acesso aos profissionais responsáveis pela pesquisa para esclarecimento de eventuais dúvidas. A principal responsável é a pesquisadora Luciana Kase Tanno que pode ser encontrada no telefone 11 - 26616098/ 11 - 26616225, Prédio dos Ambulatórios - PAMB Av. Dr. Enéas de Carvalho Aguiar, 44, 5o andar, bloco 4B Cerqueira Cesar São Paulo. Se você tiver alguma consideração ou dúvida sobre a ética da pesquisa, entre em contato com o Comitê de Ética em Pesquisa (CEP) - Rua Ovídio Pires de Campos, 225 - 5o andar - tel: 2661-6442 ramais 16, 17, 18 ou 20, FAX: 3069-6442 ramal 26 - E-mail: cappesq@hcnet.usp.br.

É garantida a liberdade da retirada de consentimento a qualquer momento e deixar de participar do estudo, sem qualquer prejuízo à continuidade de seu tratamento na Instituição. Direito de confidencialidade - As informações obtidas serão analisadas em conjunto com outros pacientes, não sendo divulgada a identificação de nenhum paciente.

É garantido o direito de ser mantido atualizado sobre os resultados parciais da pesquisa ou de resultados que sejam do conhecimento dos pesquisadores.

Despesas e compensações: não há despesas pessoais para o participante em qualquer fase do estudo, incluindo exames e consultas. Também não há compensação financeira relacionada à sua participação. Se existir qualquer despesa adicional, ela será absorvida pelo orçamento da pesquisa.

Acredito ter sido suficientemente informado(a) a respeito das informações que li ou que foram lidas para mim, descrevendo o estudo "Estudo de Associação de Fatores Genéticos em Indivíduos com Reações de Hipersensibilidade Tardia Induzida por Anticonvulsivantes Aromáticos". Eu discuti com a pesquisadora Luciana Kase Tanno sobre a minha decisão em participar desse estudo. Ficaram claros para mim quais são os propósitos do estudo, os procedimentos a serem realizados, seus desconfortos e riscos, as garantias de confidencialidade e de esclarecimentos permanentes.

Ficou claro também que minha participação é isenta de despesas e que tenho garantia do acesso a tratamento hospitalar quando necessário. Concordo voluntariamente em participar deste estudo e poderei retirar o meu consentimento a qualquer momento, antes ou durante o mesmo, sem penalidades ou prejuízo ou perda de qualquer benefício que eu possa ter adquirido, ou no meu atendimento neste Serviço.

Assinatura do paciente/representante legal
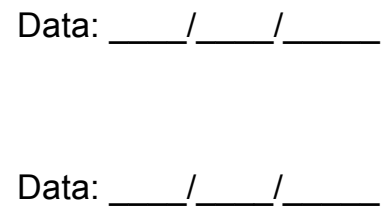

Assinatura da testemunha

Para casos de pacientes menores de 18 anos, analfabetos, semi-analfabetos ou portadores de deficiência auditiva ou visual.

(Somente para o responsável do projeto)

Declaro que obtive de forma apropriada e voluntária o Consentimento Livre e Esclarecido deste paciente ou representante legal para a participação neste estudo.

Assinatura do responsável pelo estudo

Data: 1 
Anexo 4. Questionário de avaliação clínica

$\mathrm{N}^{\circ}$ do protocolo:

Data:

QUESTIONÁRIO PARA INVESTIGAÇÃO DE HIPERSENSIBILIDADE AOS FÁRMACOS

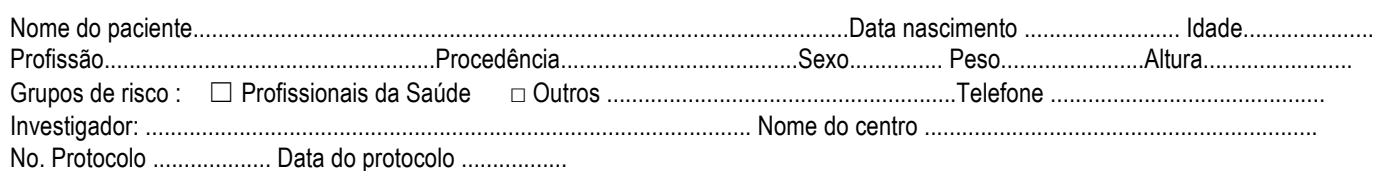

No. Protocolo

Data do protocolo

História atual -

Reação por fármaco:

$\mathrm{N}^{0}$ de episódios:

Data da última reação

(Pode assinalar várias opções; sublinhar a mais importante se necessário; utilizar números para indicar a cronologia)

MANIFESTAÇÕES CUTÂNEAS:

$\square$ Exantema maculopapular

DIAGNÖSTICO DIFERENCIAL:

$\square$ Exantema macular

$\square$ Exantema urticariforme

$\square$ Urticária

$\square$ AGEP (Pustulose Exantemática)

$\square$ Exantema eczematóide

$\square$ Eritema multiforme exudativo

$\square$ Exantema bolhoso

$\square$ Stevens Johnson/NET

$\square$ Eritema pigmentar fixo

$\square$ Púrpura - $\square$ palpável $\square$ hemorrágica $\square$ visceral

$\square$ Dermatite de contato

$\square$ Urticária vasculite

$\square$ APENAS prurido

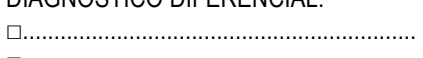

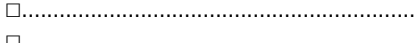

FATORES ASSOCIADOS

$\square$ Infecção viral $\square$ Síndrome Gripal $\square$ Outros...

$\square$ Febre ............... ${ }^{\circ} \mathrm{C}$

$\square$ Suspeita de fotosensibilidade $\square$ Sim $\square$ Não

$\square$ Exercício

$\square$ Outras/Especificar

$\square$ Angioedema/Local

Intensidade

$$
\text { EVOLUÇão }
$$

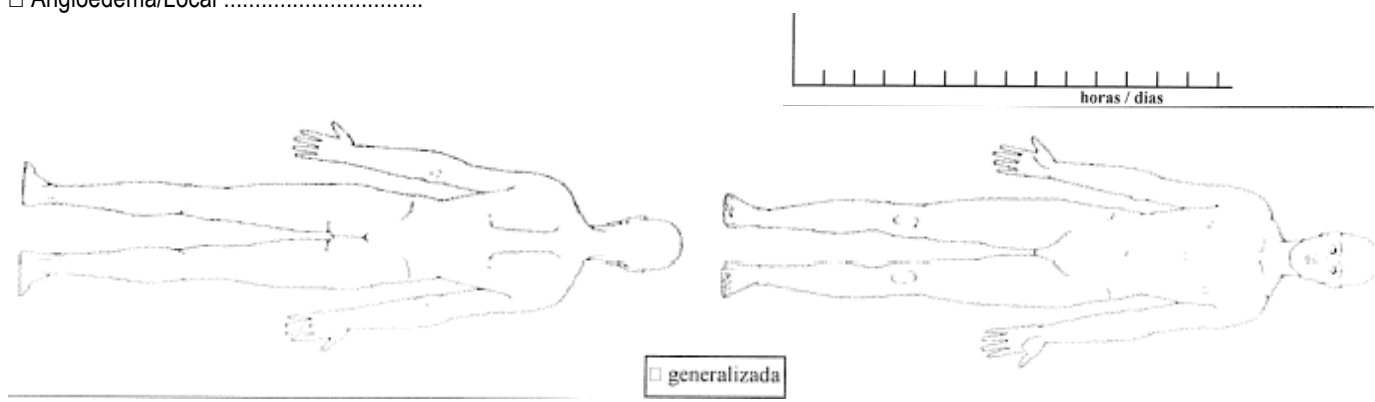

SINTOMAS GASTRINTESTINAIS:

SINTOMAS RESPIRATÓRIOS:

$\square$ Náuseas/vômitos
$\square$ Diarréia
$\square$ Cólicas

SINTOMAS CARDIOVASCULARES:

$\square$ Taquicardia

$\square$ Hipotensão

$\square$ Colapso

$\square$ Arritmia

Pulso

PA ..................

Outros ................

SINTOMAS PSÍQUICOS

$\square$ Medo/Pânico

$\square$ Sensação de desmaio

$\square$ Parestesia/hiperventilação

$\square$ Sudorese

Outros (especificar)
SINTOMAS RESPIRATORIOS:
$\square$ Tosse $\square$ Disfonia

$\square$ Broncoespasmo $\quad \square$ Dispnéia PFE ou VEF1

$\square$ Rinite

$\square$ Coriza/Rinorréia

$\square$ Espirros

$\square$ Obstrução nasal

$\square$ Outros/Especificar

SINTOMAS ASSOCIADOS:

$\square$ Envolvimento $-\square$ Rins $\square$ Fígado

$\square$ Mal-estar

$\square$ Edema - Local

$\square$ Linfadenopatia

$\square$ Dor/Queimação - Local

$\square$ Artralgia/Mialgia - Local

$\square$ Outros/Especificar 


\section{EVOLUÇÃO CLÍNICA}

Listar todas as drogas e produtos (inclusive naturais e alimentos com corantes) em uso no momento da reação:

.

\section{DROGAS SUSPEITAS :}

\begin{tabular}{|c|c|c|c|}
\hline Nome genérico & $\begin{array}{l}\text { dose / via / tempo } \\
\text { de tratamento }\end{array}$ & intervalo entre dose e reação & $\begin{array}{c}\text { Uso prévio da mesma } \\
\text { droga/Sintomas? }\end{array}$ \\
\hline $1-$ & & & \\
\hline $2-$ & & & \\
\hline $3-$ & & & \\
\hline $4-$ & & & \\
\hline $5-$ & & & \\
\hline $6-$ & & & \\
\hline 7-- & & & \\
\hline
\end{tabular}

ORIENTAÇÃO TERAPÊUTICA APÓS A CRISE AGUDA : $\square$ Não teve tratamento

$\begin{array}{lll}\square \text { Suspendeu o fármaco suspeito No. } & & \\ \square \text { Corticóide } & \square \text { local } & \square \text { sistêmico } \\ \square \text { Anti-histamínicos } & \square \text { local } & \square \text { sistêmico } \\ \square \text { Broncodilatador } & \square \text { local } & \square \text { sistêmico } \\ \square \text { Tratamento do choque : } & \square \text { adrenalina } & \square \text { plasma }\end{array}$

$\square$ Tratamento do choque : $\quad \square$ adrenalina $\quad \square$ plasma

$\square$ outro...

$\square$ Mudança para droga substituta:
$\square$ Tipo/Nome.
$\square$ Tolerância

$\square$ Outros/especificar

\section{ANTECEDENTES PESSOAIS:}

1. Observou sintomas semelhantes sem a ingestão da droga suspeita? $\quad \square \operatorname{Sim} \quad \square$ Não $\quad \square$ Desconhece

2. HISTÓRIA MÉDICA
$\square$ Asma
$\square$ Auto-imunidade
$\square$ Polipose nasal
$\square$ Linfoproliferativas
$\square$ Urt. Pigmentosa/Mastocitose Sist.
$\square$ Fibrose cística
$\square$ Cirurgia disco intervetebral
$\square$ Diabetes
$\square$ Fígado
$\square$ Urticária Crônica
$\square$ Outros/Especificar
HIV Positivo
$\square$ Rins .

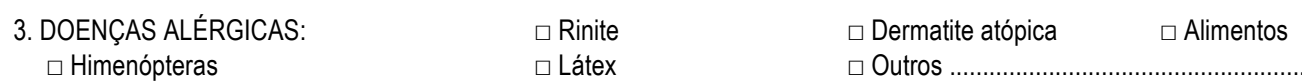
4. REAÇÕES DURANTES CIRÚRGIAS PRÉVIAS: $\square$ Cirurgias $\quad \square$ Dentista $\quad \square$ Exame radiológico

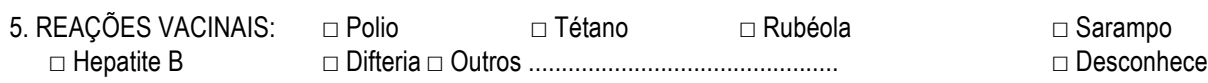

HISTÓRIA FAMILIAR: Alergias/RAD

OBSERVAÇÕES: 


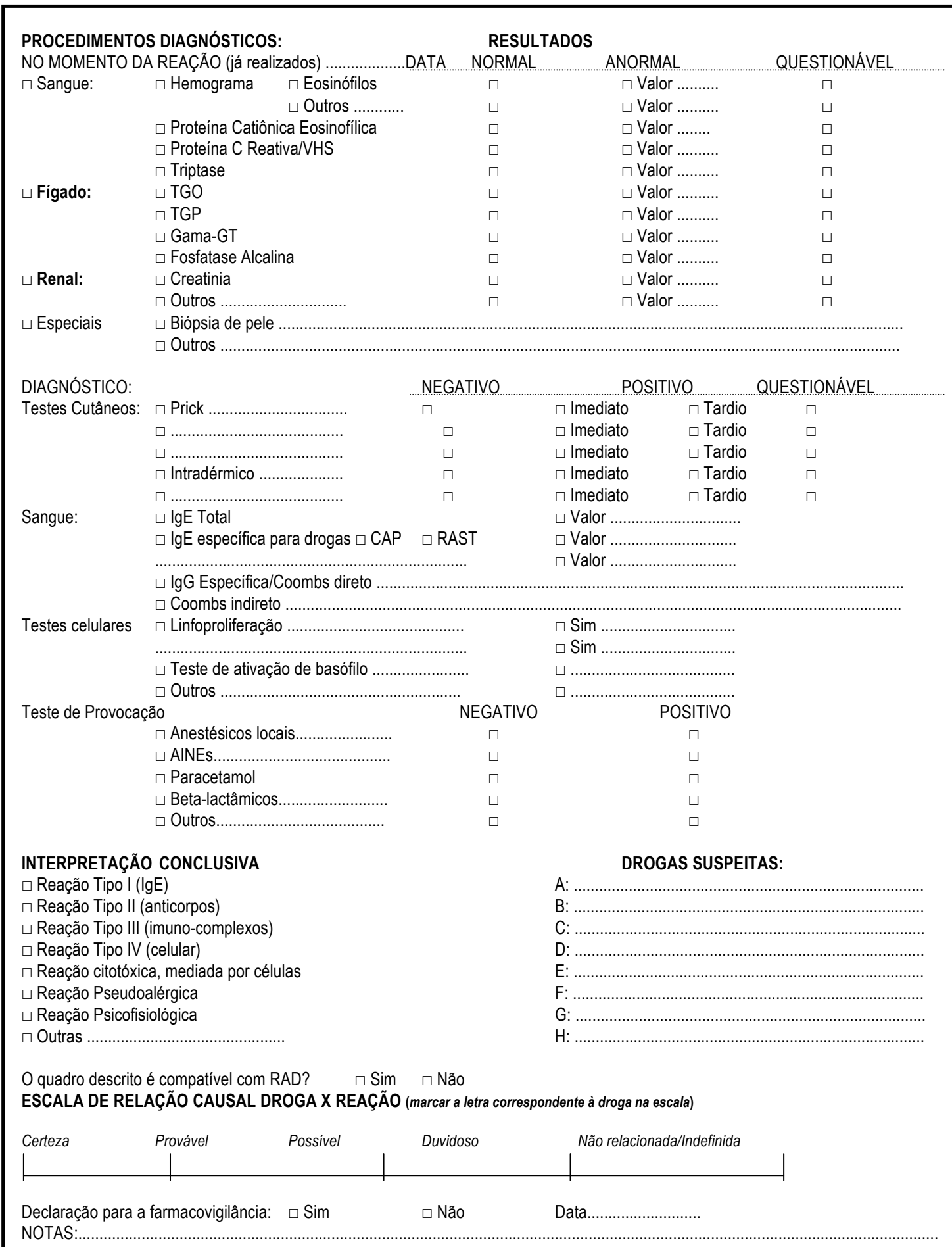


Anexo 5. Teste de contato com medicamentos

\section{Teste de contato com medicamentos na investigação das reações de hipersensibilidade não imediatas*}

Drug patch tests in evaluation of non-immediate hypersensitivity reactions

Luciana K. Tanno 1,2,4, Luis Felipe C. Ensina1,5,6, Marcelo V. Aun1,2, Marisa R. Ribeiro ${ }^{1,2}$, Adriana T. Rodrigues ${ }^{1,2}$, Laila S. Garro1,2,4, Jorge Kalil7, Pedro Gianvina-Bianchi ${ }^{8}$,

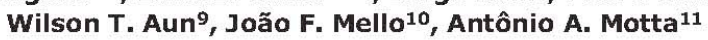

\section{Resumo}

Objetivo: Verificar a sensibilidade, a especificidade e os valores preditivos (VP) do teste de contato com medicamentos (TCM) como método complementar na investigação etiológica in vivo das reações de hipersensibilidade não-imediata (RHNI) a medicamentos.

Método: Estudo prospectivo realizado em dois Serviços de Alergia da cidade de São Paulo no período de março de 2009 a julho de 2010. Os pacientes com história de RHNI a medicamentos foram avaliados através de questionário de in vestigação adaptado. Os testes de contato foram realizados com os medicamentos suspeitos e as leituras após 48 e $72 \mathrm{~h}$ da aplicação. As concentrações e diluições, bem como a interpretação foram as sugeridas pela literatura. O TCM foi aplicado também em 10 controles.

Resultados: Foram realizados $55 \mathrm{TCM}$ em 47 pacientes, $20 \mathrm{com}$ anticonvulsivantes aromáticos (ACA), $18 \mathrm{com}$ antibióticos $\beta$-lactâmicos $($ ATB- $\beta$ ), $8 \mathrm{com}$ anti-inflamatórios não-esteroidais (AINEs), $3 \mathrm{com}$ sulfonamidas (sulfas) e $6 \mathrm{com}$ outras medicações. Dezesseis pacientes apresentaram história de exantema maculo-papular 10 de Síndrome de Stevens-Johnson (SSJ), 9 de Drug Reaction with Eosinophilia Systemic Symptoms (DRESS), 4 de rash cutâneo, 2 de eritema multiforme, 2 de eritema pigmentar fixo, 2 de fotodermatose, 1 de urticária tardia e 1 de eczema. Trinta e cinco pacientes referiram uso concomitante de outro eczema. Trinta e cinco pacientes referiram uso concomitante de outro
fármaco no período da reação. Dos TCM 18 foram positivos ( 8 para ACA, 5 para ATB- $\beta, 1$ para AINEs e 4 para outros medicamentos), 10 em reações graves (SSJ e DRESS). Nenhum paciente apresentou reação ad versa ao TCM. A sensibilidade e a especificidade foram de 33\% e de $100 \%$, respectivamente. O VP positivo dos TCM foi de $100 \%$ eo negativo de $70,8 \%$. Nas reações graves, a sensibilidade chegou a $53 \%$ e o VP negativo foi de $90,9 \%$.

Conclusão: Os TCM podem constituir métodos diagnósticos importantes em $\mathrm{RHNI}_{r}$ e auxiliar na orientação adequada uma vez que se mostraram seguros e apresentaram VP altos, principalmente nas reações graves.

Rev, bras. alerg. imunopatol. 2011;34(6):251-6: Teste de contato com medicamentos, reações adversas a drogas, hipersensibilidade a medicamentos, hipersensibilidade não-imediata a medicamentos.

\section{Abstract}

Objective: To analyze the sensitivity specificity and predictive value of drug patch test (PT) as an in vivo complementary method of investigation to assess the culpability of a drug in non-immediate hypersensitivity reactions (NIHR).

Methods: A prospective study was developed in Allergy Clinics of two Services in São Paulo from March 2009 to July 2010. The patients were studied based on a positive history of non-immediate hypersensitivity reactions to drugs using an adapted questionnaire. Patch tests were performed using the culprit drug and were evaluated 48 and $72 \mathrm{~h}$ after the application of the test. The concentrations, dilutions and interpretation were those suggested by literature. PT were also performed in 10 healthy subjects as controls.

Results: We performed 55 PT in 47 patients, 20 with aromatic anticonvulsants (ACA), 18 with $\beta$-lactams antibiotics (ATB- $\beta$ ), 8 with non-steroidal anti-inflammatory drugs (NSAIDs), 3 with sulfonamides e 6 with other drugs. Sixteen patients had a history of maculo-papular exanthema, 10 of Stevens-Johnson Syndrome (SSJ), 9 of Drug Reaction with Eosinophilia and Systemic Symptoms (DRESS), 5 of cutaneous rash, 2 of multiform erithema, 2 of fixed eruption, 2 of photodermatosis, 1 of late urticaria e 1 of local eczema. Thirty-five patients reported the intake late urticaria e 1 of local eczema. Thirty-five patients reported the intake
of other drugs at the same time of the reaction. Of all PT, 18 were positive ( 8 for ACA, 5 for ATB- $\beta, 1$ for NSAIDs and 4 for other drugs), 10 in severe reactions (SSJ and DRESS). No adverse reactions were observed during the tests. The sensitivity and specificity of PT in NIHR were $33 \%$ and $100 \%$, respectively. The positive and negative predictive values were $100 \%$ and $70.8 \%$, respectively, Of severe reactions, the sensitivity was $53 \%$ and the negative predictive value was $90.9 \%$.

Conclusion: The PT may be an important diagnostic method for NIHR and can help to advise correctly these patients. The tests were safe and the predictive values were high, particularly in severe reactions.

Rev. bras. alerg. imunopatol. 2011;34(6):251-6: Drug patch test, drug adverse reactions, drug hypersensitivity, non-immediate hypersensitivity to drugs.

1. Especialista em Alergia e Imunologia Clínica pela ASBAI.

2. Médico colaborador do Serviço de Imunologia Clínica e Alergia do HC-FMUSP.

3. Médica assistente do Serviço de Alergia e Imunologia do Hospital do Servidor Público Estadual de São Paulo.

4. Pós-graduanda da Disciplina de Imunologia Clínica e Alergia da FMUSP.

5. Professor Adjunto da Faculdade de Medicina de Santo Amaro.

6. Professor Colaborador da Disciplina de Reu matologia da UNIFESP.

7. Professor Titular da Disciplina de Imunologia Clínica e Alergia da FMUSP.

8. Professor Livre-Docente da Disciplina de Imunologia Clínica e Alergia da FMUSP.

9. Diretor de Seção do Serviço de Alergia e Imunologia do Hospital do Servidor Público Estadual de São Paulo.

10. Diretor do Serviço de Alergia e Imunologia do Hospital do Servidor Público Estadual de São Paulo.

11. Doutor em Medicina pela FMUSP. Médico Assistente responsável pelo Ambulatório de Reações Adversas a Medicamentos do HC-FMUSP.

Instituições: Disciplina de Imunologia Clínica e Alergia da Faculdade de Medicina da Universidade de São Paulo, Serviço de Imunologia Clínica e Alergia do Hospital das Clínicas da Faculdade de Medicina da Universidade de São Paulo. Serviço de Alergia e Imunologia do Hospital Servido Público Estadual de São Paulo.

* Trabalho agraciado com o prêmio Lain Pontes de Carvalho durante o XXXVII Congresso Brasileiro de Alergia e Imunopatologia em 2010.]

Artigo submetido em ??.??.2011, aceito em 21.12.2011. 


\section{Introdução}

As reações de hipersensibilidade a medicamentos (RHM) provocam sintomas e/ou sinais objetivamente reprodutíveis, iniciadas por exposição a um estímulo definido em doses toleradas por indivíduos normais. São classificadas em alérgicas ou não-alérgicas, sendo que as alérgicas são aquelas iniciadas por mecanismos imunológicos ${ }^{1}$. De acordo com intervalo de tempo entre o uso do medicamento e o aparecimento da reação podem ser denominadas reações de hipersensibilidade imediatas (RHI), quando ocorrem na primeira hora após a utilização do medicamento, e reações de hipersensibilidade não-imediatas (RHNI), quando ocorrem após este período ${ }^{2}$. As manifestações mais frequentes das RHNI são o exantema maculo-papular (EMP) e a urticaria/ angioedema de início tardio, mas outras apresentações clínicas podem ocorrer, algumas com maior gravidade como a Síndrome de Stevens-Johnson (SSJ), a Necrólise Epidérmica Tóxica (TEN) e a Síndrome de Hipersensibilidade a Medicamentos, também conhecida como Drug Reactions with Eosinophilia and Systemic Symptoms (DRESS) ${ }^{3}$. Os mecanismos envolvidos nas RHM são heterogêneos, entretanto, o mecanismo do tipo IV de Gell e Coombs é observado na maioria das RHNI ${ }^{4}$.

O teste de linfoproliferação constitui o principal método para diagnóstico in vitro das RHNI. No entanto, é de difícil padronização e sua sensibilidade e especificidade são indefinidas ${ }^{5}$. Os testes cutâneos de leitura tardia, como o teste de contato com medicamentos (TCM) e o teste intradérmico de leitura tardia e, em casos específicos, o teste de provocação, são os métodos diagnósticos in vivo disponíveis para a investigação das RHNI. O TCM com o medicamento suspeito têm sido descrito como método complementar que auxilia na determinação causal das RHNI de apresentação cutânea ${ }^{6-9}$. Há poucas publicações em reações graves ${ }^{10}$, mas parece ser uma importante ferramenta diagnóstica onde o teste de provocação, considerado como padrão-ouro, está contra-indicado 11,12

O objetivo deste estudo foi de verificar a sensibilidade, a especificidade e os valores preditivos (VP) do TCM como método complementar na investigação etiológica in vivo das (RHNI) a medicamentos.

\section{Métodos}

Este estudo prospectivo foi realizado em dois centros formadores de especialistas em Alergia e Imunologia Clínica da cidade de São Paulo, no período de março de 2009 a julho de 2010. Todos os 47 pacientes com história de RHNI a medicamentos foram avaliados através de questionário de investigação da European Network for Drug Allergy (ENDA) adaptado para caracterização clínica e demográfica ${ }^{11}$. Foram consideradas como reações graves a SSJ, a NET e a DRESS. Todos os TCM realizados no período foram incluídos no trabalho.

Todos os pacientes foram orientados em relação aos riscos e benefícios do teste, e assinaram o termo de consentimento livre e esclarecido. Foram orientados a retornar aos respectivos ambulatórios se houvesse qualquer manifestação.
Os testes de contato (TC) foram realizados nos ambulatórios dos dois Serviços. Foram testados os medicamentos suspeitos, além do veículo utilizado para cada diluição. As concentrações e diluições utilizadas foram as sugeridas pela literatura ${ }^{9,13-17}$. Os medicamentos diluídos foram aplicados sobre a pele do dorso do paciente em câmaras do tipo Finn Chamber ${ }^{\circledR}$. Nos casos de eritema pigmentar fixo, o teste foi aplicado sobre local da lesão. As leituras foram realizadas por um examinador que não teve acesso à história clínica ou ao fármaco testado, após 48 e 72 horas da aplicação. Os testes foram realizados em no mínimo seis semanas após a resolução da reação. As recomendações a respeito de medicações ou outras condições que pudessem prejudicar a interpretação do teste seguiram as orientações da European Society of Contact Dermatitis $(E S C D)^{6}$. A interpretação foi baseada nas recomendações do European Environmental Contact Dermatitis Research Group (Tabela 1). O TCM foi aplicado em 10 indivíduos saudáveis como controles. Todos os grupos farmalógicos testados foram aplicados nestes indivíduos.

Tabela 1 - Interpretação do teste de contato com medicamentos*

\begin{tabular}{lc}
\hline Avaliação clínica & Escore \\
\hline Eritema & ? ou + ? \\
Eritema, infiltração, discretas, pápulas & + \\
Eritema, infiltração, pápulas, vesículas & ++ \\
Intenso, eritema, infiltração, vesículas, coalescentes & +++ \\
Ausência de reação & - \\
\hline
\end{tabular}

* Segundo Barbaud A et al. ${ }^{6}$

Os TCM foram realizados com: anticonvulsivantes aromáticos (ACA), antibióticos $\beta$-lactâmicos (ATB- $\beta$ ), antiinflamatórios não-esteroidais (AINEs), sulfonamidas (sulfas) e outras medicações (Heparina, Enoxaparina, Prednisolona, Riluzol, Aminofilina, Losartana).

A história clínica foi considerada como padrão-ouro para cálculo de sensibilidade, especificidade e valores preditivos. Os dados coletados foram registrados em um banco de dados. Para calcular a significância estatística foi utilizado o teste do Qui-quadrado $\left(\chi^{2}\right)$ de Pearson para as variáveis estudadas, considerando $\mathrm{p}$ menor ou igual a 0,05 .

\section{Resultados}

Foram realizados 55 TCM em 47 pacientes, 20 com ACA, $18 \mathrm{com}$ ATB- $\beta, 8 \mathrm{com}$ AINEs, $3 \mathrm{com}$ sulfas e $6 \mathrm{com}$ as outras medicações (Tabela 2). 
Tabela 2 - Resultados dos testes de contato de acordo com os grupos farmacológicos e apresentações clínicas*

\begin{tabular}{|c|c|c|c|}
\hline $\begin{array}{l}\text { Grupo farmacológico } \\
\text { testado }(n=55)\end{array}$ & $\begin{array}{l}\text { Apresentação } \\
\text { clínica (número) }\end{array}$ & $\begin{array}{l}\text { Positivos } \\
(n=18)\end{array}$ & $\begin{array}{c}\text { Negativos } \\
(n=37)\end{array}$ \\
\hline \multirow[t]{5}{*}{ ATB $-\beta(N=18)$} & EMP (11) & 3 & 8 \\
\hline & E MULTIFORME (3) & 0 & 3 \\
\hline & SSJ (2) & 2 & 0 \\
\hline & Urticária (1) & 0 & 1 \\
\hline & Rash (1) & 0 & 1 \\
\hline \multirow[t]{4}{*}{ ACA $(N=20)$} & DRESS (9) & 5 & 4 \\
\hline & SSJ (6) & 3 & 3 \\
\hline & EMP (4) & 0 & 4 \\
\hline & E Pig Fixo (1) & 0 & 1 \\
\hline \multirow[t]{4}{*}{ AINES $(N=8)$} & SS] (3) & 0 & 3 \\
\hline & $\operatorname{EMP}(2)$ & 0 & 2 \\
\hline & Rash (2) & 1 & 0 \\
\hline & E Pig Fixo (1) & 0 & 1 \\
\hline \multirow{2}{*}{ SULFAS $(N=3)$} & Fotodermatoses (2) & 0 & 2 \\
\hline & EMP (1) & 0 & 1 \\
\hline \multirow[t]{3}{*}{ OUTROS $(N=6)$} & Rash (2) & 2 & 0 \\
\hline & EMP (2) & 0 & 2 \\
\hline & Eczema (2) & 2 & 0 \\
\hline
\end{tabular}

* ATB- $\beta=$ antibióticos $\beta$-lactâmicos, ACA = anticonvulsivantes aromaticos, AINES = anti-inflamatórios não-esteroidais, SULFAS = sulfonamidas. EMP = exantema maculo-papular, E MULTIFORME = eritema multiforme, SSJ $_{r}=$ Síndrome de Stevens-Johnson, DRESS= Drug Reaction with Eosinophilia and Systemic Symptoms, E pig Fixo =eritema pigmentar fixo.

A média de idade dos pacientes testados foi de 48,6 anos, sendo que a 41 foram do sexo feminino. Dos 47 pacientes, 16 apresentaram história de EMP, 10 de SSJ, 09 de DRESS, 4 de rash cutâneo, 2 de eritema multiforme, 2 de eritema pigmentar fixo, 2 de fotodermatose, 1 de urticária tardia e 1 de eczema.

O intervalo médio de tempo entre as reações e os testes foi de 26 meses (Figura 1). Trinta e cinco pacientes referiram uso concomitante de outro fármaco no período da reação, com o máximo de seis medicamentos por paciente (Figura 2).

Dos TCM 18 foram positivos ( $p=0,003$; Figura 3 ), sendo 10 em pacientes com história de reação grave (Tabela 2 ). Nenhuma reação adversa foi relatada durante os testes. Todos os controles apresentaram resultados negativos.

A sensibilidade e a especificidade dos TCM nas RHNI foram de $33 \%$ e de $100 \%$, respectivamente. O valor preditivo positivo dos TCM foi de $100 \%$ e o negativo de $70,8 \%$. Nas reações graves, a sensibilidade chegou a $53 \%$ e o valor preditivo negativo foi de $90,9 \%$ (Tabela 3 ).

\section{Discussão}

Nos últimos anos, numerosos relatos vêm enfatizando a utilidade dos testes cutâneos na investigação das $\mathrm{RHNI}^{6-8,16}$. No entanto, existem poucos estudos em nosso meio avaliando a sensibilidade e a especificidade dos TCM nestas reações. Uma das grandes dificuldades deste teste é estabelecer uma padronização adequada, bem como relacionar o seu resultado às diferentes apresentações clínicas das RHNI. Assim, neste estudo, nos propusemos a realizar o TC com o medicamento suspeito nos pacientes com história de RHNI, definir a associação entre os resultados, o quadro clínico e o grupo farmacológico envolvido, além de analisar as possíveis variáveis na interpretação dos resultados.

A caracterização das reações foi baseada principalmente na história clínica, mas a documentação médica durante a internação dos pacientes com reações graves auxiliou na identificação dos possíveis medicamentos causadores e na confirmação do quadro clínico. Em alguns casos, a história clínica pode ter sido prejudicada pelo intervalo de tempo entre a reação e a avaliação clínica (Figura 1).

Apesar do EMP ter sido o quadro clínico mais frequente, as reações graves constituíram $40 \%$ de todas as reações estudadas. Os ATB- $\beta$ foram os medicamentos mais associados aos quadros de EMP, enquanto que as reações graves foram mais relacionadas aos ACA, sendo os casos de DRESS exclusivamente associados a este grupo farmacológico. $O$ eritema multiforme, cuja principal causa é infecciosa, foi associado apenas aos ATB- $\beta$. Por outro lado, as fotodermatoses foram manifestações características das sulfas. Nenhum dos pacientes apresentou história de RHI ao mesmo grupo farmacológico testado. 


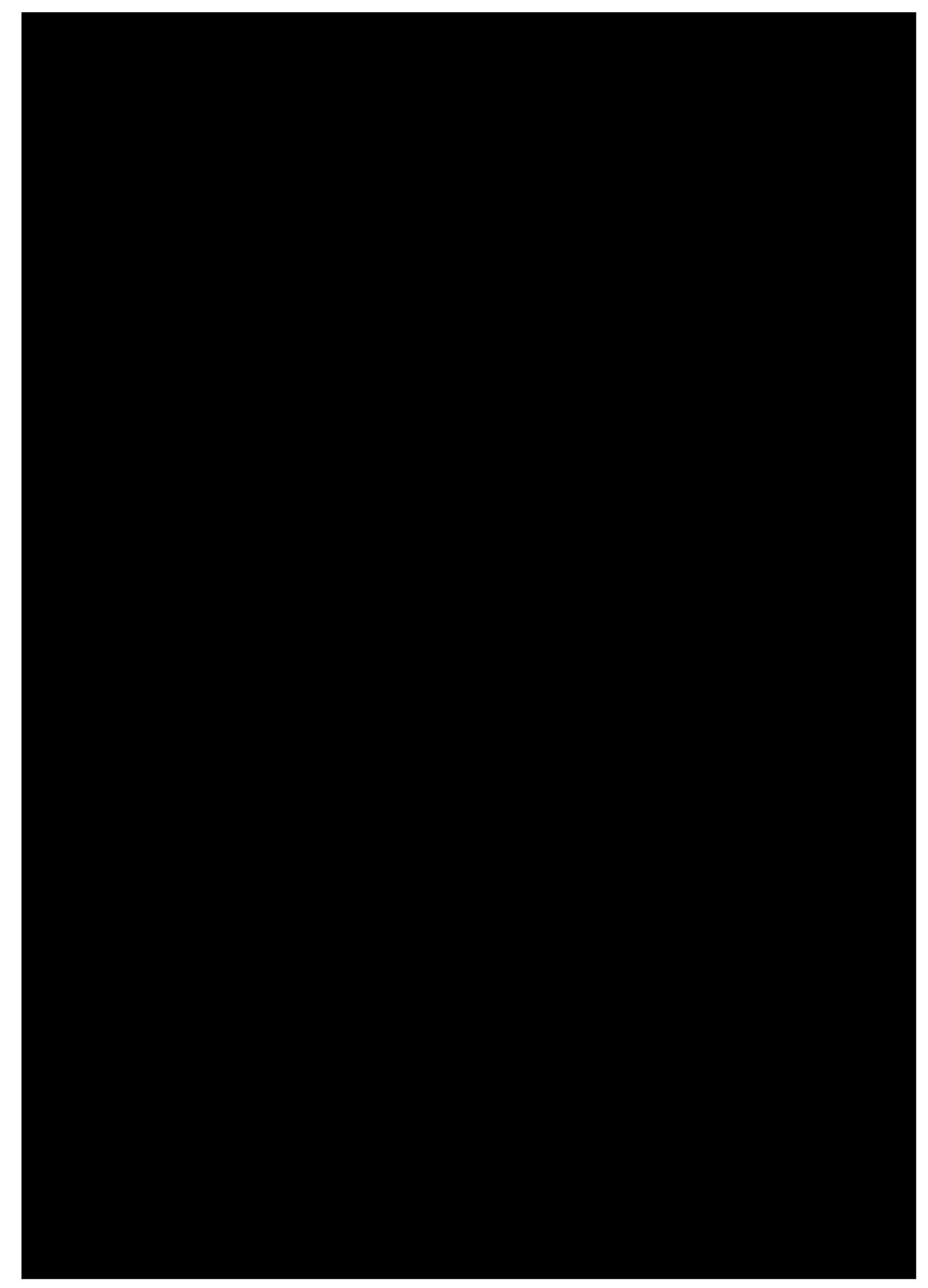


Tabela 3 - Sensibilidade, especificidade e valores preditivos positivos e negativos dos testes de contato com medicamentos de acordo com a gravidade das reações de hipersensibilidade não imediatas

\begin{tabular}{lcccc}
\hline Testes de contato & $\begin{array}{c}\text { Sensibilidade } \\
(\%)\end{array}$ & $\begin{array}{c}\text { Especificidade } \\
(\%)\end{array}$ & $\begin{array}{c}\text { Valor preditivo positivo } \\
(\%)\end{array}$ & $\begin{array}{c}\text { Valor preditivo negativo } \\
(\%)\end{array}$ \\
\hline Reações graves* & 53,0 & 100 & 100 & 90,9 \\
Reações não graves** & 28,5 & 100 & 100 & 76,2 \\
Total & 33,0 & 100 & 100 & 70,8 \\
\hline
\end{tabular}

* Síndrome de Stevens-Johnson, DRESS (Drug Reaction with Eosinophilia and Systemic Symptoms).

** Demais reações não-imediatas.

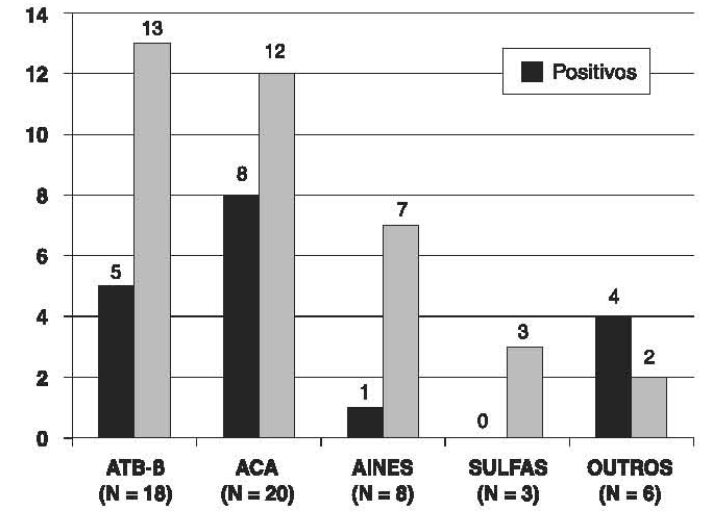

Figura 3 - Positividade dos testes de contato com medicamentos*

* Anticonvulsivantes aromáticos (ACA), antibióticos $\beta$-lactâmicos (ATB- $\beta$ ), a nti-infla matórios não-esteroidais (AINEs), sulfonamidas (sulfas) e outros medicamentos (Heparina, Enoxaparina, Prednisolona, Riluzol, Aminofilina e Losartana).

O teste intradérmico de leitura tardia, apesar de mais sensível que o TCM, apresenta menor número de medicamentos disponíveis para sua realização e menor segurança.

Primeau et al. sugerem que talvez existam características populacionais envolvidas nas reações e nos resultados destes testes $^{20}$. A grande variabilidade genotípica da população brasileira poderia explicar o número de testes negativos.

Apesar do TCM ter sido relatado em alguns casos como desencadeante de $\mathrm{RHM}^{16}$, em nosso estudo, o teste se mostrou seguro, uma vez que nenhuma reação adversa foi notificada. A concentração das drogas utilizadas, veículo e local de aplicação dos testes foram os mesmos dos trabalhos anteriormente realizados e, desta forma, não existem diferenças técnicas na realização do procedimento.
Diferentemente do descrito ${ }^{16,18,19}$, o intervalo de tempo entre a reação e a realização dos testes pareceu não ser um dado que influenciou em nossos resultados, uma vez que $27,7 \%$ dos testes positivos ocorreu mesmo após 2 anos da reação (Figura 1). Estes resultados podem estar relacionados à natureza da reação e do tipo de medicamento testado.

O número de medicamentos utilizados de forma concomitante no momento da reação parece ser um fator que influenciou em nossos resultados. Verificamos que em pacientes utilizando três ou mais medicamentos simultaneamente, a positividade dos testes foi menor (Figura 2). O maior número de medicamentos em uso de forma concomitante talvez possibilite uma sobrecarga de vias de metabolismo e/ ou de interação medicamentosa, responsáveis pela gênese das reações, ou mesmo, propicie o envolvimento de outro medicamento não testado.

Em conclusão, os TCM podem constituir métodos diagnósticos importantes nas RHNI, e auxiliar na orientação adequada dos pacientes uma vez que se mostraram seguros e apresentaram valores preditivos positivo e negativo altos, principalmente nas reações graves. O resultado variou também com o número de medicamentos em uso de forma concomitante durante a reação e do fármaco testado.

\section{Referências}

1. Demoly $P_{r}$ Hillaire-Buys D. Classification and epidemiology of hypersensitivity drug reactions. Immunol Allergy Clin North Am 2004;24:345-56.

2. Romano A, Demoly P. Recent advances in the diagnosis of drug allergy. Curr Opin Allergy Clin Immunol 2007;7:299-303.

3. Demoly $\mathrm{P}_{r}$ Kropf $\mathrm{R}_{r}$ Bircher $\mathrm{A}_{r}$ Pichler WJ. Drug hypersensitivity: questionnaire. EAACI interest group on drug hypersensitivity. Allergy 1999;54:999-1003.

4. Pichler WJ. Delayed Drug Hypersensitivity Reactions. Ann Intern Med 2003;139:683-93.

5. Torres $\mathrm{MJ}$, Mayorga $\mathrm{C}$, Blanca $\mathrm{M}$. Non-immediate allergic reactions induced by drugs: phathogenesis and diagnostic tests. J Investig Allergol Clin Immunol 2009;19(2):80-90.

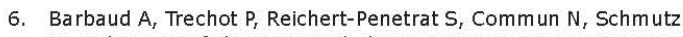
JL. Relevance of skin tests with drugs in investigating cutaneous adverse drug reactions. Contact Dermatitis 2001;45:265-8. 
7. Barbaud A, Bene MC, Faure G, Schmutz JL. Tests cutane's dans I'exploration des toxidermies supposé es de mecanisme immunoallergique. Bull Acad Natl Med 2000;184:47-63.

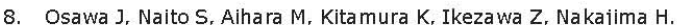
Evaluation of skin test reactions in patients with non-immediate type drug eruptions. J Dermatol 1990;17:235-9.

9. Romano $A$, Di Fonso M, Pietrantonio F, Pocobelli $D$, Giannarini L, Del Bono $A$, et al. Repeated patch testing in delayed hypersensitivity to beta-lactam antibiotics. Contact Dermatitis 1993;28:190.

10. Duong $\mathrm{T}_{t}$ Lee $\mathrm{H}_{z}$ Assier $\mathrm{H}_{t}$ Haddad $\mathrm{C}_{t}$ Gouvello SL, Wolkenstein $\mathrm{P}_{t}$ et al. Patch testing in severe cutaneous adverse reactions: a study of 111 patients. Eur Ann Allergy Clin Immunol 2010;42(2):62-3.

11. Aberer W, Bircher $A_{t}$ Romano $A_{t}$ Blanca $M$, Campi $P_{t}$ Fernandez $P_{t}$ et al. Drug provocation testing in the diagnosis of drug hypersensitivity reactions: general considerations. Allergy 2003;58:854-63.

12. Santiago $F_{r}$ Goncalo $M_{r}$ Vieira $R$. Epicutaneous patch testing in drug hypersensitivity syndrome (DRESS). Contact Dermatitis 2010;62:47-53.

13. Barbaud A. Skin testing in delayed reactions to drugs. Immunol Allergy Clin N Am 2009;29:517-35.

14. Cham MHP, Warshaw EM. Patch Testing for Evaluation Drug Reactions Due to Systemic Antibiotics. Dermatitis 2007;18(2):63-77.

15. Vervloet $D_{r}$ Pradal $M_{r}$ Birnbaum J, Koeppel MC. Drug Allergy, Editions de Condé, Paris, France. 2009.
16. Barbaud A. Drug patch testing in systemic cutaneous drug allergy. Toxicilogy 2005;209:209-16.

17. Calvin JM and Maibach HI. Delay hypersensitivity drug reactions diagnosed by patch testing. Contact Dermatitis 1993;29:223-33.

18. Romano $A$, Viola $M$, Mondino $C$. Diagnosing nonimmediate reactions to penicillin's by in vivo tests. Int Arch Allergy Immunol 2002;129:169-74.

19. Lammintantausta $K_{f}$ Kortekangas-Savolaien $O$. The usefulness of skin tests to prove drug hypersensitivity. $\mathrm{Br} J$ Dermatol 2005;152:968-74.

20. Primeau M-N, Hamilton RG, et al. Negative patch tests and skin tests in patients with delayed cuta neous manifestation to penicillin. J Allergy Clin Immunol 2002;109(1):816.

Correspondência:

Luciana Kase Tanno

Rua Professor Arthur Ramos, 183 - cj. 21. - Jd. Europa

CEP 01454-011 - São Paulo, SP

E-mail: lucianatanno@terra.com.br 